\title{
INDUCTIVELY COUPLED PLASMA AND ELECTRON CYCLOTRON RESONANCE PLASMA ETCHING OF InGaAIP COMPOUND SEMICONDUCTOR SYSTEM
}

- J. Hong ${ }^{*}$, E. S. Lambers, C. R. Abernathy and S. J. Pearton Department of Materials Science and Engineering University of Florida, Gainesville FL 32611 .

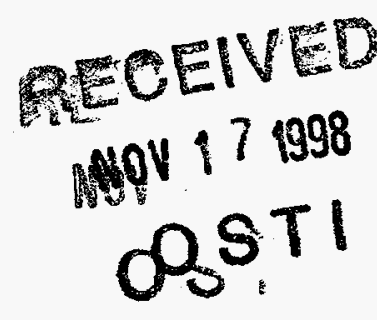

\section{R. J. Shul}

Sandia National Laboratories, Albuquerque NM 87185

W. S. Hobson

Bell Laboratories, Lucent Technologies, Murray Hill NJ 07974

\section{ABSTRACT}

Current and future generations of sophisticated compound semiconductor devices require the ability for submicron scale patterning. The situation is being complicated since some of the new devices are based on a wider diversity of materials to be etched. Conventional RIE (Reactive Ion Etching) has been prevalent across the industry so far, but has limitations for materials with high bond strengths or multiple elements. In this paper, we suggest high density plasmas such as ECR (Electron Cyclotron Resonance) and ICP (Inductively Coupled Plasma), for the etching of ternary compound semiconductors (InGaP, AllnP, AlGaP) which are employed for electronic devices like heterojunction bipolar transistors (HBTs) or high electron mobility transistors (HEMTs), and photonic devices such as light-emitting diodes (LEDs) and lasers. High density plasma sources, operating at lower pressure, are expected to meet target goals determined in terms of etch rate, surface morphology, surface stoichiometry, selectivity, etc. The etching mechanisms, which are described in this paper, can also be applied to other III-

\footnotetext{
- Current address: Samsung Electronics Semiconductor R\&D center, San $¥ 24$ Nongse-Ri, Kiheung-Eup, YonginCity, Kyungki-Do, Korea
} 


\section{DISCLAIMER}

This report was prepared as an account of work sponsored by an agency of the United States Government. Neither the United States Government nor any agency thereof, nor any of their employees, make any warranty, express or implied, or assumes any legal liability or responsibility for the accuracy, completeness, or usefulness of any information, apparatus, product, or process disclosed, or represents that its use would not infringe privately owned rights. Reference herein to any specific commercial product, process, or service by trade name, trademark, manufacturer, or otherwise does not necessarily constitute or imply its endorsement, recommendation, or favoring by the United States Government or any agency thereof. The views and opinions of authors expressed herein do not necessarily state or reflect those of the United States Government or any agency thereof. 


\section{DISCLAIMER}

\section{Portions of this document may be illegible in electronic image products. Images are produced from the best available original document.}


$\mathrm{V}$ (GaAs-based, InP-based) as well as III-Nitride since the InGaAlP system shares many of the same properties.

RECEIVED

NOV 17998

INTRODUCTION

The InGaAlP semiconductor system, which consists of $\mathrm{InGaP}$, AllnP and AlGaP, is used in a number of applications due to its interesting properties. The first motivation of investigating these materials is that $\operatorname{In}_{x} G a_{1-x} \mathrm{P}$ and $\mathrm{Al}_{x} \operatorname{In}_{1-\mathrm{x}} \mathrm{P}(\mathrm{x} \sim 0.5)$ are lattice matched to GaAs (lattice constant is $0.6532 \AA$ ), which results in the achievement of heteroepitaxy. ${ }^{[1]}$ In addition, InGaP has many attractive properties compared with $\mathrm{AlGaAs}$, which is now being used in $\mathrm{HBT}$ devices. InGaP has a larger valence band discontinuity $\left(\Delta \mathrm{E}_{\mathrm{v}}=0.3 \mathrm{eV}\right)$ leading to improved $\gamma$ (carrier injection efficiency) in HBTs (Heterojuction Bipolar Transistors), lower densities of DX centers, lower surface recombination velocity and, finally it is not prone to oxidation due to its $\mathrm{Al}$-free composition. All these properties make InGaP a potential substitute for AlGaAs in HBTs or HEMTs (High Electron Mobility Transistor). Beyond that, the InGaAlP system displays a wide range of bandgaps from $\mathrm{In}_{0.49} \mathrm{Ga}_{0.51} \mathrm{P}(1.9 \mathrm{eV})$ to $\left(\mathrm{Al}_{\mathrm{x}} \mathrm{Ga}_{1}\right.$. $\left.{ }^{x}\right)_{0.51} \operatorname{In}_{0.49} \mathrm{P}(\mathrm{x} \sim 0.66,2.3 \mathrm{eV})$, which are suitable for visible range $L E D$ and lasers. ${ }^{[2-22]}$

For the pattern transfer of these materials, some challenges must be solved. Issues for the etching of this system can be divided into two parts. The first part lies in the intrinsic properties of materials themselves. For InGaP and AllnP, the group V element $(\mathrm{P})$ is lighter than the group III elements (In, Ga). Thus, phosphorous is sensitive to preferential sputtering during the etching process, giving rise to nonstoichiometric surfaces. In addition, $\mathrm{AlGaP}$ has a higher melting point $(2282 \mathrm{~K})$ than either InGaP (1538K) or AlInP (2079K), which is a good indication of their average bond strengths. ${ }^{[23]}$ This high bond strength usually leads to very slow etch rates. The universal etchant for the etching of In-containing semiconductors has been the 
methane-hydrogen-based chemistry because of its ability to produce volatile etch products. However, the etch rates with this chemistry are too low to maintain good throughput. Secondly, the presence of methane produces polymer deposition on the mask and within the chamber. ${ }^{[24,25]}$ In addition, the presence of hydrogen in the plasma results in electrical passivation of near-surface dopants. ${ }^{[26-28]}$ While these problems can be avoided using chlorinebased chemistries, which is generally used for Ga-based semiconductors, it is generally believed that an involatile etch product of indium $\left(\mathrm{InCl}_{3}\right.$ : b.p. $\left.600^{\circ} \mathrm{C}\right)$ rapidly forms a thick reaction layer on the surface with the result of low etch rate and rough surface. Table 1 shows boiling points of possible etch products (chlorides) for the InGaAlP materials system. It turns out that there is a big difference in boiling points between group III (Indium) and group V etch products. This different volatility of group III (Indium) and group V makes etching of Incontaining materials difficult in terms of obtaining high etch rate and smooth or stoichiometric surfaces. The only way to solve this in conventional RIE (Reactive Ion Etching) is to heat the sample while etching. This approach is not desirable because the elevated temperature precludes use of photoresist as the mask and presents reproducing problems. The other approach we took is use of high density plasmas. It is expected that the high ion density available in the plasma can sputter away involatile etch products efficiently with the achievement of high etch rate and smooth surface morphology. ${ }^{[29-32]}$

In addition, we examined new gas chemistries based on iodine and bromine under high density plasma conditions. It has long been recognized that $\mathrm{I}_{2}$-based gas mixtures might be advantageous for dry etching In-containing compound semiconductors because of higher volatility of $\operatorname{InI}_{x}$ species relative to $\mathrm{InCl}_{x}$, as will be described below. Evaporation rate can be expressed as 


$$
\begin{gathered}
4 \\
u_{a}=\alpha\left[\mathrm{M}_{\mathrm{a}} / 2 \pi \mathrm{RT}\right]^{1 / 2} \mathrm{P}_{\mathrm{A}}(1-1) \\
\mathrm{P}_{\mathrm{A}}\left(\text { vapor pressure) }=\mathrm{C}_{\mathrm{A}} \mathrm{e}^{-\Delta H / R T}(1-2)\right. \\
\text { And so, } u_{a}=\alpha \mathrm{C}_{\mathrm{A}}\left[\mathrm{M}_{\mathrm{a}} / 2 \pi \mathrm{RT}\right]^{1 / 2} \mathrm{e}^{-\Delta H R T}(1-3)
\end{gathered}
$$

Figure 1 shows vapor pressure ${ }^{[33]}$ of some potential etch products as a function of temperature. As indicated in equation (1-2), the slope of this plot is enthalpy of vaporization, which is equivalent to activation energy for desorption $\left(\mathrm{E}_{\mathrm{d}}\right)$. As expected, $\mathrm{InCl}_{3}$ has much higher value of $\mathrm{E}_{\mathrm{d}}(37.8 \mathrm{kcal} / \mathrm{mole})$ than $\mathrm{GaCl}_{3}$, leading to the lower evaporation rate of $\mathrm{InCl}_{3}$, while etch product $\left(\operatorname{InI}_{3}\right)$ based upon iodine provided lower energy barrier $(20.2 \mathrm{kcal} / \mathrm{mole})$ for the desorption enhancing its evaporation. Pure $I_{2}$ is a solid requiring heating to produce a practical flow rate for etch processes (m.p. $113.5^{\circ} \mathrm{C}$ ). Alternatives such as $\mathrm{HI}, \mathrm{CH}_{3} \mathrm{I}, \mathrm{C}_{2} \mathrm{H}_{5} \mathrm{I}$ and $\mathrm{C}_{3} \mathrm{H}_{7} \mathrm{I}$ have all been investigated previously. All of these have drawbacks-HI has a shelf-life of about 6 months before decomposing to $\mathrm{H}_{2}$ and $\mathrm{I}_{2}$, while the methyl-, ethyl- and propyl- iodide are unsuitable for high density plasma sources because of excessive polymerization..$^{[34]}$ Brominebased plasma chemistries have also not received sufficient attention. $\mathrm{HBr}$ has been shown to

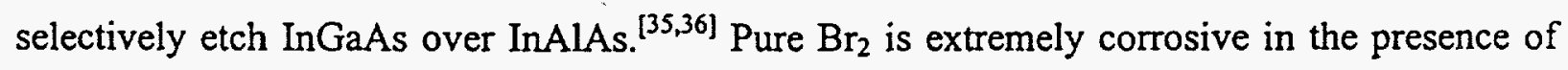
even minute quantities of water vapor in gas lines, mass flow controllers or pumping systems. It is therefore of interest to investigate an alternative source of $\mathrm{I}_{2}$ and $\mathrm{Br}_{2}$ for etching of InGaAlP. In this paper, a comparison of high density plasmas such as ECR (Electron Cyclotron Resonance) and ICP (Inductively Coupled Plasma) based on several gas chemistries $\left(\mathrm{CH}_{4} / \mathrm{H}_{2}\right.$, $\mathrm{Cl}_{2}, \mathrm{BCl}_{3}, \mathrm{ICl}, \mathrm{BI}_{3}, \mathrm{IBr}, \mathrm{BBr}_{3}$ ) will be described for the etching of InGaAlP semiconductor system.

Figure 2 shows a conventional RIE system. Radiofrequency power is deposited into the thin sheath region by capacitive coupling. The electrons, which are subject to rf power applied to the electrode, will be accelerated at the sheath regions changing direction upward and 
downward. The collisions that electrons undergo with gas molecules contribute to sustaining the plasma. The motion range of electrons is large compared to that of ions due to their smaller mass. Electrons may be lost to the electrode, which will take on a negative $\mathrm{DC}$ bias because of the charge transferred from the electrons. This self-bias may lead to damage to the sample by subsequent ion bombardment, giving rise to electrical or optical degradation. In addition, ion flux is coupled with ion energy. Thus, high ion flux can be achieved only at the expense of surface degradation due to the high ion energy.

On the other hand, the mechanism behind achieving a high density plasma is electron confinement. As described in Figure 3, Electron Cyclotron Resonance (ECR) takes advantage of an external magnetic field and a resonance effect to confine electrons. The frequency of orbital motion of electrons, confined under the action of an external magnetic field (875 Gauss) is equivalent to the drive frequency of $2.45 \mathrm{GHz}$ leading to the occurrence of resonance, called electron cyclotron resonance, if this frequency of power is applied to the plasma. Subjected to this condition, electrons will be accelerated extending their mean free path more and more before getting lost to the electrode. The power is coupled into the electrons efficiently through the dielectric window. Now that ion density is decoupled with ion energy due to the trapped electrons, ECR can provide high ion density $\left(10^{11} \sim 10^{12} \mathrm{~cm}^{-3}\right)$ compared with $\operatorname{RIE}\left(\sim 10^{9} \mathrm{~cm}^{-3}\right)$ without inducing high damage to the sample. Moreover ion energy can be controlled separately by applied chuck bias. Furthermore, ECR discharges are capable of low pressure operation due to its efficient dissociation of gases to form the discharge.

Another high density plasma, Inductively Coupled Plasma (ICP), has become popular in semiconductor processing. As shown in Figure 5, the configuration is simple compared to ECR reactor. RF current circulating around the chamber in opposite directions causes an alternating magnetic field in the upward and downward directions. $\left(\mathrm{I}_{\mathrm{RF}} \rightarrow \mathbf{B}_{\mathrm{RF}}\right)$ It is this change in rate of 
magnetic field that induces a RF electric filed. $\left(d_{B_{R F}} / d T \rightarrow E_{R F}\right.$ ) (See Figure 4) This RF field $\left(\mathrm{E}_{\mathrm{RF}}\right)$ will accelerate the electrons into the circular path, confining them in a circular motion. The power transfer through the dielectric window by inductive coupling is efficient, leading to high ion density. The plasma, first formed in the shape of a ring following the path of electrons, will diffuse to the center of the chamber and then downward toward the sample. As long as the capacitively coupled component is absent, or at least small, the electrons trapped themselves in a circular path, will have only a small chance to be lost to the chuck resulting in low DC self bias. Ion energy, separate from the ion flux, can be controlled by applying another rf source at the chuck. Unlike ECR, ICP does not use resonance or microwave power source. Hence, it can provide advantages over ECR such as easier turning and low price. Also, it is believed to be easy to scale-up for large wafer processing.

High density plasmas such as ECR and ICP achieve decoupling of ion energy and ion density by electron confinement. Then, what kind of advantages can high density plasmas produce for etch processing? First, higher dissociation of gases to ignite plasma, due to the longer mean free path or mean lifetime of electrons, which are trapped inside the plasma, can provide high ion density and large concentrations of atomic radicals. This will lead to high etch rate. Secondly, fewer electrons are lost to the wall or electrode compared to RIE, and thus less ion damage is induced. The last advantage is low pressure operation. This makes it possible to get anisotropic etching and will be major factor as the feature size etched becomes smaller.

In this paper we describe use of ICP and ECR reactor and different plasma chemistries, for the etching of the InGaAlP system. The predominant etch mechanism, i.e. physical, chemical or ion-enhanced, has been determined in each case by measurement of etch yield. 


\section{EXPERIMENTAL}

The $\mathrm{In}_{0.5} \mathrm{Ga}_{0.5} \mathrm{P}$ and $\mathrm{Al} \mathrm{l}_{0.5} \mathrm{In}_{0.5} \mathrm{P}$ were grown lattice-matched to $\mathrm{GaAs}$ substrates by either metal organic molecular beam epitaxy $(\mathrm{MOMBE})^{[37]}$ or metal organic chemical vapor deposition (MOCVD) ${ }^{[38]}$ using trimethylindium, trimethylamine alane, triethylgallium and phosphine. Layers were nominally undoped $\left(\mathrm{p} \leq 2 \times 10^{15} \mathrm{~cm}^{-3}\right)$ and were typically $1-2 \mu \mathrm{m}$ thick. The compositions were confirmed by double crystal X-ray diffraction and photoluminescence. ${ }^{[12,13]}$ The $\mathrm{Al}_{0.5} \mathrm{Ga}_{0.5} \mathrm{P}$ was grown on $\mathrm{Si}$ by MOMBE and was carbon doped $\left(\mathrm{p} \sim 10^{19} \mathrm{~cm}^{-3}\right)$.

The samples were patterned with AZ5209E photoresist in a resolution test pattern with lines and spaces of $1-100 \mu \mathrm{m}$. All the etching was performed in both Plasma Therm $790 \mathrm{ICP}$ system and Plasma Therm SLR 770 system. For 790 system, the plasma is generated in a 3-turm planar ICP source (0-1500W) operating at $2 \mathrm{MHz}$. The electrode was biased through application of rf (13.56 MHz) power (0-450W). For 770 system, a low profile ECR source (Astex 4400) operating at $2.45 \mathrm{GHz}$ was powered between $400-100 \mathrm{~W}$, with an upper magnet of $170 \mathrm{~A}$ and a lower collimating magnet current of $40 \mathrm{~A}$. The samples were thermally bonded to a mechanically clamped Si carrier wafer. The process pressure was varied from $2-15 \mathrm{mTorr}$ at a total gas flow rate of 15 standard cubic centimeter per minute $(\mathrm{sccm})$. Etch rates were obtained from stylus profilometry after removal of the resist in acetone. Surface roughness was examined by atomic force microscopy (AFM). The near-surface chemistry was investigated by Auger Electron Spectroscopy (AES) in a Perkin-Elmer system using a $0.5 \mathrm{keV}$ probe beam. Depth profiling was performed in these experiments with a $2 \mathrm{keV} \mathrm{Ar}^{+}$ion beam, producing a sputter rate of $\sim 70 \AA \min ^{-1}$. 


\section{RESUALTS AND DISCUSSION}

\section{A. ELECTRON CYCLOTRON RESONANCE AND INDUCTIVELY COUPLED PLASMA ETCHING WITH $\mathrm{CH}_{4} / \mathrm{H}_{2} / \mathrm{Ar}$ CHEMISTRY: ION-DRIVEN MECHANISM}

Figure 6 shows etch rates or sputter rates of InGaP, AlInP and AlGaP as a function of microwave source power in either $5 \mathrm{CH}_{4} / 15 \mathrm{H}_{2} / 10 \mathrm{Ar}$ or $30 \mathrm{Ar}$ discharges at constant pressure and dc self bias. Microwave source power controls ion flux and atomic neutral density by creating more efficient dissociation of the plasma. The general trend in etch rates in both discharges is higher etch rates for all three semiconductors at the higher microwave power due to the higher abundance of dissociated neutrals and ions in the plasma. The first thing we note here is that the etch rates for all materials, achieved in $\mathrm{CH}_{4} / \mathrm{H}_{2} / \mathrm{Ar}$ discharges, are lower at the whole range of microwave source power investigated than the sputter rate. Secondly, Al containing materials (AlInP, AlGaP) showed slow etching compared to InGaP. The lack of chemical enhancement with $5 \mathrm{CH}_{4} / 15 \mathrm{H}_{2} / 10 \mathrm{Ar}$ chemistry may be related with the fact that the generation of methyl radicals in the plasma is not efficient enough for the etching, or competition between polymer deposition and etching limits etch process. ${ }^{[1,39,40]}$ We tend to eliminate the latter since polymer residues were not detected on the surface. Inductively Coupled Plasma (ICP) shows a similar trend to Electron Cyclotron Resonance (ECR). Figure 7 shows etch rates and etch yield as a function of ICP source power with the same gas chemistry $\left(\mathrm{CH}_{4} / \mathrm{H}_{2} / \mathrm{Ar}\right)$ at constant dc self bias and pressure. Etch rates, obtained under ICP, are comparable to the case of ECR. Etch yield calculated remained low values constantly irrespective of source power. The increase in etch rates with $\mathrm{CH}_{4} / \mathrm{H}_{2} / \mathrm{Ar}$ chemistry, therefore, is likely to result from the increase of the ion flux at higher source power, which implies an ionassisted mechanism. 
In addition to the ion flux, the ion energy, controlled by rf chuck bias, has a significant impact on the etch rates. As shown in Figure 8, etch rates of all ternary compounds increase as the rf chuck bias is increased under both ICP (top) and ECR (bottom) conditions. The increase in rf chuck bias controls the potential between chuck and plasma resulting in higher ion energy. High ion energy along with high ion flux can provide a good condition for the desorption of etch products as well as the bond breaking of the target materials.

Pressure controls the relative contributions of the physical and chemical components of the etching. As pressure is increased, chemical component outweighs physical component due to the low electron energy and ionization efficiency. Figure 9 shows etch rate dependence on the pressure for InGaP under both ICP and ECR at constant dc self bias and source power. The etch rates dropped above $2 \mathrm{mT}$ Torr and kept constant values thereafter in both cases. This result confirms once again the ion-driven mechanism of the $\mathrm{CH}_{4} / \mathrm{H}_{2} / \mathrm{Ar}$ chemistry for the etching of InGaP. The dominance of chemical component at high pressure led to the suppression of etching above $2 \mathrm{~m}$ Torr.

Surface roughness depends upon both ICP source power and ion energy. In conventional RIE etching, the surface roughens with an increase in etch rate. ${ }^{[1,39]}$ However, Inductively Coupled Plasma (ICP) etching produces smooth surface even at high etch rates. As shown in Figure 10 (top), root-mean-square (RMS) roughness obtained from AFM for InGaP decreases at higher ICP source power in $5 \mathrm{CH}_{4} / 15 \mathrm{H}_{2} / 10 \mathrm{Ar}$ discharges at constant pressure (2mTorr) and dc self bias $(-120 \mathrm{~V})$. We believe this results from the higher ion flux available. Figure 10 (bottom) shows RMS roughness of InGaP as a function of dc self bias under both ICP (500W) and ECR (800W) conditions. Surface morphology of InGaP improved with higher ion energy in both ICP and ECR cases, probably due to the enhanced ion sputtering of etch products. AFM scans images of $\mathrm{InGaP}$ with $-100 \mathrm{~V} \mathrm{dc}, 5 \mathrm{CH}_{4} / 15 \mathrm{H}_{2} / 10 \mathrm{Ar}$ discharges at the 
different microwave source powers are shown in Figure 11. A Smoother surface was obtained with higher ion flux from RMS value of $22.4 \mathrm{~nm}$ at $800 \mathrm{~W}$ ECR to $5.4 \mathrm{~nm}$ at $1000 \mathrm{~W}$ ECR. SEM pictures of $\mathrm{InGaP}$ with $\mathrm{CH}_{4} / \mathrm{H}_{2} / \mathrm{Ar}$ chemistry are shown in Figure 12 at $2 \mathrm{mTorr}, 350 \mathrm{~W}$ rf, 750W ICP (top) or $1.5 \mathrm{mT}$ Torr, 100W rf, $800 \mathrm{~W}$ ECR (bottom) discharges. The etched surface was rough with tilted sidewalls (top) and In droplets on the surface were observed. Reduced if power led to more sloped sidewalls due to the suppressed ionic component (bottom).

Turning to the near-surface chemistry, Figure 13 shows AES surface scan (top) and depth profile (bottom) from InGaP after etching in $5 \mathrm{CH}_{4} / 15 \mathrm{H}_{2} / 10 \mathrm{Ar}$ discharges at the ICP source power $(1000 \mathrm{~W})$ that maximizes etch rate $(1435 \AA / \mathrm{min})$. There is oxygen present from the native oxide that grows on the sample during the transfer from the etch reactor to the AES chamber, and also carbon from the same exposure to ambient air. There is indium enrichment (In droplet formation) apparent in the near surface region, and this may confirm the claim regarding inefficient generation of reactive radicals in the plasma with this chemistry. The depletion of phosphorous from the surface extended into the sample around $100 \AA$, probably due to the high volatility of the $\mathrm{P}$ etch product, phosphine $\left(\mathrm{PH}_{3}\right)$.

\section{B. INDUCTIVELY COUPLED PLASMA ETCHING $\mathbb{N}^{\mathrm{N}} \mathrm{Cl}_{2}$-BASED CHEMISTRIES CHEMICALLY DRIVEN MECHANISM}

Figure 14 shows the comparison of plasma species obtained from mass spectroscopy measurements in either $\mathrm{Cl}_{2} / \mathrm{Ar}$ (bottom) or $\mathrm{Cl}_{2} / \mathrm{H}_{2}$ (top) discharges at fixed source power (750W), dc bias (-100V) and pressure (2mTorr). Dominant species in $\mathrm{Cl}_{2} / \mathrm{Ar}$ mixture were atomic chlorine (35 37AMU) and molecular chlorine in the range from 70 to 74AMU. Most chlorine species increased in intensity with $\mathrm{Cl}_{2}$ concentration, while chlorine ion $37 \mathrm{Cl}^{2+}$, detected at 18.5AMU, did not show any variation in intensity regardless of gas composition 
change. On the contrary, adding hydrogen created new species $(\mathrm{HCl})$ with suppression of chlorine molecules. $\mathrm{HCl}$, with its components in 35 38AMU, has high thermodynamic stability relative to $\mathrm{Cl}$ and $\mathrm{Cl}_{2} \cdot{ }^{[41]}$ Two possible gas phase reaction mechanisms to produce $\mathrm{HCl}$ are as follows.

$$
\begin{aligned}
& \mathrm{Cl}+\mathrm{H}_{2} \rightarrow \mathrm{H}+\mathrm{HCl}, \Delta \mathrm{H}^{\circ}{ }_{298}=4.2 \mathrm{~kJ} / \mathrm{mole}, \mathrm{E}_{\mathrm{a}}=21.3 \mathrm{~kJ} / \mathrm{mole}(4-1)^{[42]} \\
& \mathrm{Cl}_{2}+\mathrm{H} \rightarrow \mathrm{Cl}+\mathrm{HCl}, \Delta \mathrm{H}^{\circ}{ }_{298}=189.1 \mathrm{~kJ} / \mathrm{mole}, \mathrm{E}_{\mathrm{a}}=5.0 \mathrm{~kJ} / \mathrm{mole}(4-2)^{[43]}
\end{aligned}
$$

These reactions can proceed easily in the plasma to produce $\mathrm{HCl}$, due to the low activation energy barriers for both reactions. Maximum intensities for $\mathrm{HCl}$ (35 38AMU) occurred at $33.3 \% \mathrm{Cl}_{2}$ concentration. Above that composition, intensities of $\mathrm{HCl}$ decreased with chlorine molecule appearance.

Figure 15 shows the etch rate dependence of $\operatorname{In}_{0.5} \mathrm{Ga}_{0.5} \mathrm{P}, \mathrm{Al}_{0.5} \mathrm{In}_{0.5} \mathrm{P}$ and $\mathrm{Al}_{0.5} \mathrm{Ga}_{0.5} \mathrm{P}$ (top), and change of intensities for plasma species (center, bottom) on discharge composition for either $\mathrm{Cl}_{2} / \mathrm{Ar}$ or $\mathrm{Cl}_{2} / \mathrm{H}_{2}$ at fixed pressure (2mTorr), ICP source power (750W) and dc selfbias (-100V). The rf power was varied between $150-175 \mathrm{~W}$ to hold dc bias constant. The general trend in both discharges is for the etch rates to go through a maximum with percentage $\mathrm{Cl}_{2}$ in the discharge. The pure $\mathrm{Ar}$ sputter rates are low for all these materials, and as $\mathrm{Cl}_{2}$ is added, the etch rates rise rapidly, indicating a strong chemical enhancement. However, beyond particular plasma compositions, the etch rates fall and are low again for pure $\mathrm{Cl}_{2}$ discharges. We interpret this behavior in terms of a competition between formation of chlorinated etch products and their removal by ion-assisted desorption. As indicated in Figure 15 (center), atomic chlorines and molecular chlorines increase at the expense of $\mathrm{Ar}$ with $\mathrm{Cl}_{2}$ concentration. At optimized ion-to-neutral ratios of these etch products there will be a balance between the formation and removal rates of these etch products. ${ }^{[30,31,44-46]}$ At high atomic chlorine conditions, there will be a build-up of a thick selvedge or reaction layer which is not efficiently 
removed by ion sputtering. This is the typical situation in $\mathrm{Cl}_{2}$-based reactive ion etching of Incontaining III-V semiconductors, ${ }^{[1,47-50]}$ or of strongly-bonded materials like AlGaP. For $\mathrm{Cl}_{2} / \mathrm{H}_{2}$, the etch rate maximum occur at relatively low $\mathrm{Cl}_{2}$ compositions, and the maximum rate obtained for $\mathrm{InGaP}$ in $\mathrm{Cl}_{2} / \mathrm{H}_{2}$ is significantly faster than with Ar addition. We believe this is due to the creation of new species $(\mathrm{HCl})$ in the plasma since the etch rate of $\mathrm{InGaP}$ is consistent with $\mathrm{HCl}$ intensity change, as represented in Figure 115 (bottom).

The etch rate of AlGaP was found to be a strong function of AlP mole fraction, and this is useful when considering structures in which an etch-stop layer is required. For the $\mathrm{x}=0.5$ alloys, AlGaP has a higher melting point (2282K) than either InGaP (1538K) or AlInP (2079K) which is s good indication of higher bond strength for AlGaP, and this difference in bond strength increases as the AlP mole fraction in AlGaP is increased. The standard enthalpy of formation for AlP $(-39.6 \mathrm{kcal} / \mathrm{mole})$ is higher than that for GaP $(-30 \mathrm{kcal} / \mathrm{mole}) \cdot{ }^{[23]}$ We observed reduced etch rate of $\mathrm{Al}_{\mathrm{x}} \mathrm{Ga}_{1-\mathrm{x}} \mathrm{P}$ as the $\mathrm{Al}$ composition was increased, from $\sim 1100 \AA \cdot \mathrm{min}^{-1}$ for $\mathrm{Al}_{0.06} \mathrm{Ga}_{0.94} \mathrm{P}$ to $\sim 160 \AA \cdot \mathrm{min}^{-1}$ for $\mathrm{Al}_{0.7} \mathrm{Ga}_{0.3} \mathrm{P}$ in $5 \mathrm{Cl}_{2} / 10 \mathrm{Ar}, 750 \mathrm{~W}$ source power, $-100 \mathrm{~V}$ dc bias discharges, as shown in Figure 16. Since the volatilities of the etch products for AlGaP should be on average higher than for the In-containing compounds $\left(\mathrm{InCl}_{\mathrm{x}}\right.$ has the lowest vapor pressure), this indicates that the etch rate for $\mathrm{AlGaP}$ is at least in part limited by the initial bond breaking that must precede formation of the etch products.

In an ICP system, the ion flux increases as the source power is increased. Figure 17 (top) shows that at constant ion energy (dc self-bias is held constant by also increasing the rf power on the chuck from $\sim 70 \mathrm{~W}$ to $225 \mathrm{~W}$ as the source power is increased), the increased ion flux at higher source powers leads to an increase in etch rates of all three materials. There are well-defined threshold source powers for the onset of etching, indicating that a certain ion flux is required to both break the bonds, and help desorb the resultant etch products. While InGaP 
showed a very high etch rate $(>1 \mu \mathrm{m} / \mathrm{min})$ at high source power $(1000 \mathrm{~W})$, the more strongly bonded AlGaP and AllnP did not show the same increase in etch rate at high source power. There is an etch selectivity of $\sim 3: 1$ for InGaP over the other two ternaries at high source powers in this chemistry. Figure 17 (bottom) shows the etch yields of three ternary materials as a function of ICP source power. In contrast to the $\mathrm{CH}_{4} / \mathrm{H}_{2}$-based chemistry, the ion-assisted desorption is more efficient with $\mathrm{Cl}_{2} / \mathrm{Ar}$ discharges and this provides the necessary chemical enhancement to overcome the barrier of desorption of involatile In etch products. Etch yield of InGaP above 750W ICP source power went up rapidly, a good indication of chemical-driven mechanism.

Apart from ion flux, the ion energy, controlled by rf power applied to the chuck position also has a strong influence on etch rates. Figure 18 shows the etch rate dependence on ion energy for all three semiconductors. All materials showed a monotonic increase in etch rates above $-35 \mathrm{~V}$ dc bias, suggesting the presence of the threshold ion energy for the etching to commence. We believe that threshold ion energy is related with the energy barrier of either bond breaking or desorption of etch products. Even under high density plasma conditions in which ion flux is high enough, a certain ion energy is necessary to provide a good chemical enhancement. Only well-controlled combinations of ion flux and ion energy can lead to the ionneutral synergism. AlInP showed a slower etching compared to other two materials. This might be related with the native oxide, which grows on the surface to form relatively stable $\mathrm{Al}_{2} \mathrm{O}_{3}$. We did not observe much difference in etching behavior between InGaP and AlInP in ECR reactor, which is equipped with load-lock system, with $\mathrm{Cl}_{2}$-based chemistry. ${ }^{[1,53]}$ Exposure to the atmosphere for ICP chamber is likely to be sensitive for oxidation of Al-containing materials. 
Ion/neutral ratio has a strong effect on the etched surface roughness. As shown in Figure $19, \mathrm{Cl}_{2} / \mathrm{Ar}$ discharges produced smooth surface of $\mathrm{InGaP}$ after etching in the range of $33 \sim 67 \% \mathrm{Cl}_{2}$ which is consistent with the high etch rate of $\mathrm{InGaP}$. Below the optimized range, the surface became rough due to the preferential sputtering of group $V$ element, phosphorous (P). The $\mathrm{Cl}_{2} / \mathrm{H}_{2}$ chemistry showed a somewhat different trend. The smoothest surfaces were obtained at $33 \%$, at which the maximum etch rate $(\sim 3800 \AA / \mathrm{min})$ of InGaP was achieved, and above this composition, the surface was degraded. Surface roughness also depends upon the source power. Figure 20 shows AFM surface images of the etched surface of InGaP with $10 \mathrm{Cl}_{2} / 5 \mathrm{Ar}$ chemistry at constant dc bias $(-100 \mathrm{~V})$. RMS roughness value, obtained from Atomic Force Microscopy (AFM), was decreased from $4.1 \mathrm{~nm}$ to $2.8 \mathrm{~nm}$ as source power is increased. High ion flux available at the high source power enhanced sputter desorption of involatile etch products, leading to the smoother surface with high etch rate. AlInP shows a similar behavior to InGaP in terms of surface roughness. Figure 21 shows surface roughness dependence on ion energy and source power for AlInP. Both high ion energy and high ion flux resulted in smooth surface, respectively. SEM micrographs for AlInP etched under two different conditions are shown in Figure 22. At $-100 \mathrm{~V}$ dc bias, $2 \mathrm{mTorr}$ pressure, the surfaces are reasonably good over an optimized range of plasma compositions.

AES surface scans and depth profiles after etching in either $\mathrm{Cl}_{2} / \mathrm{Ar}$ or $\mathrm{Cl}_{2} / \mathrm{H}_{2}$ at the plasma compositions that approximately maximizes etch rate (i.e. $10 \mathrm{Cl}_{2} / 5 \mathrm{Ar}, 5 \mathrm{Cl}_{2} / 10 \mathrm{H}_{2}$ ) are shown in Figure 23 and Figure 24, respectively. There is oxygen present in all cases from the native oxide that grows on the sample during transfer from the etch reactor to the AES analysis chamber, and also carbon from the same exposure to ambient air. No chlorine-containing residues were detected in both discharges, indicating no chlorinated layers built up on the surface. The surface etched in $10 \mathrm{Cl}_{2} / 5 \mathrm{Ar}$ discharges revealed no In-enrichment at the near 
surface $(\sim 100 \AA)$ and there was no sign of phosphorous deficiency. The result provided by $5 \mathrm{Cl}_{2} / 10 \mathrm{H}_{2}$ discharges was comparable to the case of Ar addition.

Figure 25 shows etch rates of three ternary semiconductors as function of gas composition change in either $\mathrm{BCl}_{3} / \mathrm{Ar}$ (top) or $\mathrm{BCl}_{3} / \mathrm{H}_{2}$ (bottom) discharges at fixed source power (750W) and pressure (2mTorr). Two different dc biases were chosen in both discharges for comparison. Etch rates of all three materials peak around $20 \% \mathrm{BCl}_{3}$, which is lower compared to the case of $\mathrm{Cl}_{2}$ chemistry at $-100 \mathrm{~V}$ dc with $\mathrm{Ar}$ addition. $\mathrm{AlGaP}$ showed a faster etching than In-based materials at pure $\mathrm{BCl}_{3}$. However, increasing bias up to $-200 \mathrm{~V}$ led to drastic increase in etch rates for all three semiconductors, indication of a strong chemical enhancement involved. Note that etching proceeded without any suppression until pure $\mathrm{BCl}_{3}$ at high ion energy (dc $-200 \mathrm{~V}$ ), suggesting reaction-limited, whereas etching is controlled by desorption limited above $20 \% \mathrm{BCl}_{3}$ at low ion energy $(\mathrm{dc}-100 \mathrm{~V}) . \mathrm{BCl}_{3} / \mathrm{H}_{2}$ discharges showed a similar behavior. InGaP, AlInP and AlGaP showed much higher etch rates with high ion energy ( $\mathrm{dc}-200 \mathrm{~V}$ ) at the whole range of gas composition. Peak in etch rate for InGaP occurred at $33.3 \% \mathrm{BCl}_{3}$ concentration at low dc bias $(-100 \mathrm{~V})$, just like the case of $\mathrm{Cl}_{2} / \mathrm{H}_{2}$ discharges. Higher etch rate for InGaP with $\mathrm{BCl}_{3} / \mathrm{H}_{2}$ discharges arises from the creation of $\mathrm{HCl}$ species in the plasma.

Mass spectra of plasma species in both $5 \mathrm{BCl}_{3} / 10 \mathrm{Ar}$ and $5 \mathrm{BCl}_{3} / 10 \mathrm{H}_{2}$ discharges are compared in Figure 26, at fixed source power $(750 \mathrm{~W})$, dc bias $(-100 \mathrm{~V})$ and pressure (2mTorr). Atomic chlorine components occurred at 35, 36, 37AMU with appearance of $\mathrm{Ar}$ components at 20 and $40 \mathrm{AMU}$ in $\mathrm{BCl}_{3} / \mathrm{Ar}$ combination. With addition of hydrogen in place of $\mathrm{Ar}, \mathrm{HCl}$ components showed up in the range of 35 38AMU. We suspect that gas phase reaction in the plasma, in which hydrogens were combined with atomic or molecular chlorines creating $\mathrm{HCl}$ and $\mathrm{Cl}$ radicals, led to the enhanced etch rate for $\mathrm{InGaP}$. The optical emission spectroscopy data 
is in good agreement with the results obtained from mass spectroscopy. $5 \mathrm{BCl}_{3} / 10 \mathrm{Ar}$ chemistry showed strong chlorine peak at $808.3 \mathrm{~nm}$ with $\mathrm{Ar}$ at $750 \mathrm{~nm}$ at $750 \mathrm{~W}$ ICP, $-200 \mathrm{~V}$ dc and $2 \mathrm{mTorr}$, as represented in Figure 27 (top). By contrast, $5 \mathrm{BCl}_{3} / 10 \mathrm{H}_{2}$ mixture revealed no chlorine peak, showing only hydrogen at 486 and $656 \mathrm{~nm}$ at the same condition, as indicated in Figure 27 (bottom), which suggests the reaction of chlorine with hydrogen to create $\mathrm{HCl} . \mathrm{Cl}$ components might be overlapped with those of $\mathrm{HCl}$ in the mass spectrum in $\mathrm{BCl}_{3} / \mathrm{H}_{2}$ discharges but chances are that most chlorines were converted into the $\mathrm{HCl}$, resulting in the disappearance of $\mathrm{Cl}$ peak in optical emission spectroscopy.

In an ICP tool, source power controls dissociation of gas molecules into ions and reactive neutrals in the plasma. Optical emission spectrum (Figure 28, top) and peak intensity of chlorine and argon (Figure 28, bottom) shows this role of source power to provide radicals. Strongest peak for chlorine appeared at $808.3 \mathrm{~nm}$ in $2 \mathrm{mTorr}, 1000 \mathrm{~W}$ ICP, $5 \mathrm{BCl}_{3} / 10 \mathrm{Ar}$ discharges at $-200 \mathrm{~V}$ dc bias. We normalized the chlorine peak with $750 \mathrm{~nm}$ Ar as a function of source power. Normalized intensity increased steadily up to $1000 \mathrm{~W}$ source power, a good indication of more radicals available at high source power.

Figure 29 shows either etch rates (top) or etch yields (bottom) for InGaP, AlInP and $\mathrm{AlGaP}$ as a function of source power at the two different ion energies. Etch rates of three ternaries increased with source power due to the higher density of neutrals and ions available, as confirmed partly in Figure 28. Ion energy had a strong effect on the etching behavior. Etch yields of InGaP, AlInP and AlGaP remained at near constant values for the whole range of source power we investigated at $-100 \mathrm{~V} \mathrm{dc}$, suggesting an ion-driven mechanism. Increasing dc bias to $-200 \mathrm{~V}$ resulted in much enhanced etch rates of all semiconductors, with InGaP reaching more than $1 \mu \mathrm{m} \cdot \mathrm{min}^{-1}$. Etch yields of InGaP and AllnP increased above $750 \mathrm{~W}$ ICP source power, indicating chemical-driven mechanism. 
Since the etching was strongly dependent on ion energy with the $\mathrm{BCl}_{3} / \mathrm{Ar}$ chemistry, we investigated etch rates of $\mathrm{InGaP}, \mathrm{AllnP}$ and $\mathrm{AlGaP}$ as a function of de self bias in $2 \mathrm{mTorr}$, $750 \mathrm{~W} \mathrm{ICP}, 5 \mathrm{BCl}_{3} / 10 \mathrm{Ar}$ discharges, as shown in Figure 30 . Rapid etching of all three materials was obtained above $-100 \mathrm{~V}$ dc self bias, an indication of the presence of a threshold ion energy. Threshold ion energy was reported around $-35 \mathrm{~V}$ dc self bias with $\mathrm{Cl}_{2} / \mathrm{Ar}$ chemistry. We believe that this threshold ion energy is related to the activation energy barrier for both desorption of involatile In etch products and bond breaking of strong materials. Since InGaP has the lowest bond strength, it showed the fastest etching once ions get an energy high enough to provide sputter-enhanced desorption of involatile In etch products $\left(\mathrm{InCl}_{\mathbf{x}}\right)$.

Smooth surface morphologies with low RMS roughness values were obtained at optimized ion-to-neutral ratio. As represented in Figure 31, increasing $\mathrm{BCl}_{3}$ percentage from $20 \%$ to $33.3 \%$ produced improved surfaces of InGaP with RMS roughness value of $5.9 \mathrm{~nm}$. Hydrogen addition produced an even better surface with high etch rate $\left(2000 \AA \cdot \min ^{-1}\right)$. Representative scanning electron micrographs of features etched into $\mathrm{InGaP}$ using $\mathrm{SiN}_{\mathrm{x}}$ masks are shown in Figure 32. Under conditions where etch rate is near maximum at low ion energy (dc $-100 \mathrm{~V}$ ), i.e. $5 \mathrm{BCl}_{3} / 10 \mathrm{Ar}, 750 \mathrm{~W}$ source power, $2 \mathrm{mTorr}$, the surface is rough and shows the presence of In droplets (top, left). Enhanced ion-assisted desorption of $\mathrm{InCl}_{\mathrm{x}}$ at high ion energy (dc $-200 \mathrm{~V}$ ) led to quite smooth surface and anisotropic profiles in $750 \mathrm{~W} \mathrm{ICP,} 10 \mathrm{BCl} / 5 \mathrm{Ar}$ discharges (bottom, left and right). $5 \mathrm{BCl}_{3} / 10 \mathrm{H}_{2}$ discharges also provided a comparable surface and profile at $-200 \mathrm{~V}$ dc self bias (top, right). SEM micrographs for AlInP etched under two different conditions are shown in Figure 33. At low ion energy $(-100 \mathrm{~V} \mathrm{dc}), 5 \mathrm{BCl}_{3} / 10 \mathrm{Ar}$ discharges produced rough surface and undercut profile (top). On the country, the surface etched at high dc bias of $-200 \mathrm{~V}$ with $10 \mathrm{BCl}_{3} / 5 \mathrm{Ar}$ discharges was smooth without any sign of $\mathrm{Cl}$ residues on the surface and profile was quite vertical (bottom). Auger Electron Spectroscopy 
(AES) surface scans from AlInP before and after etching in $5 \mathrm{BCl}_{3} / 10 \mathrm{Ar}$ discharges as a function of source power and dc self bias are shown in Figure 34 . There is oxygen present in all cases from the native oxide during transfer from the etch reactor to the AES analysis chamber, and also carbon from the same exposure to ambient air. The sample etched at low ion energy (dc $-100 \mathrm{~V}$ ) has a high coverage of chlorine-containing residues, consistent with rough surface and low etch rate. Increasing ion flux reduced the concentration of the chlorinated residues, which is most likely related to the improved sputtering efficiency at higher source power. High ion energy (dc $-200 \mathrm{~V}$ ) led to drastic reduction of $\mathrm{Cl}$ peak on the surface, which is in good agreement with fast etching at this condition.

Figure 35 shows optical emission spectra from $\mathrm{Cl}_{2} / \mathrm{BCl}_{3} / 5 \mathrm{Ar}$ discharges as a function of $\mathrm{Cl}_{2} / \mathrm{BCl}_{3}$ composition at fixed source power $(500 \mathrm{~W})$, dc bias $(-150 \mathrm{~V})$ and pressure (2mTorr). Strong peaks occurred at $413 \mathrm{~nm}$ for $\mathrm{Cl}^{+}$and $837.5 \mathrm{~nm}$ for $\mathrm{Cl}$. First thing to note is that all peaks corresponding to $\mathrm{Cl}$ showed maximum intensity at $32 \mathrm{Cl}_{2} / 8 \mathrm{BCl}_{3} / 5 \mathrm{Ar}$ composition. It is believed that $\mathrm{Cl}_{2}$ can produce more $\mathrm{Cl}$ neutrals than $\mathrm{BCl}_{3}$. One more additional feature is that adding a small amount of $\mathrm{BCl}_{3}$ to $\mathrm{Cl}_{2}$ creates many more neutrals than either pure $\mathrm{Cl}_{2}$ or pure $\mathrm{BCl}_{3}$. Secondly, $\mathrm{BCl}_{3}$ is more sensitive to the creation of molecular species than $\mathrm{Cl}_{2}$. As shown in Figure 35 (top), molecular continua in the spectrum becomes much more dominant as $\mathrm{BCl}_{3}$ concentration is increased. We have used mass spectrometry to identify the plasma species available. As shown in Figure 36 , heavy molecular $\mathrm{BCl}_{\mathrm{x}}$ species $(81,83$, and $85 \mathrm{AMU})$ were detected from $\mathrm{BCl}_{3}$ relative to $\mathrm{Cl}_{2}\left(70 \mathrm{Cl}_{2}, 72 \mathrm{Cl}_{2}\right.$, and $\left.74 \mathrm{Cl}_{2}\right)$. Figure 37 shows etch rates of InGaP and AlInP (top), and normalized optical emission intensity (bottom) as a function of $\mathrm{Cl}_{2} / \mathrm{BCl}_{3}$ composition change at fixed source power (750W), dc bias $(-150 \mathrm{~V})$ and pressure (2mTorr). Etch rates of the two semiconductors are increased in the range from $40 \% \mathrm{Cl}_{2}$ to $80 \% \mathrm{Cl}_{2}$ and then dropped to minimum at pure $\mathrm{Cl}_{2}$, which is in good agreement with the optical 
emission intensities. We can divide etching mechanism into two regions at these conditions. Etching is controlled by neutral species in the range from $40 \%$ to $100 \% \mathrm{Cl}_{2}$, an indication of reaction-limited conditions, whereas heavy $\mathrm{BCl}$ or $\mathrm{BCl}_{2}$ molecular ions made contribution to the increase of etch rates in the range of $0 \sim 40 \% \mathrm{Cl}_{2}$, a sign of desorption-limited etching. It is likely that molecular continua from optical emission arised from $\mathrm{BCl}$ or $\mathrm{BCl}_{2}$ molecular species.

Figure 38 shows the dependence of InGaP and AlInP etch rates on source power in $2 \mathrm{mTorr}, 32 \mathrm{Cl}_{2} / 8 \mathrm{BCl}_{3} / 5 \mathrm{Ar}$ discharges at constant dc bias of $-150 \mathrm{~V}$. InGaP showed an increase in its etch rate up to $1800 \AA \cdot \mathrm{min}^{-1}$ at $1000 \mathrm{~W}$ source power due to the abundant ion flux at high source power. AlInP showed a similar behavior to InGaP, suggesting the same etching mechanism at these conditions.

Ion energy is likely to be most dominant factor for the etching of InGaP and AlInP with $\mathrm{Cl}_{2} / \mathrm{BCl}_{3} / 5 \mathrm{Ar}$ chemistry. As indicated in Figure 39 (top), etch rates of InGaP increased monotonically up to $\sim 6000 \AA \cdot \mathrm{min}^{-1}$ at $-400 \mathrm{~V}$ dc bias. On the contrary, AlInP showed somewhat different trends, with a rapid increase in its etch rate above $-300 \mathrm{~V} \mathrm{dc}$ bias. Selectivity of AlInP over InGaP was around 2 at high de bias (-400V). Selectivity for AlInP over InGaP has never been previously reported. This might be related to the oxidation breakthrough step during the etching for AlInP in an ICP tool, equipped with loadlock system. Figure 39 (bottom) showed normalized optical emission intensity as a function of dc self bias in 2mTorr, 500W ICP, $32 \mathrm{Cl}_{2} / 8 \mathrm{BCl}_{3} / 5 \mathrm{Ar}$ discharges. Intensities of all species increased from $-50 \mathrm{~V}$ to $-150 \mathrm{~V} \mathrm{dc}$ and then remained constant above $-150 \mathrm{~V}$. We believe that capacitively coupling made a small contribution to the production of species in the range $-50 \mathrm{~V} \sim 150 \mathrm{~V} \mathrm{dc}$, which did not have much effect on etch rate since ion energy was a dominant factor for the etching. 
Figure 40 shows etch rates of the two semiconductors (top) and normalized intensities of mass spectra (bottom) as a function of process pressure. Pressure controls the ion-to-neutral ratio. The general belief is that the chemical component of the etching becomes dominant as pressure is increased. Intensity corresponding to $37 \mathrm{Cl}^{++}$decreased relative to atomic chlorines $(35 \mathrm{Cl}, 36 \mathrm{Cl})$ with pressure, indicating neutral species become dominant over the ionic component at high pressure. Additionally, $\mathrm{Cl}_{2}$ and $\mathrm{BCl}_{3}$ molecular species are increasing above $2 \mathrm{mTorr}$, possibly due to the recombination of atomic species. The maximum etch rates of InGaP and AlInP were achieved at the pressure of 5mTorr, which provided optimized ion-toneutral ratio. The suppression of etching above $5 \mathrm{~m}$ Torr should be related to the shortage of either ions or etchants.

Surface roughness of InGaP etched in $2 \mathrm{mTorr},-150 \mathrm{~V} \mathrm{dc}, 32 \mathrm{Cl}_{2} / 8 \mathrm{BCl}_{3} / 5 \mathrm{Ar}$ discharges showed a strong dependence on ICP source power. As shown in Figure 41, root-mean-square (RMS) of InGaP, measured by Atomic Force Microscopy (AFM), dropped to $3.2 \mathrm{~nm}$ at $750 \mathrm{~W}$ source power, due to the efficient sputter desorption of In etch products $\left(\mathrm{InCl}_{\mathrm{x}}\right)$. However, increasing source power up to $1000 \mathrm{~W}$ degraded the etched surface, arising from the preferential sputtering of phosphorous $(\mathrm{P})$. Figure 42 shows etched surface of AlInP as a function of source power and ion energy in $2 \mathrm{mTorr}, 32 \mathrm{Cl}_{2} / 8 \mathrm{BCl}_{3} / 5 \mathrm{Ar}$ discharges. Smooth surface, with low RMS value $(2.1 \mathrm{~nm})$, was obtained at the moderate source power $(500 \mathrm{~W})$ and ion energy $(-150 \mathrm{~V} \mathrm{dc})$. The surface becomes roughened at high source power $(1000 \mathrm{~W})$ and ion energy $(-400 \mathrm{~V} \mathrm{dc})$, probably due to its non-stoichiometry surface. Surface morphologies of InGaP and AlInP etched at different source power and ion energy are shown in Figure 43. The profiles of InGaP (top, left) and AlInP (top, right) were almost anisotropic at moderate source power (750W) and ion energy $(-150 \mathrm{~V} \mathrm{dc})$. High dc bias $(-400 \mathrm{~V})$ resulted in smooth surface of InGaP (bottom, right) without the presence of In droplets, which indicates the equirate removal of different etch 
products. Using photoresist as a mask led to the rough sidewalls, (striations transferred from photoresist, bottom, left), while $\mathrm{SiN}_{\mathrm{x}}$ masks degraded themselves upon exposure to the plasma (top, left and right, or bottom, right).

\section{INDUCTIVELY COUPLED PLASMA ETCHNG BASED ON NEW PLASMA} CHEMISTRIES: $\mathrm{BI}_{3} \mathrm{AND} \mathrm{BBr}_{3}$

$\mathrm{BI}_{3}$ is a solid with a melting point of $44^{\circ} \mathrm{C}$, while $\mathrm{BBr}_{3}$ is a liquid with a boiling point of $91.2^{\circ} \mathrm{C}$. Approximately $50 \mathrm{~g}$ of each material was placed in a quartz container within a stainless steel vacuum vessel that was heated to $\sim 45^{\circ} \mathrm{C}$ to enhance the respective vapor pressures. The vapor was allowed to enter the reactor chamber through a $\mathrm{Cl}_{2}$-compatible mass flow controller. Maximum flow rates of 5 and 10 standard cubic per minute $(\mathrm{sccm})$ were obtained for $\mathrm{BI}_{3}$ and $\mathrm{BBr}_{3}$, respectively, and the total flow rate was typically held at $10 \mathrm{sccm}$ by adding in $\mathrm{Ar}$.

Both $\mathrm{BI}_{3}$ and $\mathrm{BBr}_{3}$ were found to be readily dissociated in the ICP source, producing blue-violet discharges. Figure 44 shows an optical emission spectrum of pure $\mathrm{BI}_{3}$ discharges in this wavelength range, revealing a large number of atomic transitions. Figure 45 shows etch rates (top) and etch yields (bottom) for the three ternary alloys in $4 \mathrm{BI}_{3} / 6 \mathrm{Ar}$ and $4 \mathrm{BBr}_{3} / 6 \mathrm{Ar}$ discharges ( $750 \mathrm{~W}$ source power, $5 \mathrm{mT}$ Torr) as a function of dc chuck bias. There are several key features of the data. First, the etch rates for all three alloys are much higher in $\mathrm{BI}_{3} / \mathrm{Ar}$. Second, the threshold biases for the onset of etching are significantly lower for $\mathrm{BI}_{3}$ than $\mathrm{BBr}_{3}$, indicating the etch products are more volatile and require less ion-assistance for desorption. Third, the etch yields with $\mathrm{BI}_{3}$ are linearly dependent on dc bias, which indicates that the etching is still desorption-limited. For $\mathrm{BBr}_{3}$ etching of $\mathrm{InGaP}$, the rate decreases at high biases, partly due to removal of the active bromine species by sputtering before they can react with the semiconductor surface. 
Figure 46 shows etch rates for the three ternary alloys as a function of discharge composition in either $150 \mathrm{~W} \mathrm{rf,} \mathrm{BI}_{3} / \mathrm{Ar}$ (top) or $350 \mathrm{~W} \mathrm{rf} \mathrm{BBr}_{3} / \mathrm{Ar}$ (center) at fixed source power (750W) and pressure (5mTorr). Note that the dc self chuck bias decreases as $\mathrm{BI}_{3}$ content increases, suggesting that $\mathrm{BI}_{3}$ is readily ionized than $\mathrm{Ar}$ since dc bias decreases with increasing ion density in the plasma. By contrast, dc bias increases with $\mathrm{BBr}_{3}$ percentage, which indicates that $\mathrm{BBr}_{3}$ is more difficult to ionize than Ar. For both plasma chemistries, the etch rate of AlInP is almost independent of discharge composition, whereas that of InGaP increases almost monotonically with boron halide content. In developing device fabrication processes it is necessary to have wet and dry etches that are highly selective for one material over another. There has been little work on selective dry etches for the InGaP/AlInP system. The bottom of Figure 46 shows the etch selectivity of InGaP over AlInP as a function of plasma composition for both mixtures. These values are the highest reported for InGaP/AlInP and are easily high enough for device processing schemes. It is well established that $\operatorname{InI}_{x}$ etch products are quite volatile, as are $\mathrm{PI}_{3}$ species. ${ }^{[34]}$ In $\mathrm{BI}_{3}$ etching therefore, the etch selectivity for InGaP over AlInP arises from the relatively involatile $\mathrm{AlI}_{\mathrm{x}}$ products. Similar reasoning applies to the $\mathrm{BBr}_{3}$ plasma chemistries. For $\mathrm{AlGaP}$ we observed some deposition at low $\mathrm{BI}_{3}$ contents, and a practical, controllable rate of $\sim 3000 \AA \cdot \mathrm{min}^{-1}$ at a $50 \%$ composition. (Figure 46 , top).

One of the advantages of high density plasma sources is the ability to increase ion density at moderate ion energies. Figure 47 shows the dependence of alloy etch rate on ICP source power for fixed if chuck power $(150 \mathrm{~W})$ and plasma composition $(4 \mathrm{BI} / 6 \mathrm{Ar})$. Note that as source power increases the $\mathrm{dc}$ chuck bias decreases due to the higher ion density. Under these conditions only InGaP shows a significant etch rate, with a relatively high etch yield $(1 \sim 1.5)$ at $750 \mathrm{~W}$ source power. Similar data is shown in Figure 48 for $\mathrm{BBr}_{3} / \mathrm{Ar}$ discharges. 
Once again the chuck self-bias decreases as the source power increases, and only InGaP shows a high etch rate and corresponding etch yield.

Since both plasma chemistries are effective for etching InGaP, we focused on the quality of the etched surface morphology for this material. Figure 49 shows some representative AFM scans. We found that the root-mean-square (RMS) roughness decreased with both $\mathrm{BI}_{3}$ content and if chuck power. Note that increasing the $\mathrm{BI}_{3}$ percentage from 40 to 50 at fixed rf chuck power produces slightly better surfaces than that of an unetched control sample (RMS value $1.1 \mathrm{~nm}$ for the latter). A smooth surface almost always indicates that the etch products for $\mathrm{In}, \mathrm{Ga}$ and $\mathrm{P}$ are being removed at essentially equal rates.

Basically similar trends were observed for $\mathrm{BBr}_{3}$ etching of InGaP. Figure 50 shows some representative AFM scans for different plasma compositions at fixed source power and if chuck power. Note again that the surface becomes smoother as $\mathrm{BBr}_{3}$ percentage increases. For both $\mathrm{BBr}_{3}$ and $\mathrm{BI}_{3}$ we observed there was no incubation time for the onset of etching, indicating that these gases efficiently remove the native oxide on InGaP, similar to the case of $\mathrm{BCl}_{3}$.

The etched features were anisotropic under all the conditions we investigated. Figure 51 shows some typical SEM micrographs of features etched into InGaP with $\mathrm{BBr}_{3}$ and $\mathrm{BI}_{3}$ discharges at different rf chuck powers and plasma compositions. The sidewalls are smooth and vertical, with the etched surface morphologies also being quite good.

Figure 52 shows surface scan (top) and depth profile (bottom) from AlInP after etching in $8 \mathrm{BBr}_{3} / 2 \mathrm{Ar}$ discharges at fixed source power $(750 \mathrm{~W})$ and rf chuck power (350W). The surface etched with this chemistry revealed Al-enrichment at the near surface region $(\sim 100 \AA)$ leading to the oxidation upon exposure to the atmosphere after etching. This indicates the 
existence of involatile $\mathrm{Al}$ etch product on the surface, which is the source of low etch rate for AlInP.

One of the key considerations in evaluating a plasma chemistry is selectivity with respect to common masking materials. Figure 53 (top) shows the etch selectivity for InGaP over plasma enhanced chemical vapor deposited $\mathrm{SiO}_{2}$ and $\mathrm{SiN}_{\mathrm{x}}$ as a function of ICP source power in $\mathrm{BBr}_{3} / \mathrm{Ar}$ discharges ( $350 \mathrm{~W}$ chuck power, $5 \mathrm{mTorr}$ ). The selectivities basically increase as the source power increases because the etch rate of $\operatorname{InGaP}$ increases rapidly under these conditions. The values obtained at high source powers (8-10) are acceptable for device processing and quite high for etching under high density conditions. Even higher values were obtained with $\mathrm{Bl}_{3} / \mathrm{Ar}$ discharges. Figure 53 (bottom) shows a comparison of selectivities obtained for $\mathrm{InGaP}_{\text {over }} \mathrm{SiO}_{2}$ and $\mathrm{SiN}_{\mathrm{x}}$ in the two chemistries, as a function of $\mathrm{rf}$ chuck power. Note that the selectivities with $\mathrm{BI}_{3} / \mathrm{Ar}$ actually increase with chuck power because the etch rate of InGaP rises faster than that of the dielectrics.

\section{ELECTRON CYCLROTRON RESONANCE PLASMA ETCHING BASED ON ICI AND $\mathrm{IBr}$}

Figure 54 shows the semiconductor etch rates in $1.5 \mathrm{mTorr}, 1000 \mathrm{~W}$ ECR, $150 \mathrm{~W}$ if discharges of ICV $\mathrm{Ar}$ and $\mathrm{IBr} / \mathrm{Ar}$, as a function of the gas compositions measured by flow rate. The rates increase up to $50 \% \mathrm{ICl}$ or $\mathrm{IBr}$ and are basically constant thereafter. The slight reduction in rates for pure $\mathrm{ICl}$ or $\mathrm{IBr}$ discharges may be due to a reduced ion-assisted sputtering efficiency for the etch products. Note that the rates are much faster for $\mathrm{ICl}$ compared to $\mathrm{IBr}$, as expected from the volatilities of their resulting etch products. At $1000 \mathrm{~W}$ microwave power the rates with $\mathrm{ICl} / \mathrm{Ar}$ are similar to those achieved in our system with $\mathrm{Cl} / \mathrm{Ar}$ for the same pressure, gas compositions and rf power. ${ }^{[51]}$ 
One of the major advantages with these new gases is shown in Figure 55. For InGaP and AlInP the etch rates are essentially independent of microwave power in the range 400 1000W. At OW microwave (i.e. RIE conditions) the etch rates were only a few hundred angstroms per minute, but the bond strengths of the $\mathrm{I}-\mathrm{Cl}$ and $\mathrm{I}-\mathrm{Br}$ are sufficiently low that $400 \mathrm{~W}$ of microwave power efficiently dissociates the molecules, producing active iodine and chlorine neutral atoms. The ion density at $400 \mathrm{~W}$ also appears sufficient to efficiently desorb the etch products. AlGaP has a higher average bond strength than the other two materials, as mentioned in the previous chapters and the increase in etch rate at higher microwave powers may be due to the need for a higher ion density to assist in bond breaking and/or etch product desorption. As mentioned earlier we have found that at microwave powers of $400-600 \mathrm{~W}$, photoresist masks hold up well to plasma exposure with little distortion of their original geometries. ${ }^{[52]}$ However, at $1000 \mathrm{~W}$ there is generally reticulation of the resist after even a short ( $\sim 1 \mathrm{~min})$ exposure. For ICl/Ar, etch rates in excess of $1 \mu \mathrm{m} / \mathrm{min}$ are achieved even at $400 \mathrm{~W}$ ECR source power, which are approximately a factor of five faster than $\mathrm{Cl}_{2} / \mathrm{Ar}$ under the same conditions in our reactor. ${ }^{[53]}$

The dependence of semiconductor etch rates on $\mathrm{rf}$ chuck power at fixed microwave power and pressure is shown in Figure 56. There is a general increase in rate as the average ion energy increases and produces more efficient etch product desorption. At 250W rf the ICV/Ar etch rates for InGaP $(2.2 \mu \mathrm{m} / \mathrm{min})$ and AlInP $(1.7 \mu \mathrm{m} / \mathrm{min})$ are the fastest we have achieved for any plasma chemistry $\left(\mathrm{Cl}_{2} / \mathrm{Ar}, \mathrm{Cl}_{2} / \mathrm{H}_{2}, \mathrm{Cl}_{2} / \mathrm{N}_{2}, \mathrm{BCl}_{3} / \mathrm{Ar}\right.$ and $\left.\mathrm{CH}_{4} / \mathrm{H}_{2} / \mathrm{Ar}\right)$.

Typical AFM scans of ICV/Ar etched surfaces are shown in Figure 57. At a plasma composition of $4 \mathrm{ICV} / 4 \mathrm{Ar}, 150 \mathrm{~W}$ of $\mathrm{rf}$ power and $1.5 \mathrm{mTorr}$ pressure, higher microwave powers always produced rougher surfaces. For InGaP etched at $600 \mathrm{~W}$, the root-mean-square (RMS) roughness measured over a $5 \times 5 \mu \mathrm{m}^{2}$ area was $7.5 \mathrm{~nm}$ for an etch depth of $1.7 \mu \mathrm{m}$. An unetched 
control sample had typical RMS values of $1-1.8 \mathrm{~nm}$. The sample etched at $1000 \mathrm{~W}$ microwave power, with a comparable etch depth of $1.6 \mu \mathrm{m}$, had an RMS roughness of $9.9 \mathrm{~nm}$, and shows the spiky surface typical of those that have preferentially lost P. A similar result was obtained for AllnP, with the RMS value increasing from $4.9 \mathrm{~nm}$ at $800 \mathrm{~W}$ microwave and $150 \mathrm{~W}$ rf, to $27 \mathrm{~nm}$ at $1000 \mathrm{~W}$ microwave and $250 \mathrm{~W}$ rf (lower part of Figure 57).

AFM scans from AlInP etched in 1000W microwave, $150 \mathrm{~W}$ if $\mathrm{IBr} / \mathrm{Ar}$ discharges are shown in Figure 58 for different IBr-to-Ar ratios. The surface morphology is a strong function of the plasma composition. RMS values for both AllnP and InGaP as a function of $\mathrm{IBr}$ percentage are shown in Figure 59. For InGaP the $\mathrm{IBr}$ flow must be kept to low values to achieve acceptable morphologies, while the surfaces for AlInP are best at either high or low $\mathrm{IBr}$ percentages. At intermediate plasma composition the morphology is quite rough, with the appearance of bullocks. This might be due to residual $\mathrm{InBr}_{3}$, which is not particularly volatile, whereas with pure $\mathrm{IBr}$ the absence of $\mathrm{Ar}$ ions reduces the removal rate of $\mathrm{Ga}$ and $\mathrm{P}$ etch products and leaves a somewhat better morphology.

An AES surface scan of AlInP after a 8IBr, 1000W ECR power, $150 \mathrm{~W}$ rf etch is shown in Figure 60. The $\mathrm{C}$ and $\mathrm{O}$ come from exposure of the sample to atmosphere in transferring to the AES chamber. The small Si signal appears to result from sputtering or redeposition from the Si carrier wafer. There is no detectable $\mathrm{Br}$ on the surface, and there is no change in stoichiometry relative to the unetched control sample.

Figure 61 shows SEM micrographs of features etched into InGaP (top) or AlInP (bottom) with a $4 \mathrm{IBr} / 4 \mathrm{Ar}, 750 \mathrm{~W}$ ECR power, $150 \mathrm{~W}$ rf, $1.5 \mathrm{mTorr}$ discharge. The morphologies are quite good for both materials, although the sidewalls are not completely vertical. Smooth surfaces were also achieved with ICV/Ar - Figure 62 shows SEM micrographs of features etched into InGaP (top) or AlInP (bottom) with 4ICl/4Ar, 1000W ECR power, 250W rf, $1.5 \mathrm{mTorr}$ 
discharges. It is noticeable that the photoresist mask failed at several regions during this etch and thus our earlier discussion concerning the benefits of lower microwave powers.

We have previously found that the etch rate of $\mathrm{Al}_{x} \mathrm{Ga}_{1-\mathrm{x}} \mathrm{P}$ alloys is fairly constant for $\mathrm{x}=$

$0 \rightarrow 0.6$, and decreases thereafter in $\mathrm{Cl}_{2}$ and $\mathrm{BCl}_{3}$ plasma chemistries. ${ }^{[53]}$ Similar results were obtained with $\mathrm{IBr} / \mathrm{Ar}$, as shown in Figure 63. Thus Al-rich $\mathrm{AlGaP}$ alloys are good candidates as etch stop layers in device structures requiring close control of etch depth, provided of course that they do not interfere with carrier transport within the device.

\section{CONCLUSION}

We have compared several gas chemistries based on $\mathrm{CH}_{4} / \mathrm{H}_{2} / \mathrm{Ar}, \mathrm{Cl}_{2} / \mathrm{Ar}, \mathrm{Cl}_{2} / \mathrm{H}_{2}$, $\mathrm{BCl}_{3} / \mathrm{Ar}, \mathrm{BCl}_{3} / \mathrm{H}_{2}, \mathrm{BI}_{3} / \mathrm{Ar}, \mathrm{BBr}_{3} / \mathrm{Ar}, \mathrm{IC} V \mathrm{Ar}$ and $\mathrm{IBr} / \mathrm{Ar}$ in Inductively Coupled Plasma (ICP) and Electron Cyclotron Resonance (ECR) tools. The characteristics for each are summarized in Table 2. $\mathrm{CH}_{4} / \mathrm{H}_{2}$-based chemistry combined with high density plasma tools (ICP, ECR) did not provide good results. Etch rates of all three materials (InGaP, AlInP, AlGaP) were low without ion-neutral synergism. Etched features did not show anisotropic profiles, and etched surfaces were rather rough and non-stoichiometric with In-enrichment at the near surface $(\sim 100 \AA)$. Most of all, etching with this chemistry proceeded through an ion-driven mechanism.

$\mathrm{Cl}_{2}$-based chemistries provided better results than $\mathrm{CH}_{4} / \mathrm{H}_{2} / \mathrm{Ar}$ in the ICP tool, as a whole. $\mathrm{Cl}_{2} / \mathrm{Ar}$ discharges showed a strong chemical enhancement for the etching of InGaP at high source power $(1000 \mathrm{~W})$ with high etch yield $(\sim 4)$. The surface etched with this chemistry revealed no chlorine residues without any indication of phosphorous $(\mathrm{P})$ deficiency. Hydrogen addition to $\mathrm{Cl}_{2}$ produced new plasma species $(\mathrm{HCl})$ as confirmed by Optical Emission Spectroscopy (OES) and Mass Spectrometry, with higher etch rate of InGaP and stoichiometric surface. $\mathrm{BCl}_{3} / \mathrm{Ar}$ discharges showed a strong dependence of ion energy for the etching of all 
three ternary compounds, with well-defined threshold ion energy ( $-20 \mathrm{~V} \mathrm{dc})$. The etching mechanism changed from ion-driven at low ion energy $(-100 \mathrm{~V} \mathrm{dc})$ to chemical-driven at high ion energy $(-200 \mathrm{~V} \mathrm{dc})$. Surface morphologies improved with ion energy with less chlorine residues on the surface at high ion energy. The combination of $\mathrm{Cl}_{2}$ with $\mathrm{BCl}_{3}$ resulted in high selectivity of AlInP over InGaP at high ion energy.

Iodine based chemistries provided high etch rates for InGaP, as predicted from the low activation energy for desorption of $\mathrm{InI}_{3}$. Both $\mathrm{BI}_{3}$ and $\mathrm{BBr}_{3}$ provide high etch rates for InGaP under ICP conditions, with the former producing faster rates. These rates are strongly dependent on source power, if power and plasma composition, and etched surface morphologies improve with increasing $\mathrm{BI}_{3}$ or $\mathrm{BBr}_{3}$ content in the discharge. AlInP has very low etch rates in both chemistries due to the involatile $\mathrm{Al}$ etch products, and provides an excellent etch stop for InGaP or AlGaP. Chuck dc bias decreases with increasing $\mathrm{BI}_{3}$ content at fixed source power, but increases with increasing $\mathrm{BBr}_{3}$ content, which indicates that $\mathrm{BI}_{3}$ ionizes more readily than $\mathrm{Ar}$ and $\mathrm{BBr}_{3}$. Etch selectivities above 10 are obtained for InGaP over $\mathrm{SiO}_{2}$ and $\mathrm{SiN}_{\mathrm{x}}$ in $\mathrm{BI}_{3}$ discharges.

$\mathrm{ICl}$ provided the fastest etching for $\operatorname{InGaP}(\sim 2.0 \mu \mathrm{m} / \mathrm{min})$ and AlInP $(1.6 \mu \mathrm{m} / \mathrm{min})$ under ECR conditions. Etching achieved with $\mathrm{ICl}$ and $\mathrm{IBr}$ was not strongly dependent on microwave power in the range $400 \sim 1000 \mathrm{~W}$, suggesting that the $\mathrm{ICl}$ and $\mathrm{IBr}$ are easily dissociated and thus provide a high density of reactive neutrals. The rates are significantly faster with $\mathrm{ICl}$ under all conditions, consistent with the higher volatilities of the chloride etch products. The etched surface morphologies are a strong function of microwave power and rougher above $\sim 750 \mathrm{~W}$, where photoresist mask degradation is also apparent even for short plasma exposures.

In summary, $\mathrm{CH}_{4} / \mathrm{H}_{2}$-based chemistry appeared to be not suitable for the etching of compound semiconductors in high density plasma tools (ICP, ECR), whereas $\mathrm{Cl}_{2}$-based 
Spectroscopy (OES) and mass spectrometry proved to be useful in detecting plasma species as a function of process variables such as (gas composition, source power, ion energy and pressure). However, one concern is that it is hard to detect etch products with mass spectrometry due to the relatively low sensitivity, leading to a difficulty in specifying the surface reaction mechanism. Moreover, OES, applied to ICP tools, is not capable of analyzing plasma on the surface, due to the geometry of chamber.

\section{ACKNOWLEDGEMENT}

The work at the University of Florida is performed in the Microfabritech facility, whose staff is greatly appreciated. The work is partially supported by a DOD University Research Initiative administered by AFOSR (H. C. DeLong), Contract No. F49620-96-0026. Sandia is a multi-program laboratory operated by Sandia Corporation for Lockheed-Martin under DOE grant DEAC04-AL85000. 


\section{REFERENCES}

1. T. R. Hayes in InP and Related Materials-Processing, Technology and Devices, ed. A. Katz (Artech House, Norwood, MA 1992).

2. J. M. Kuo, Thin Solid Films $\underline{231} 158$ (1993).

3. M. J. Hafich, H. Y. Lee, T. E. Crumbaker, T. J. Vogt, P. Silvestre and G. Y. Robinson, J. Vac. Sci. Technol. B 10969 (1992).

4. K. Ozasa, M. Yuri and H. Matsunami, J. Cryst. Growth 10231 (1990).

5. Y. J. Chan, D. Pavlidis, M. Razheghi and F. Omnes, IEEE Trans Electron. Dev. ED- $\underline{7}$ $2141(1990)$.

6. J. M. Kuo, and Y. J. Chan, J. Vac. Sci. Technol. B 11976 (1993).

7. M. J. Mondry and H. Kroemer, IEEE Electron. Dev. Lett. EDL- 175 (1985).

8. M. O. Watanabe and Y. Ohba, Appl. Phys. Lett. $\underline{50} 906$ (1987).

9. W. Liu and S. K. Fan, IEEE Electron. Dev. Lett. EDL-13 510 (1992).

10. S. L. Delage, M. A. DiForte-Poisson, H. Blanck, C. Brylinski, E. Chartier and P. Collot, Electron. Lett. 27253 (1991).

11. W. Pletschen, K. H. Bachem and T. Lautybach, Proc. Mat. Res. Soc. Symp. Proc $\underline{240} 493$ (1992).

12. W. S. Hobson, F. Ren, J. R. Lothian and S. J. Pearton, Semicon. Sci. Technol. 7598 (1992).

13. C. R. Abernathy, F. Ren, P. Wisk, S. J. Pearton and R. Esagui, Appl. Phys. Lett. 611092 (1992).

14. M. Ikeda, Y. Mori, H. Sato, K. Kaneko and N. Watanabe, Appl. Phys. Lett. 471027 (1985).

15. A. Kikuchi, Y. Kaneko, I. Nomura and K. Kishino, Electron. Lett. 261668 (1990).

16. A. Gomyo, T. Suzuki, K. Kobayashi, S. Kawata and I. Hino, Appl. Phys. Lett. $\underline{50} 673$ (1987).

17. K. Kishino, A. Kikuchi, Y. Kaneko and I. Nomura, Appl. Phys. Lett. $\underline{58} 1882$ (1991).

18. W. S. Hobson, Proc. Symp. Wide Bandgap Semiconductors and Devices (ECS, Pennington, NJ) pp. 26-42 (1995).

19. S. J. Groves, J. N. Walpole and C. J. Missaggia, Appl. Phys. Lett. 61255 (1992).

20. A. W. Hanson, S. A. Stockman and G. E. Stillman, IEEE Electron. Dev. Lett. 1425 (1993). 
21. D. P. Bour, in Quantum Well Lasers, ed. P. S. Zory (Academic Press, NJ 1993) PP. 415460.

22. See for example, Surface Emitting Semiconductor Lasers and Alloys, ed. G. A. Evans and J. M. Hammer.

23. CRC Handbook of Chemistry and Physics (CRC Press, Boca Raton, FL 1990).

24. U. Niggebrugge, M. Klvg and G. Ganvs, Int. Phys. Conf. Ser. 79367 (1985).

25. S. J. Peareton, C. R. Abernathy, P. Wisk and F. Ren, J. Appl. Phys. 741610 (1993).

26. F. Ren, J. R. Lothian, S. J. Pearton, C. R. Abernathy, P. Wisk, T. Fullowon, B. Tseng, S. N. G. Chu, Y. K. Chen, L. Yang, S. Fu, R. Brozovich, H. H. Lin, C. L. Henming and T. Henary, J. Vac. Sci. Technol. B 122916 (1994).

27. F. Ren, J. R. Lothian, W. S. Hobson, J. Lopata, J. Caballero and S. J. Pearton, Appl. Phys. Lett. 672497 (1995).

28. J. G. van Hassel, C. M. van Es and P. A. M. Nouwens, Electron. Lett. 31834 (1995).

29. F. Ren, J. R. Lothian, W. S. Hobson, J. Lopata, J. Caballero and S. J. Pearton, Appl. Phys. Lett. $\underline{67} 2497$ (1995).

30. J. W. Lee, J. Hong and S. J. Pearton, Appl. Phys. Lett. 68847 (1996).

31. S. Thomas III, K. K. Ko and S. W. Pang, J. Vac. Sci. Technol. A 13894 (1995).

32. K. K. Ko and S. W. Pang, J. Electrochem. Soc. 113945 (1995).

33. D. C. Flanders, L. D. Pressman and G. Pinelli, J. Vac. Sci. Technol. B $\underline{8}$ (6), Nov/Dec. (1990).

34. S. J. Pearton, Int. J. Mod. Phys. B 1781 (1994).

35. I. Adesida, K. Nummila, E. Andideh, J. Hughes, C. Caneau, R. Bhat and R. Holmstrom, J. Vac. Sci. Technol. B 1357 (1990).

36. S. J. Pearton, U. K. Chahrabarti, W. S. Hobson, C. R. Abernathy, A. Katz, F. Ren, T. A. Fullowan and A. P. Perley, J. Electrochem. Soc. 1391763 (1992).

37. C. R. Abernathy, J. Vac. Sci. Technol. A11, 883 (1993).

38. W. S. Hobson, Mater. Res. Soc. Symp. Proc. 300, 75 (1993).

39. T. R. Hayes, U. K. Chakrabarti, F. A. Baiocchi, A. B. Emerson, H. S. Luffman, and W. C. Dautremont-Smith, J. Appl. Phys. 68, 715 (1990). 
40. T. R. Hayes, M. A. Dreisbach, P. M. Thomas, W. C. Dautremont, and L. A. Heimbrook, J. Vac. Sci. Technol. BI, 2608 (1989).

41. Fransis Teyssandier and Mark D. Allendorf, J. Electrochem. Soc. $\underline{6}$, 2167 (1998).

42. G. Y. Adusei and A. Fontijn, J. Phys. Chem. 97, 1409 (1993).

43. D. L. Baulch, J. Duxbury, S. J. Grant and D. C. Montague, J. Phys. Cem. Ref. Data, 10, Suppl. 1 (1981).

44. R. J. Shul, G. B. McClellan, R. D. Briggs, D. J. Rieger, S. J. Pearton, C. R. Abernathy, J. W. Lee, C. Constantine and C. Barratt, J. Vac. Sci. Technol. A 15673 (1997).

45. F. Ren, J. R. Lothian, J. M. Kuo, W. S. Hobson, J. Lopata, J. A. Caballero, S. J. Pearton and M. W. Cole, J. Vac. Sci. Technol. B14 1203 (1995).

46. F. Ren, W. S. Hobson, J. R. Lothian, J. Lopata, J. A. Cballero, S. J. Pearton and M. W. Cole, Appl. Phys. Lett. 672497 (1995).

47. M. Vernon, T. R. Hayes and V. M. Donnelly, J. Vac. Sci. Technol. A10 3499 (1992).

48. G. A. Vawter and C. I. H. Ashby, J. Vac. Sci. Technol. 123374 (1994).

49. D. G. Lishan and E. L. Hu, Appl. Phys. Lett. $\underline{56} 1667$ (1990).

50. S. Dzioba, S. Jatar, T. V. Herak, J. P. D. Cook, J. Marks, T. Jones and F. R. Shepherd, Appl. Phys. Lett. $\underline{62} 2486$ (1993).

51. J. Hong, J. W. Lee, C. R. Abernathy and S. J. Pearton, J. Elect. Mat. 9, (1996).

52. J. W. Lee, R. Crockett, and S. J. Pearton, J. Vac. Sci. Technol. B, 1752 (1996).

53. J. Hong, J. W. Lee, C. J. Santana, C. R. Abernathy, E. S. Lambers, S. J. Pearton, W. S. Hobson, and F. Ren, Solid-state Electron., 39, 1406 (1996). 
Figure Captions

Figure 1. Vapor pressure of some potential etch products based on chlorine and iodine gas chemistry as a function of temperature.

Figure 2. Conventional RF (RIE) system

Figure 3. Hybrid ECR - RF system

Figure 4. Schematic diagram of inductive coupling

Figure 5. Inductively Coupled Plasma (ICP) reactor

Figure 6. Etch rates or sputter rates of $\mathrm{InGaP}, \mathrm{AlInP}$ and $\mathrm{AlGaP}$ as a function of microwave source power with either $5 \mathrm{CH}_{4} / 15 \mathrm{H}_{2} / 10 \mathrm{Ar}$ or $40 \mathrm{Ar}$ discharges at the constant pressure (1.5mTorr) and dc self bias $(-100 \mathrm{~V})$.

Figure 7. Etch rates and etch yields of $\operatorname{InGaP}, \mathrm{AlInP}$ and $\mathrm{AlGaP}$ as a function of ICP source power at $4 \mathrm{mTorr},-120 \mathrm{~V} \mathrm{dc}, 5 \mathrm{CH}_{4} / 15 \mathrm{H}_{2} / 10 \mathrm{Ar}$ discharges.

Figure 8. Etch rates of InGaP, AlInP and AlGaP as a function of $\mathrm{rf}$ chuck power in either $2 \mathrm{mTorr}$, 500W ICP, $5 \mathrm{CH}_{4} / 15 \mathrm{H}_{2} / 10 \mathrm{Ar}$ discharges (top) or $1.5 \mathrm{mTorr}, 800 \mathrm{~W} \mathrm{ECR}$, $5 \mathrm{CH}_{4} / 15 \mathrm{H}_{2} / 10 \mathrm{Ar}$ discharges (bottom).

Figure 9. Etch rates of InGaP as a function of process pressure in either 750W ICP or $750 \mathrm{~W}$ $\mathrm{ECR}, 5 \mathrm{CH}_{4} / 15 \mathrm{H}_{2} / 10 \mathrm{Ar}$ discharges at the constant dc self bias (-150V).

Figure 10. RMS surface roughness as a function of ICP source power in $2 \mathrm{mT}$ Torr, $-120 \mathrm{~V} \mathrm{dc}$, $5 \mathrm{CH}_{4} / 15 \mathrm{H}_{2} / 10 \mathrm{Ar}$ discharges (top) and of dc self bias in $1.5 \mathrm{mTorr}$, $800 \mathrm{~W}$ ECR, $5 \mathrm{CH}_{4} / 15 \mathrm{H}_{2} / 10 \mathrm{Ar}$ discharges (bottom).

Figure 11. AFM scan images of InGaP in $1.5 \mathrm{mTorr},-100 \mathrm{~V} \mathrm{dc}, 5 \mathrm{CH}_{4} / 15 \mathrm{H}_{2} / 10 \mathrm{Ar}$ discharges at either 800W ECR (top) or 1000W ECR (bottom).

Figure 12. SEM micrographs of features etched into InGaP in either $2 \mathrm{mTorr}, 350 \mathrm{~W} \mathrm{rf}, 750 \mathrm{~W}$ ICP (top) or $1.5 \mathrm{~m}$ Torr, $100 \mathrm{~W}$ rf, $800 \mathrm{~W}$ ECR (bottom) $5 \mathrm{CH}_{4} / 15 \mathrm{H}_{2} / 10 \mathrm{Ar}$ discharges. 
Figure 13. AES surface scan (top) and depth profile (bottom) from InGaP after etching in $1000 \mathrm{~W} \mathrm{ICP}, 5 \mathrm{CH}_{4} / 15 \mathrm{H}_{2} / 10 \mathrm{Ar}$ discharges at constant dc bias $(-120 \mathrm{~V})$ and pressure (4mTorr).

Figure 14. Mass spectra in $2 \mathrm{mTorr},-100 \mathrm{~V} \mathrm{dc}, 750 \mathrm{~W} \mathrm{ICP} \mathrm{Cl}_{2} / \mathrm{Ar}$ (bottom) or $\mathrm{Cl}_{2} / \mathrm{H}_{2}$ (top) discharges at the different gas compositions.

Figure 15. Etch rates of InGaP, AlInP and AlGaP (top) or intensities of plasma species from mass spectra (center, bottom) as a function $\mathrm{Cl}_{2}$ percentage in either $\mathrm{Cl}_{2} / \mathrm{Ar}$ or $\mathrm{Cl}_{2} / \mathrm{H}_{2}$ discharges at fixed pressure (2mTorr), dc bias (-100V) and ICP source power (750W).

Figure 16. Etch rate of $\mathrm{AlGaP}$ as a function of $\mathrm{Al}$ composition in $2 \mathrm{mTorr},-100 \mathrm{~V} \mathrm{dc}, 750 \mathrm{~W}$ ICP, $5 \mathrm{Cl}_{2} / 10 \mathrm{Ar}$ discharges.

Figure 17. Etch rates (top) and etch yields (bottom) of InGaP, AlInP and AlGaP as a function of ICP source power in $2 \mathrm{mTorr},-100 \mathrm{~V} \mathrm{dc}, 10 \mathrm{Cl}_{2} / 5 \mathrm{Ar}$ discharges.

Figure 18. Etch rates of three ternary compound semiconductors as a function of dc self bias in 2mTorr, $750 \mathrm{~W} \mathrm{ICP}, 10 \mathrm{Cl}_{2} / 5 \mathrm{Ar}$ discharges.

Figure 19. RMS surface roughness of InGaP as a function of gas composition in either $\mathrm{Cl}_{2} / \mathrm{Ar}$ or $\mathrm{Cl}_{2} / \mathrm{H}_{2}$ discharges at constant dc bias $(-100 \mathrm{~V})$ and source power $(750 \mathrm{~W})$.

Figure 20. AFM scan images of InGaP in $2 \mathrm{mTorr},-100 \mathrm{~V} \mathrm{dc} 10 \mathrm{Cl}_{2} / 5 \mathrm{Ar}$ discharges at either 750W ICP source power (top) or 1000W ICP source power (bottom).

Figure 21. AFM scan images of AlInP at the different rf power and source power in $10 \mathrm{Cl}_{2} / 5 \mathrm{Ar}$ discharges.

Figure 22. SEM micrographs of features etched into AlInP in $2 \mathrm{mTorr}, 1000 \mathrm{~W} \mathrm{ICP}, 10 \mathrm{Cl}_{2} / 5 \mathrm{Ar}$ discharges (top) or $2 \mathrm{mTorr}, 750 \mathrm{~W}$ ICP, $5 \mathrm{Cl}_{2} / 10 \mathrm{Ar}$ discharges (bottom) at constant dc bias ($100 \mathrm{~V})$.

Figure 23. AES surface scan (top) and depth profile (bottom) from InGaP after etching in $2 \mathrm{mT}$ Trr, $-100 \mathrm{~V}$ dc, $750 \mathrm{~W}$ source power, $10 \mathrm{Cl}_{2} / 5 \mathrm{Ar}$ discharges. 
Figure 24. AES surface scan (top) and depth profile (bottom) from InGaP after etching in $2 \mathrm{mTorr},-100 \mathrm{~V} \mathrm{dc}, 750 \mathrm{~W}$ source power, $5 \mathrm{Cl}_{2} / 10 \mathrm{H}_{2}$ discharges.

Figure 25. Etch rates of InGaP, AlInP and AlGaP as a function of gas composition in either $\mathrm{BCl}_{3} / \mathrm{Ar}$ (top) or $\mathrm{BCl}_{3} / \mathrm{H}_{2}$ (bottom) at the fixed source power (750W) and pressure (2mTorr) with two different dc biases $(-100 \mathrm{~V},-200 \mathrm{~V})$.

Figure 26. Mass spectra of plasma species from both $5 \mathrm{BCl}_{3} / 10 \mathrm{Ar}$ and $5 \mathrm{BCl}_{3} / 10 \mathrm{H}_{2}$ discharges at fixed source power $(750 \mathrm{~W})$, dc bias (-100V) and pressure ( $2 \mathrm{mTorr})$.

Figure 27. Optical emission spectra in either $5 \mathrm{BCl}_{3} / 10 \mathrm{Ar}$ or $5 \mathrm{BCl}_{3} / 10 \mathrm{H}_{2}$ discharges at fixed source power $(750 \mathrm{~W})$, dc bias $(-200 \mathrm{~V})$ and pressure (2mTorr).

Figure 28. Optical emission spectra in $2 \mathrm{mTorr}, 1000 \mathrm{~W} \mathrm{ICP}, 5 \mathrm{BCl}_{3} / 10 \mathrm{Ar}$ discharges at $-200 \mathrm{~V}$ $\mathrm{dc}$ (top) and normalized intensity as a function of source power (bottom).

Figure 29. Etch rates (top) and etch yields of InGaP, AlInP and AlGaP as a function of ICP source power in $2 \mathrm{mTorr}, 5 \mathrm{BCl}_{3} / 10 \mathrm{Ar}$ discharges at two different ion energies.

Figure 30. Etch rates of InGaP, AlInP and AlGaP as a function of de self bias in $2 \mathrm{mTor}, 750 \mathrm{~W}$ ICP, $5 \mathrm{BCl}_{3} / 10 \mathrm{Ar}$ discharges.

Figure 31. AFM surface scan images of $\mathrm{InGaP}$ in $2 \mathrm{mTorr}, 750 \mathrm{~W} \mathrm{ICP},-100 \mathrm{~V} \mathrm{dc}, \mathrm{BCl} / \mathrm{Ar}$ or $\mathrm{BCl}_{3} / \mathrm{H}_{2}$ discharges at the different gas compositions.

Figure 32. SEM micrographs of features etched into InGaP in different ion energies and gas compositions.

Figure 33. SEM micrographs for AlInP etched in either $-100 \mathrm{~V} \mathrm{dc}, 5 \mathrm{BCl}_{3} / 10 \mathrm{Ar}$ discharges (top) or $-200 \mathrm{~V} \mathrm{dc}, 10 \mathrm{BCl}_{3} / 5 \mathrm{Ar}$ discharges (bottom) at fixed source power $(750 \mathrm{~W})$ and process pressure (2mTorr).

Figure 34. AES surface scans from AlInP before and after etching in $2 \mathrm{mTorr}, 5 \mathrm{BCl} / 3 / 10 \mathrm{Ar}$ discharges at the different source powers and ion energies. 
Figure 35. Optical emission spectra from $2 \mathrm{mTorr}, \mathrm{Cl}_{2} / \mathrm{BCl}_{3} / 5 \mathrm{Ar}$ discharges as a function of $\mathrm{Cl}_{2} / \mathrm{BCl}_{3}$ composition at fixed source power (500W) and dc bias (-150V).

Figure 36. Mass spectra from $2 \mathrm{mTorr}, \mathrm{Cl}_{2} / \mathrm{BCl}_{3} / 5 \mathrm{Ar}$ discharges as a function of $\mathrm{Cl}_{2} / \mathrm{BCl}_{3}$ composition at fixed source power (750W) and dc bias (-150V).

Figure 37. Etch rates of InGaP and AlInP (top), and normalized intensity of optical emission spectra as a function of gas composition in $2 \mathrm{mTorr},-150 \mathrm{~V}$ dc, $500 \mathrm{~W} \mathrm{ICP}, \mathrm{Cl}_{2} / \mathrm{BCl}_{3} / 5 \mathrm{Ar}$ discharges.

Figure 38. Etch rates of $\operatorname{InGaP}$ and AlInP as a function of source power in $2 \mathrm{mTorr}$, $32 \mathrm{Cl}_{2} / 8 \mathrm{BCl}_{3} / 5 \mathrm{Ar}$ discharges at $-150 \mathrm{~V}$ dc bias.

Figure 39. Etch rates of $\mathrm{InGaP}$ and AlInP (top), and normalized intensities from optical emission spectra (bottom) as a function of dc self bias in $2 \mathrm{mTorr}, 500 \mathrm{~W} \mathrm{ICP}, 32 \mathrm{Cl}_{2} / 8 \mathrm{BCl}_{3} / 5 \mathrm{Ar}$ discharges.

Figure 40. Etch rate of InGaP and AlInP (top), and Normalized intensities from mass spectra (bottom) as a function of process pressure in $32 \mathrm{Cl}_{2} / 8 \mathrm{BCl}_{3} / 5 \mathrm{Ar}$ discharges at fixed source power $(750 \mathrm{~W})$ and dc self bias $(-150 \mathrm{~V})$.

Figure 41. RMS roughness of InGaP after etching in $2 \mathrm{mTorr},-150 \mathrm{~V} \mathrm{dc}, 32 \mathrm{Cl}_{2} / 8 \mathrm{BCl}_{3} / 5 \mathrm{Ar}$ discharges as a function of ICP source power.

Figure 42. AFM surface scan images of AllnP etched in $2 \mathrm{mTorr}, 32 \mathrm{Cl}_{2} / 8 \mathrm{BCl}_{3} / 5 \mathrm{Ar}$ discharges at the different source power and ion energy.

Figure 43. SEM micrographs of features etched into InGaP (top, left or bottom, left and right) and AlInP (top, right) with $750 \mathrm{~W}$ (top) or $500 \mathrm{~W}$ (bottom) ICP and $-150 \mathrm{~V} \mathrm{dc}$ (top), $-300 \mathrm{~V} \mathrm{dc}$ (bottom, left) or $-400 \mathrm{~V} \mathrm{dc}$ (bottom, right) in $32 \mathrm{Cl}_{2} / 8 \mathrm{BCl}_{3} / 5 \mathrm{Ar}$ discharges. The photoresist mask (bottom, left) has been removed and $\operatorname{SiN}_{x}$ masks are still in phase (top, left and right, and bottom, right). 
Figure 44. Optical emission spectrum from $\mathrm{BI}_{3}$ discharge.

Figure 45. Etch rates (top) and etch yields (bottom) for InGaP, AlInP and AlGaP in 750W source power, $5 \mathrm{mTorr}$ discharges of $4 \mathrm{BI}_{3} / 6 \mathrm{Ar}$ or $4 \mathrm{BBr}_{3} / 6 \mathrm{Ar}$ discharges as a function of chuck dc bias.

Figure 46. Etch rates of $\mathrm{InGaP}, \mathrm{AlInP}$ and $\mathrm{AlGaP}$ in (top) $\mathrm{BI}_{3} / \mathrm{Ar}$ discharges (750W source power, 150W rf chuck power) as a function of plasma composition; (center) $\mathrm{BBr}_{3} / \mathrm{Ar}$ discharges ( $750 \mathrm{~W}$ source power, $350 \mathrm{~W}$ rf chuck power) as a function of plasma composition; or (bottom) etch selectivity of InGaP over AlInP under these conditions.

Figure 47. Etch rates (top) and etch yields (bottom) for InGaP, AlInP and AlGaP in $4 \mathrm{BI} / 6 \mathrm{Ar}$, $150 \mathrm{~W}$ rf power, $5 \mathrm{~m}$ Torr discharges as a function of ICP source power.

Figure 48. Etch rates (top) and etch yields (bottom) for InGaP, AlInP and $\mathrm{AlGaP}$ in $4 \mathrm{BBr}_{3} / 6 \mathrm{Ar}$, $350 \mathrm{~W}$ rf power, $5 \mathrm{mT}$ Torr discharges as a function of ICP source power.

Figure 49. AFM scans from $\mathrm{InGaP}$ etched in $750 \mathrm{~W}$ source power, $\mathrm{BI}_{3} / \mathrm{Ar}$ discharges with different compositions and rf powers.

Figure 50. AFM scans from InGaP etched in $750 \mathrm{~W}$ source power, $350 \mathrm{~W}$ if power $\mathrm{BBr}_{3} / \mathrm{Ar}$ discharges with different compositions.

Figure 51. SEM micrographs of features etched into InGaP using $750 \mathrm{~W}$ source power discharges of (top left) $2 \mathrm{BI}_{3} / 8 \mathrm{Ar}, 250 \mathrm{~W}$ rf power, (top right) $4 \mathrm{BI}_{3} / 6 \mathrm{Ar}, 150 \mathrm{~W}$ rf power, (bottom left) $8 \mathrm{BBr}_{3} / 2 \mathrm{Ar}, 350 \mathrm{~W}$ rf power and (bottom right) $10 \mathrm{BBr}_{3}, 350 \mathrm{~W}$ rf power. The $\mathrm{SiN}_{\mathrm{x}}$ masks are still in place in all cases.

Figure 52. AES surface scan (top) and depth profile (bottom) from AlInP after etching in $5 \mathrm{mTorr}, 8 \mathrm{BBr}_{3} / 2 \mathrm{Ar}$ discharges at fixed source power $(750 \mathrm{~W})$ and rf chuck power $(350 \mathrm{~W})$. 
Figure 53. Etch selectivities of $\mathrm{InGaP}_{\text {over }} \mathrm{SiO}_{2}$ and $\mathrm{SiN}_{\mathrm{x}}$ in (top) $4 \mathrm{BBr}_{3} / 6 \mathrm{Ar}$ discharges, $350 \mathrm{~W}$ rf power, $5 \mathrm{mTorr}$, as a function of ICP source power, and (bottom) in $4 \mathrm{BI}_{3} / 6 \mathrm{Ar}$ or $4 \mathrm{BBr}_{3} / 6 \mathrm{Ar}$, $750 \mathrm{~W}$ source power, $5 \mathrm{mT}$ Torr discharges, as a function of $\mathrm{rf}$ power.

Figure 54. Etch rates of ternary alloys as a function of plasma composition in $\mathrm{ICV} / \mathrm{Ar}$ or $\mathrm{BBr} / \mathrm{Ar}$ discharges (1000W microwave power, $150 \mathrm{~W}$ if power, $1.5 \mathrm{mTorr}$ ).

Figure 55. Etch rates of ternary alloys as a function of microwave power in $4 \mathrm{ICl} / 4 \mathrm{Ar}$ or 4IBr/4Ar discharges (150W rf power, $1.5 \mathrm{mTorr}$ ).

Figure 56. Etch rates of ternary alloys as a function of if power in $4 \mathrm{ICV} / 4 \mathrm{Ar}$ or $4 \mathrm{IBr} / 4 \mathrm{Ar}$ discharges (1000W microwave power, $1.5 \mathrm{mTorr}$ ).

Figure 57. AFM scans of InGaP (top) or AlInP (bottom) after etching in $4 \mathrm{ICV} / 4 \mathrm{Ar}, 1.5 \mathrm{mTorr}$ discharges at $1000 \mathrm{~W}$ microwave power, $150 \mathrm{~W}$ rf (top, left), $600 \mathrm{~W}$ microwave, $150 \mathrm{~W}$ rf (top, right), $800 \mathrm{~W}$ microwave, $150 \mathrm{~W}$ rf (bottom, left), or $1000 \mathrm{~W}$ microwave, $250 \mathrm{~W}$ rf (bottom, right).

Figure 58. AFM scans of AlInP after etching in $1000 \mathrm{~W}$ microwave, $150 \mathrm{~W}$ rf, $1.5 \mathrm{mTorr}$ discharges of $2 \mathrm{IBr} / 6 \mathrm{Ar}$ (top), $4 \mathrm{IBr} / 4 \mathrm{Ar}$ (center), or $8 \mathrm{IBr}$ (bottom).

Figure 59. RMS surface roughness of InGaP and AlInP samples after etching in $1000 \mathrm{~W}$ microwave, $150 \mathrm{~W}$ rf, $1.5 \mathrm{~m}$ Torr $\mathrm{IBr} / \mathrm{Ar}$ discharges as a function of plasma composition.

Figure 60. AES surface scan of AlInP after etching in a $1000 \mathrm{~W}$ microwave, $150 \mathrm{~W}$ rf, $1.5 \mathrm{mTorr}$ discharges of $8 \mathrm{BBr}$.

Figure 61. SEM micrographs of features etched into InGaP (top) or AlInP (bottom) with a $750 \mathrm{~W}$ microwave, $150 \mathrm{~W}$ rf, $1.5 \mathrm{mTorr}$ discharges of $4 \mathrm{IBr} / 4 \mathrm{Ar}$. The photoresist mask has been removed. 
Figure 62. SEM micrographs of features etched into InGaP (top) or AlInP (bottom) with $1000 \mathrm{~W}$ microwave, $250 \mathrm{~W}$ rf, $1.5 \mathrm{~m}$ Torr discharges of $4 \mathrm{ICV} / 4 \mathrm{Ar}$. The photoresist masks have been removed.

Figure 63. Etch rates of $\mathrm{Al}_{\mathrm{x}} \mathrm{Ga}_{1-\mathrm{P}} \mathrm{P}$ alloys as a function of $\mathrm{Al}$ compositions in $1000 \mathrm{~W}$ microwave, $150 \mathrm{~W}$ rf, $1.5 \mathrm{mTorr}$ discharges of $4 \mathrm{IBr} / 4 \mathrm{Ar}$. 


\section{List of Tables}

Table 1. Boiling points of possible etch products (chlorides) of the InGaAlP materials system

Table 2. Typical results for the etching of InGaAlP ternary compounds in High Density Plasma tools. 


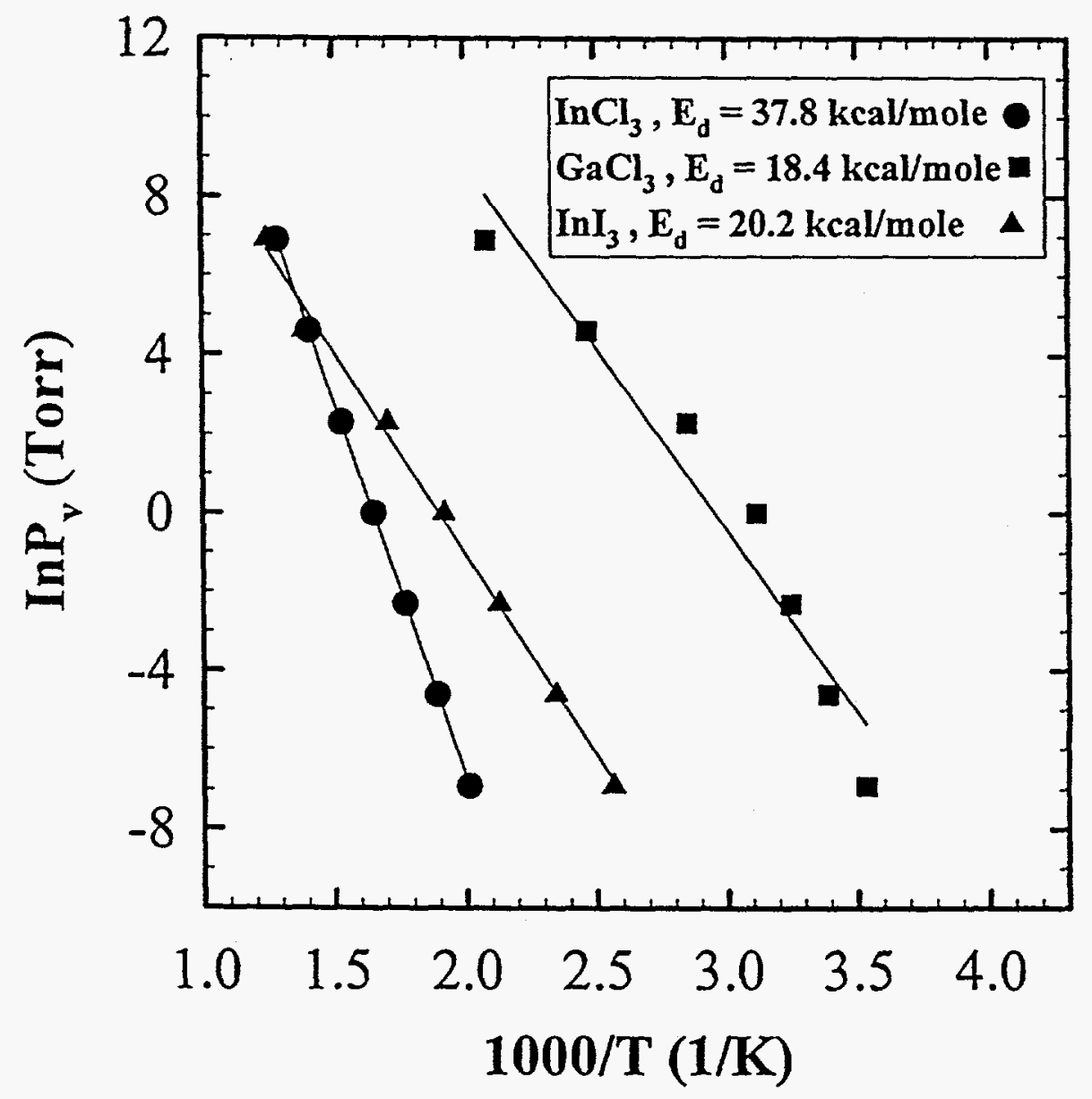

Fig lofts 


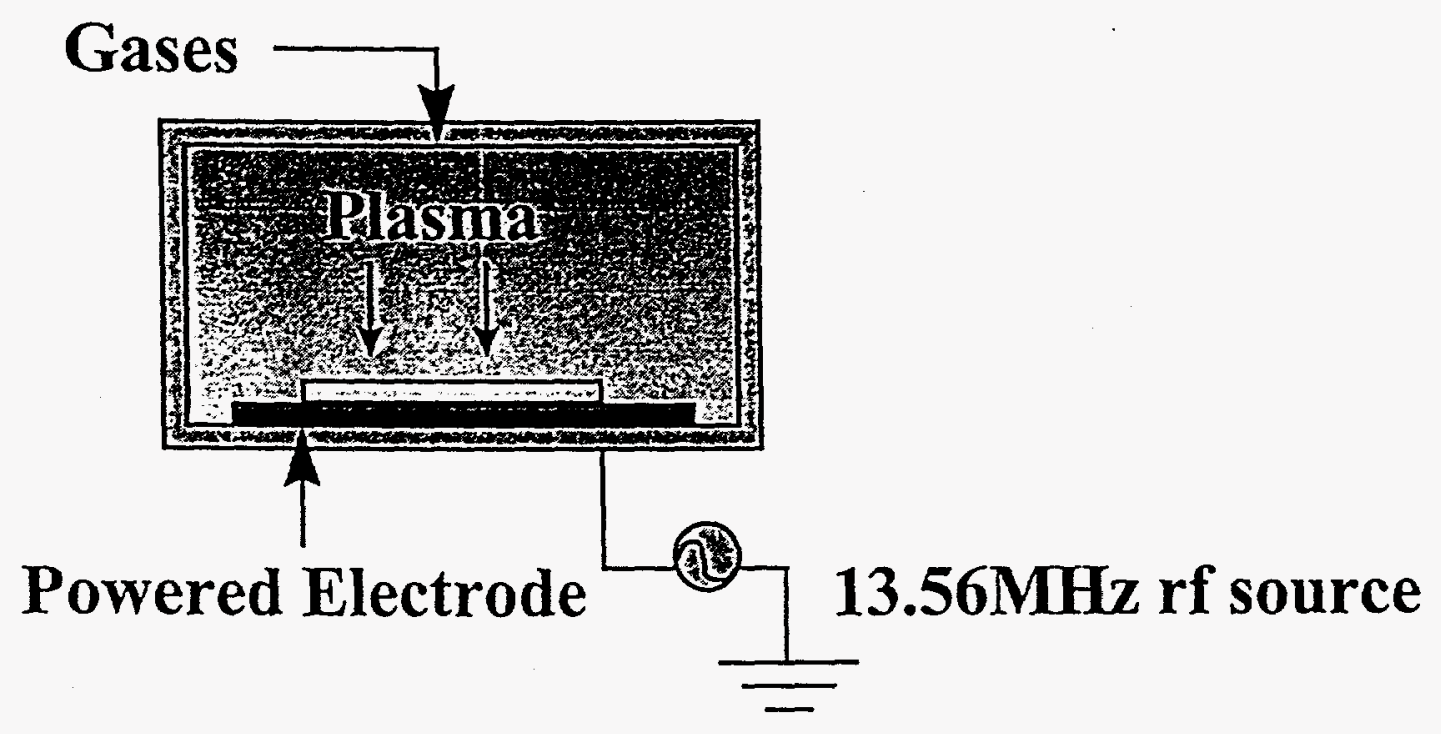




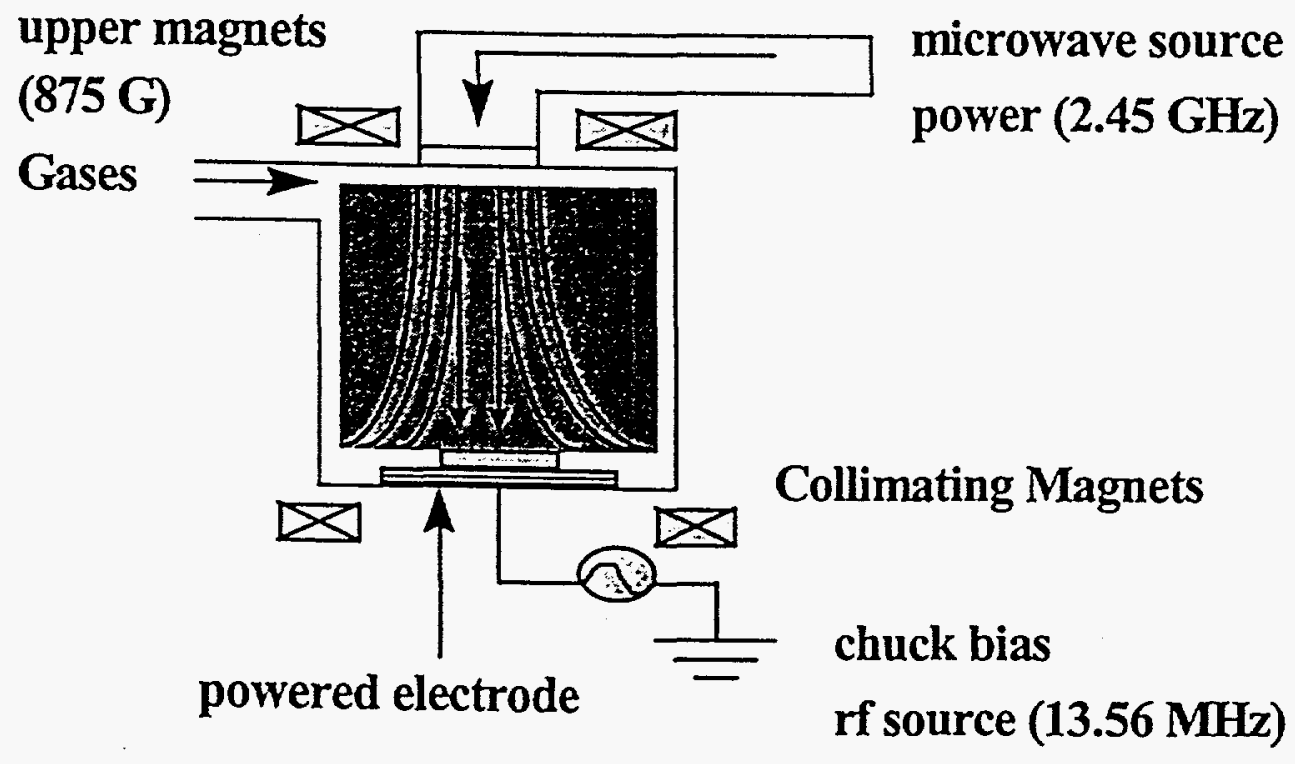




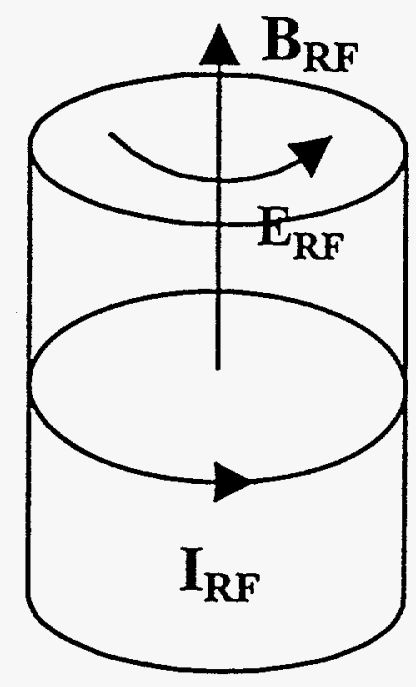

Frigutis Hinjetiof 


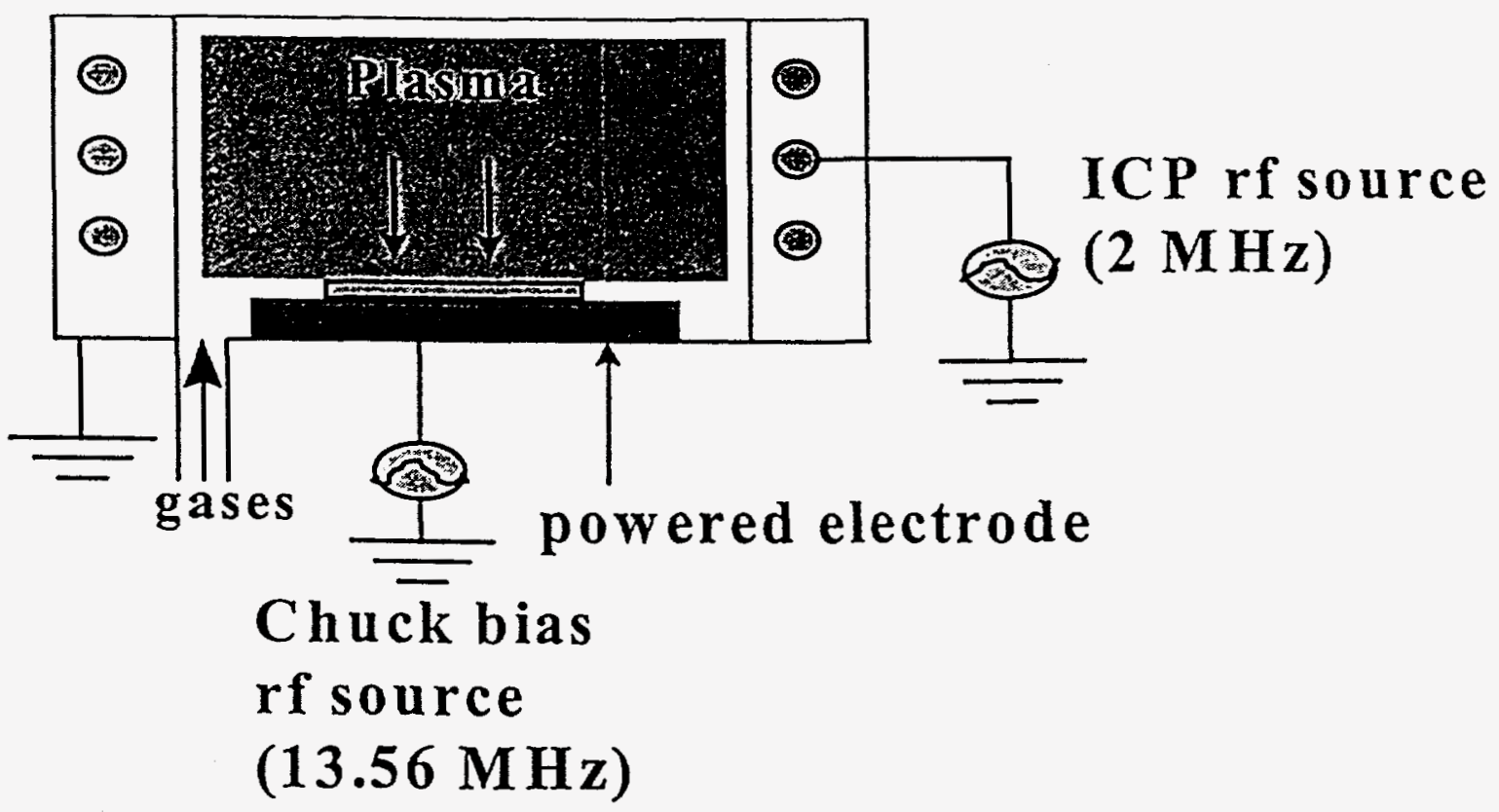

Fig 5 of 63 Hingetiol. 


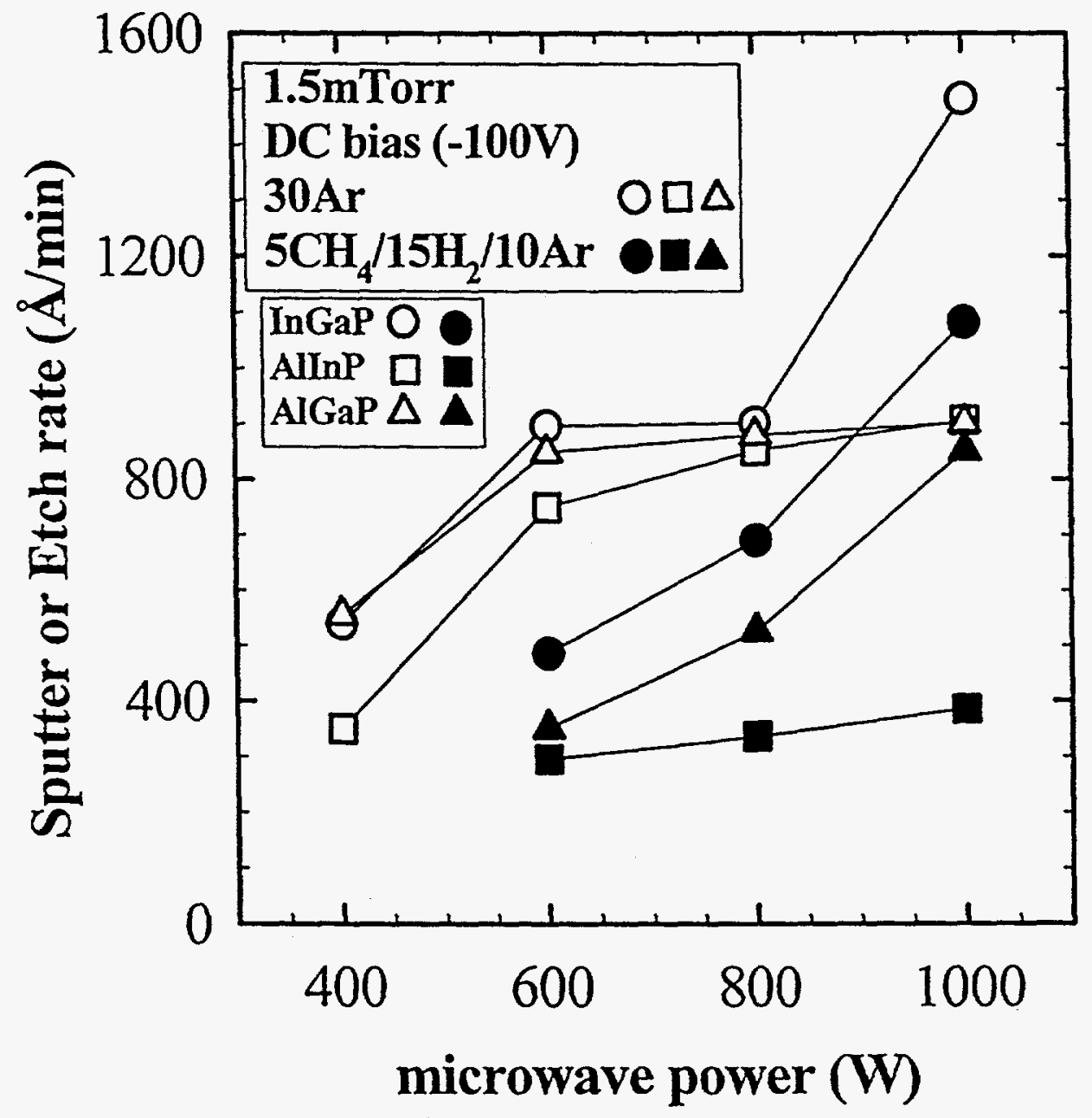

Figlofos

Hing et. al. 


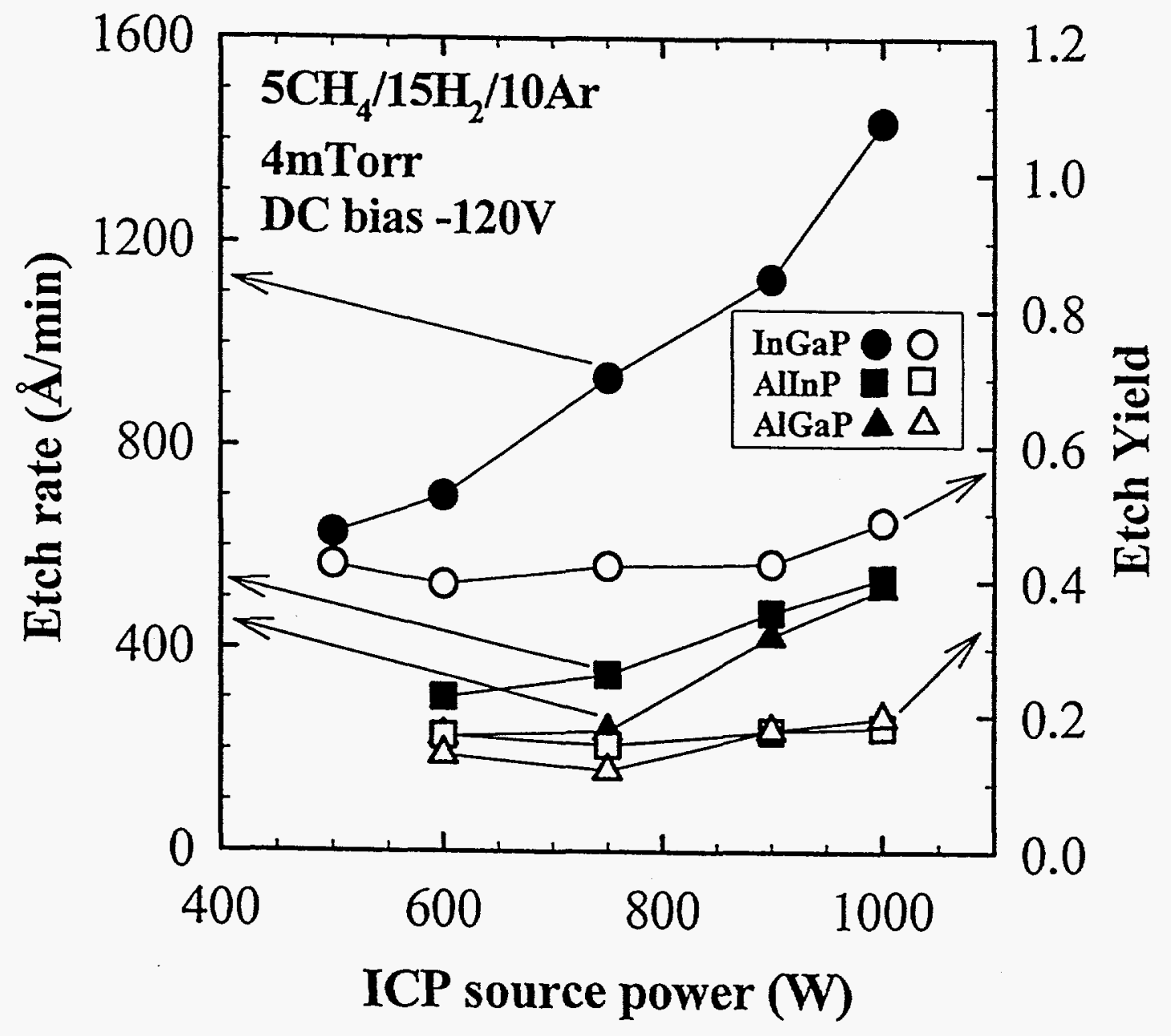

Fig 7.665 

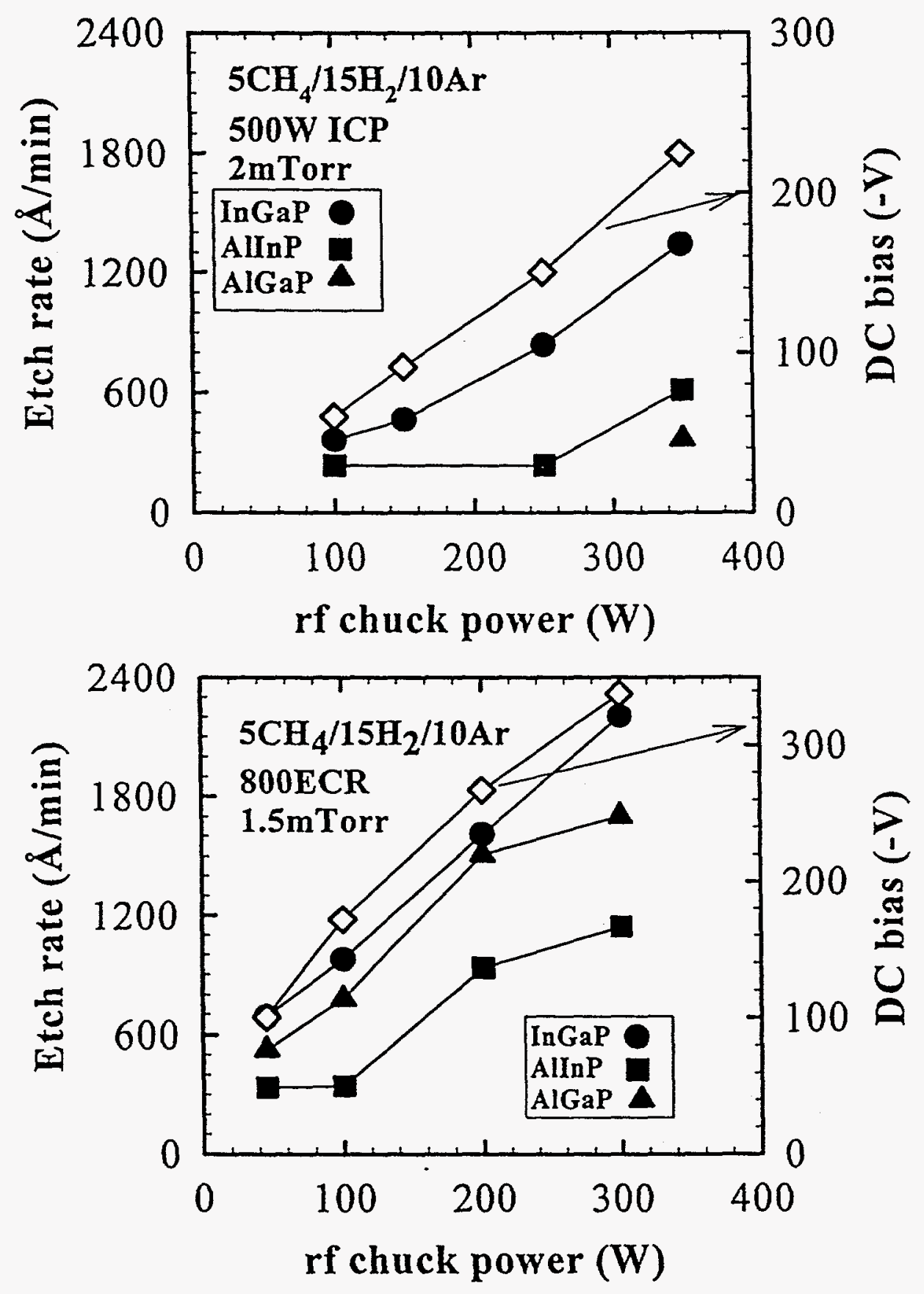

Figy of 63 Hoing ot all. 


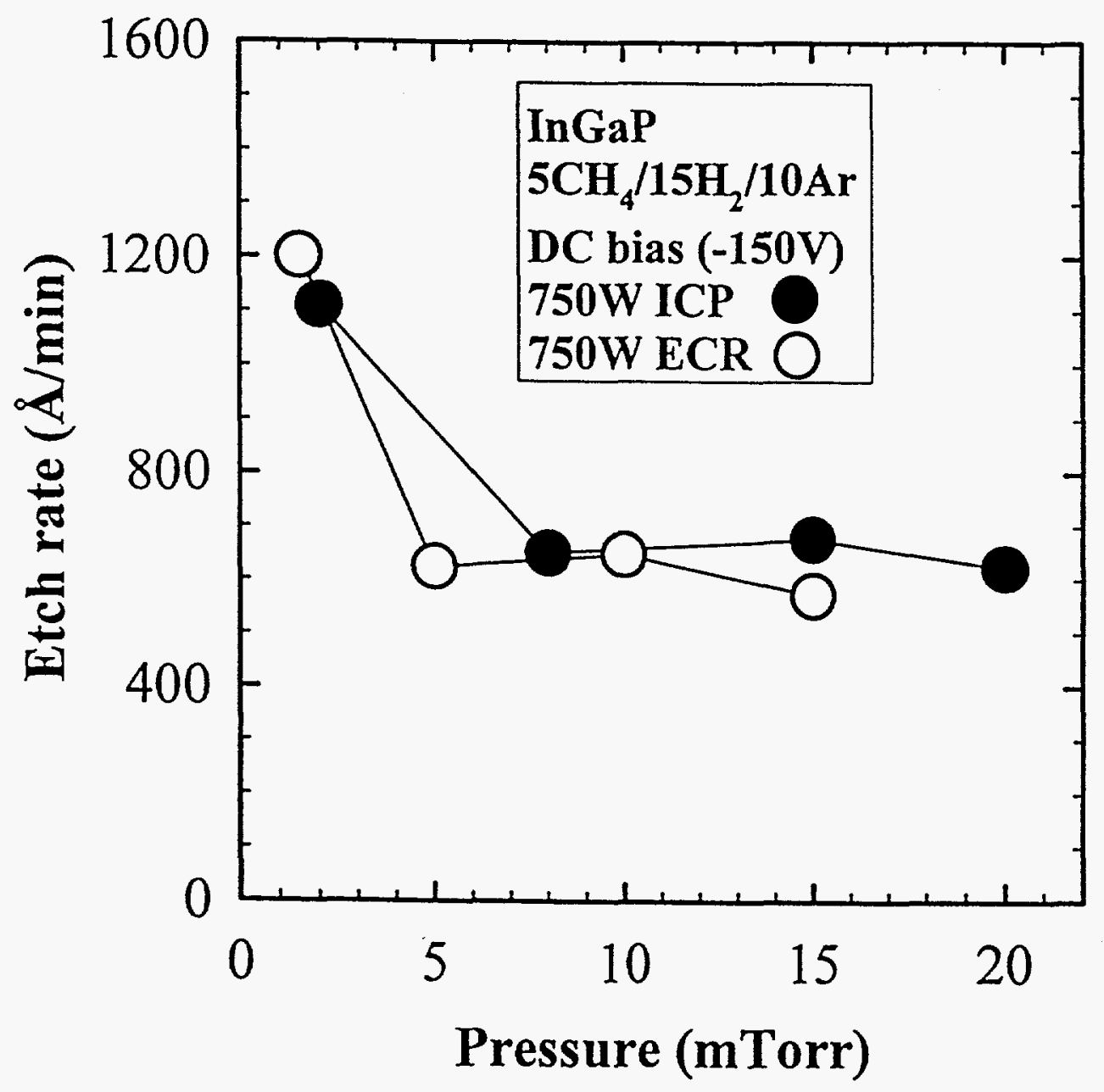

Figgoflis
Hongetial. 

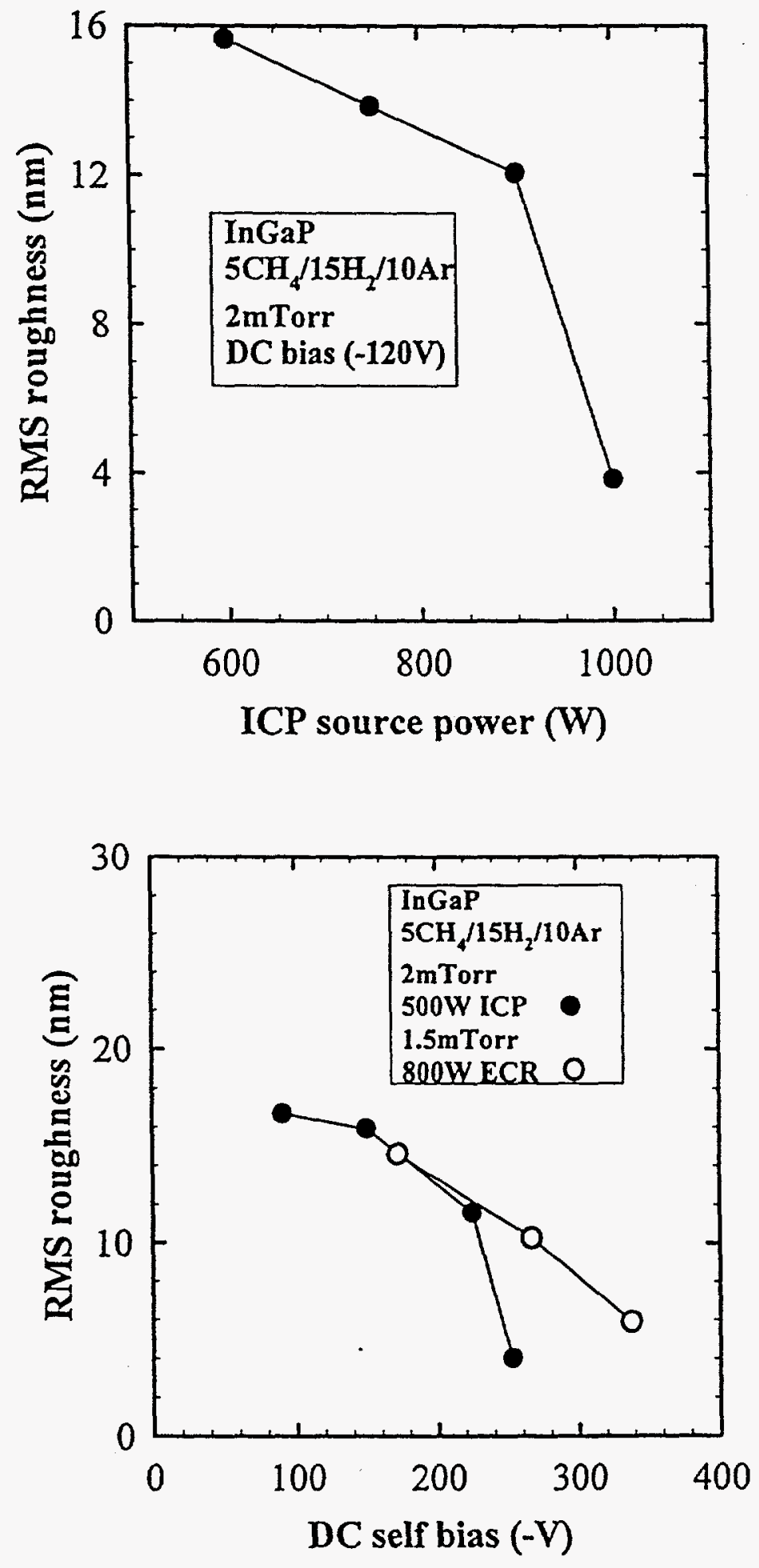

Figlo of $/ 3$ 


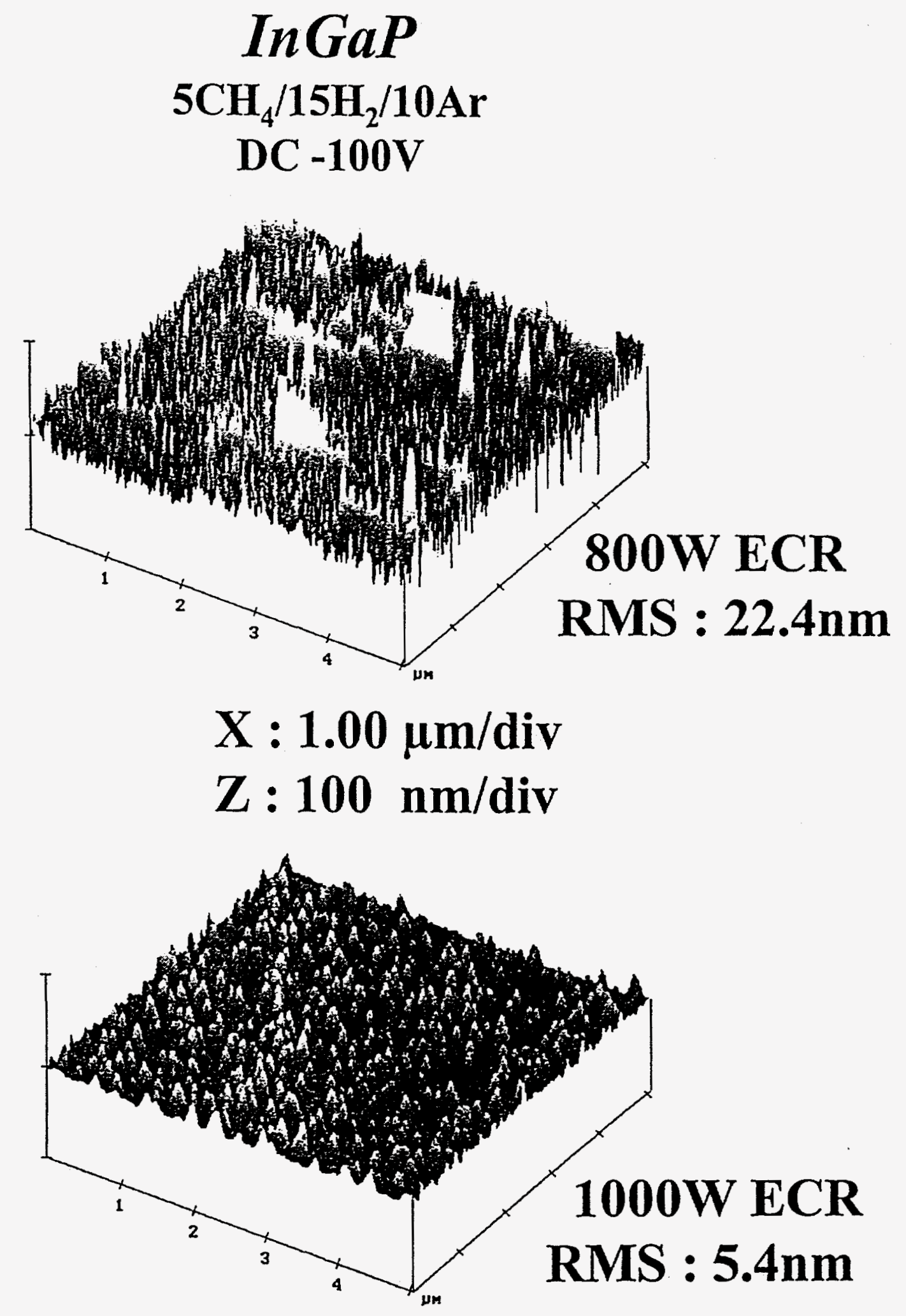

Figl" of 63

Hong at. all. 

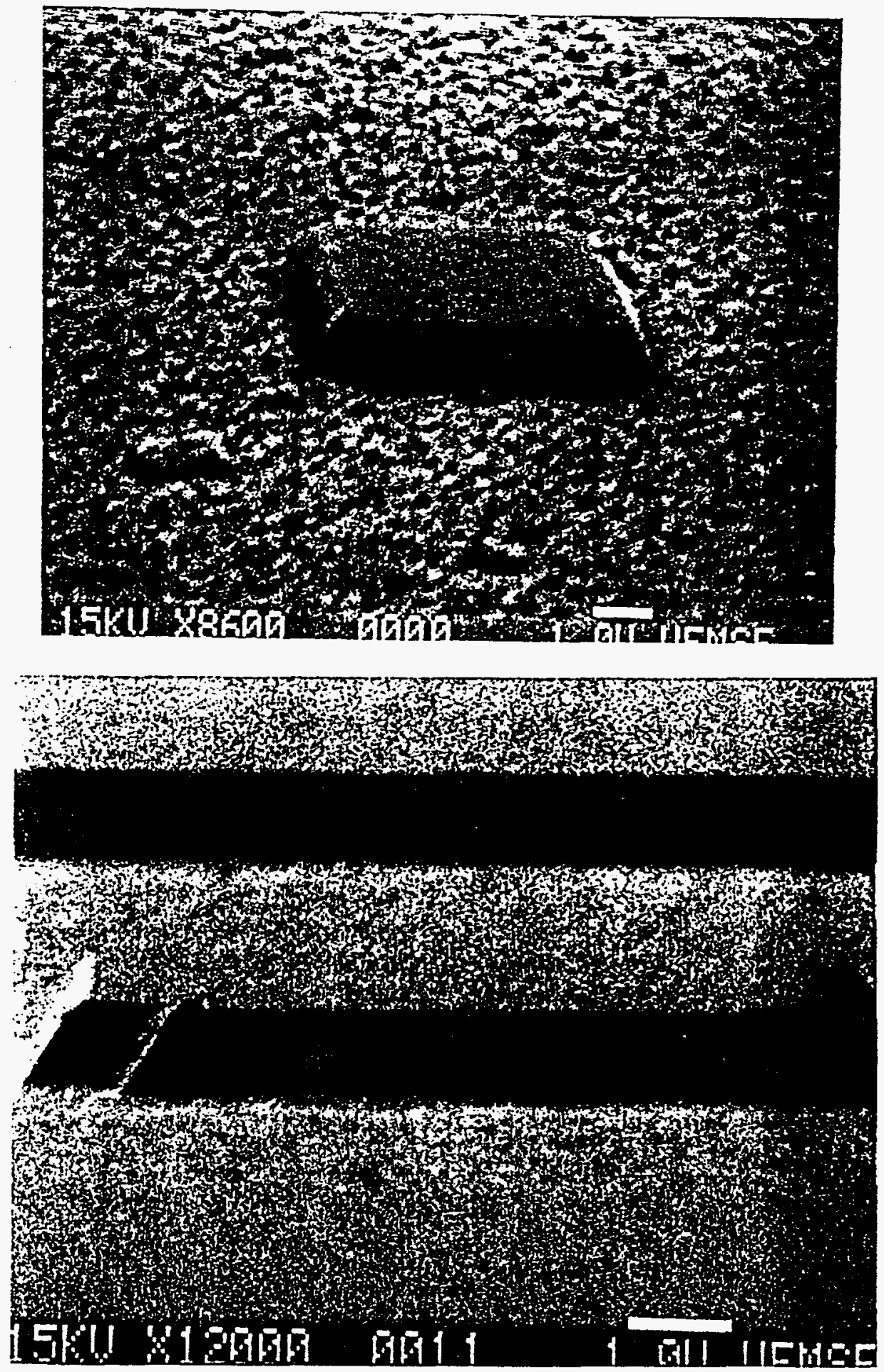

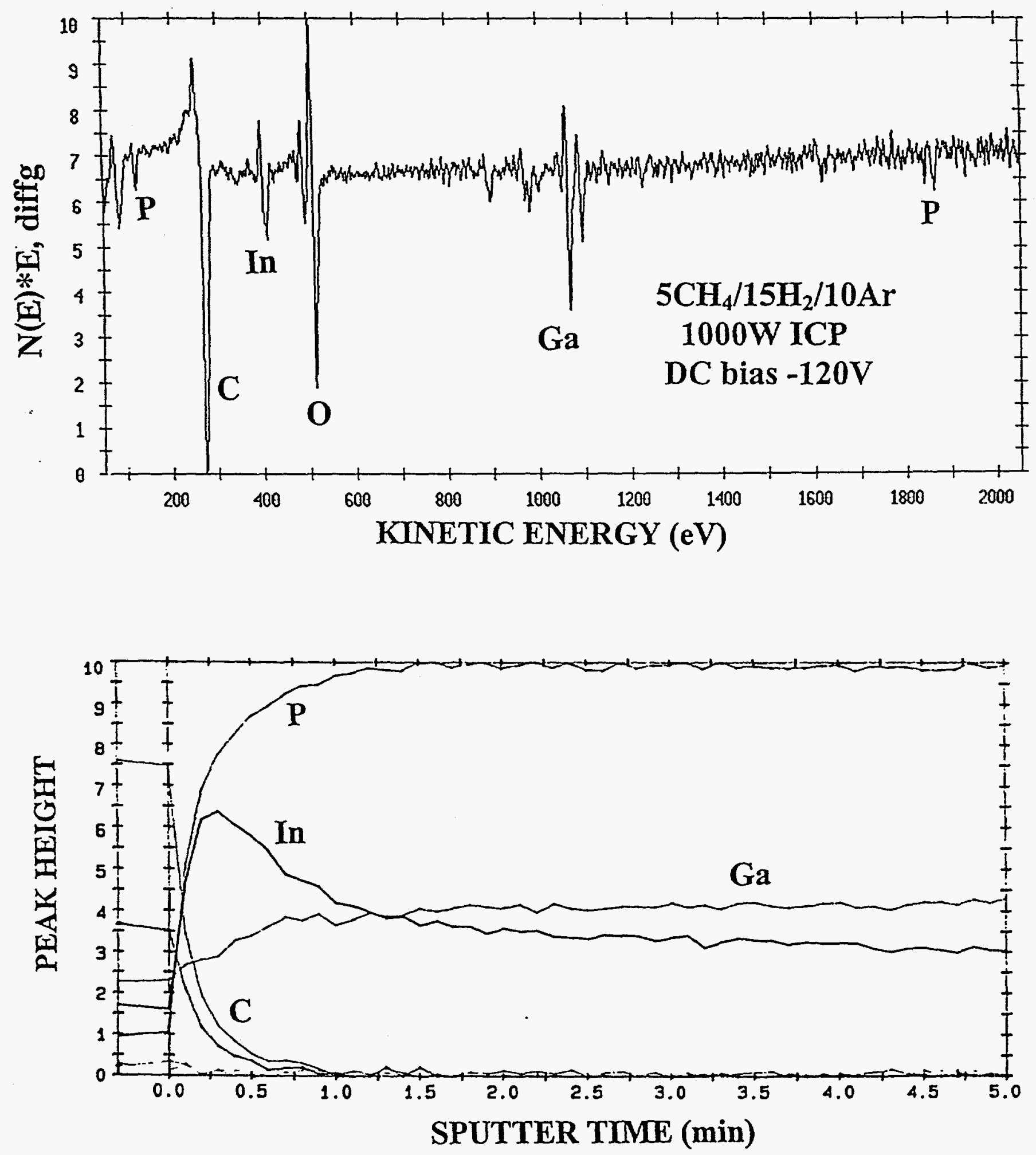

Figla ofts 

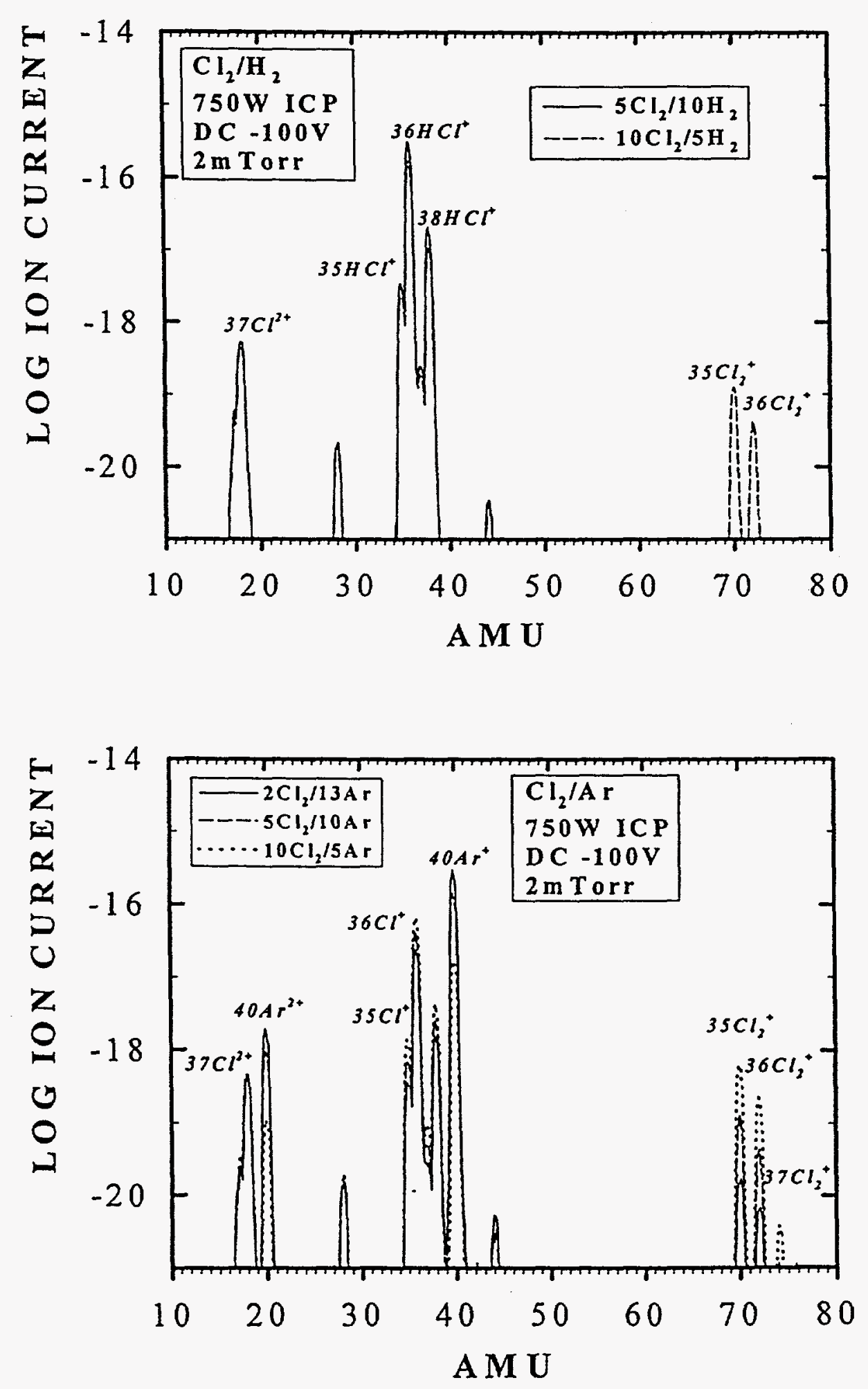

Fig $14 \cdot 66 j$ Honj at.at. 

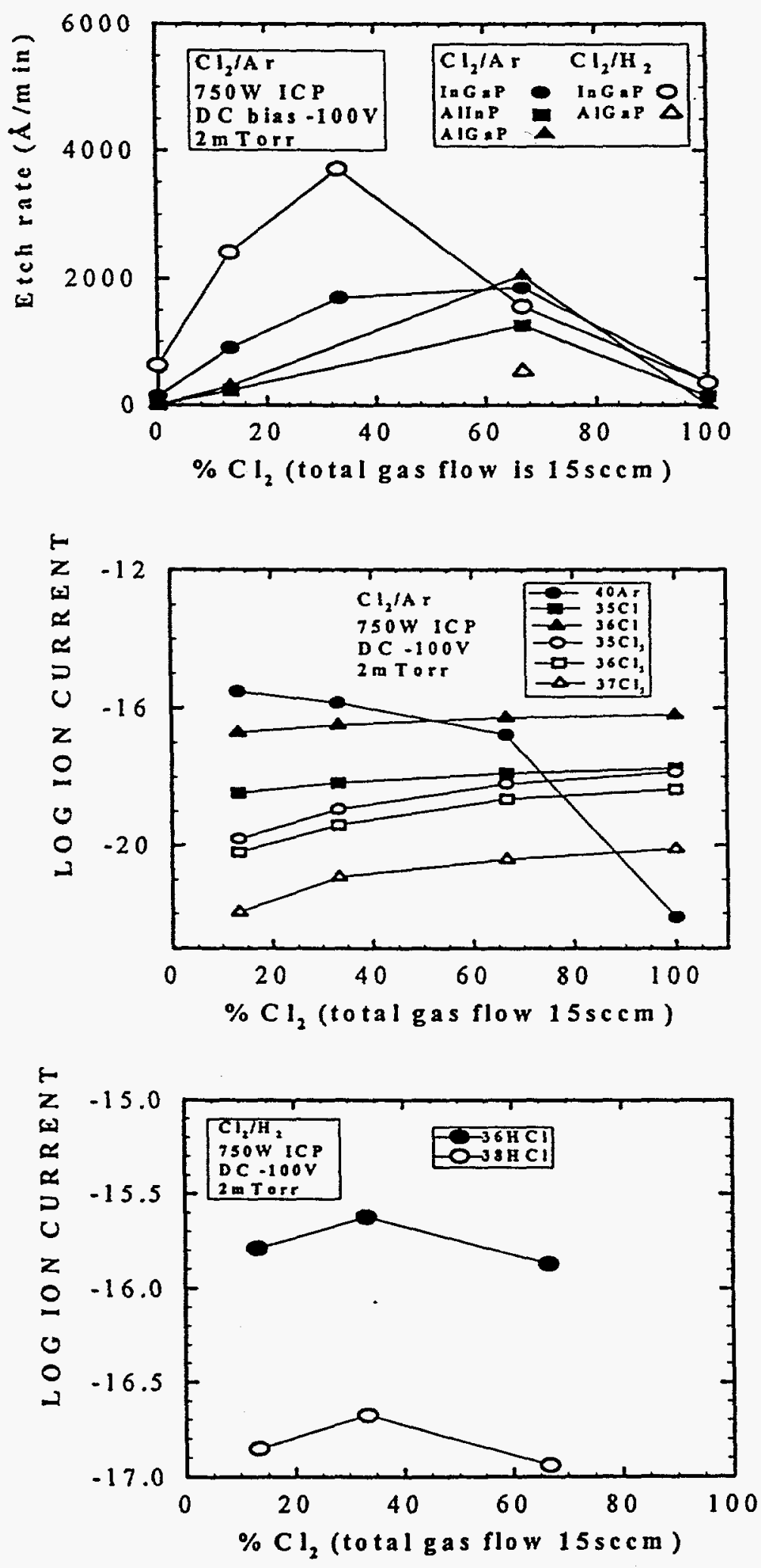

Figig 15 of 63 Hoogetial. 


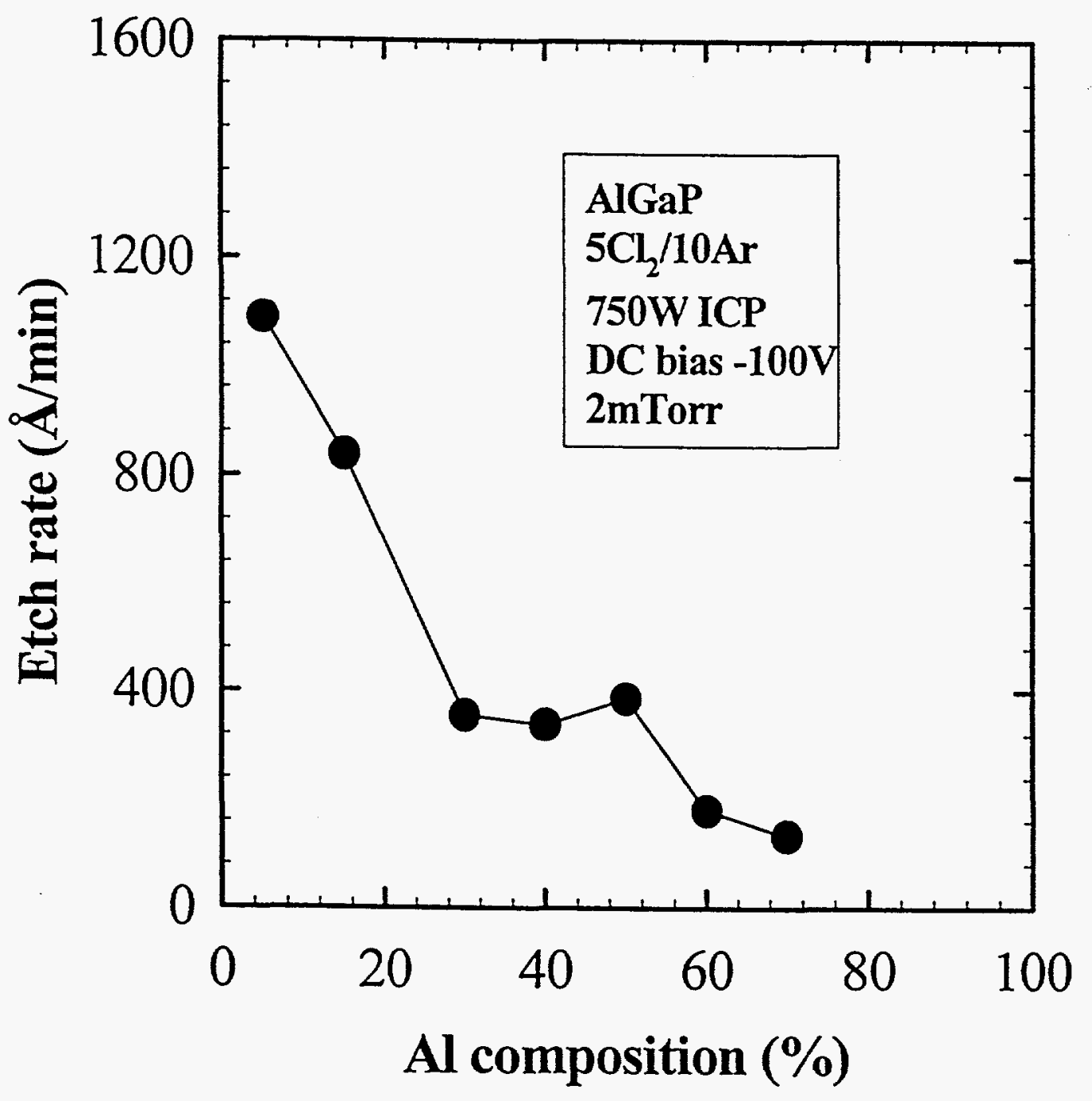

Fig 16 of 13 Honget.al. 

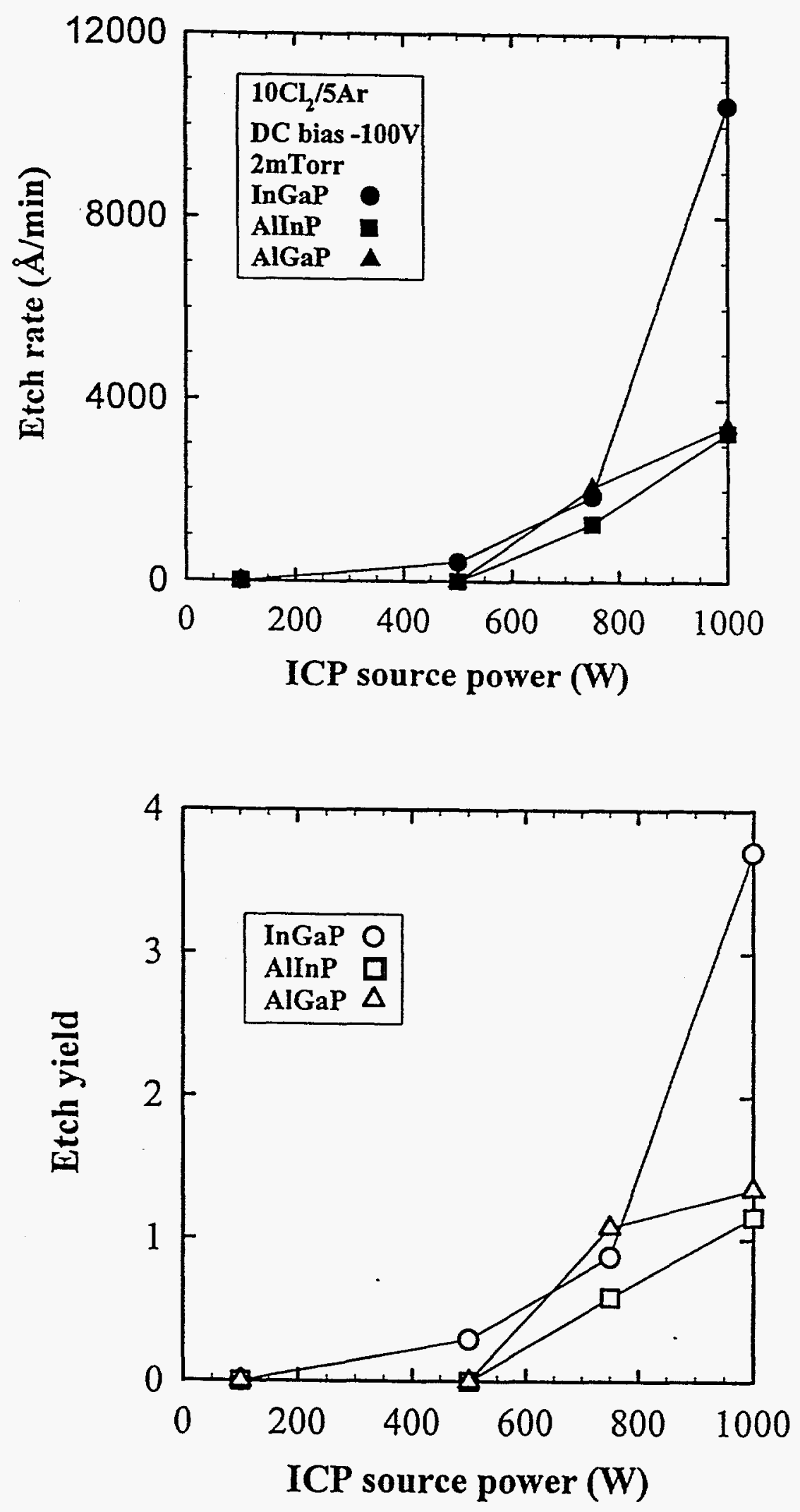

Fig $17 \cdot 665$ Hing et. if. 


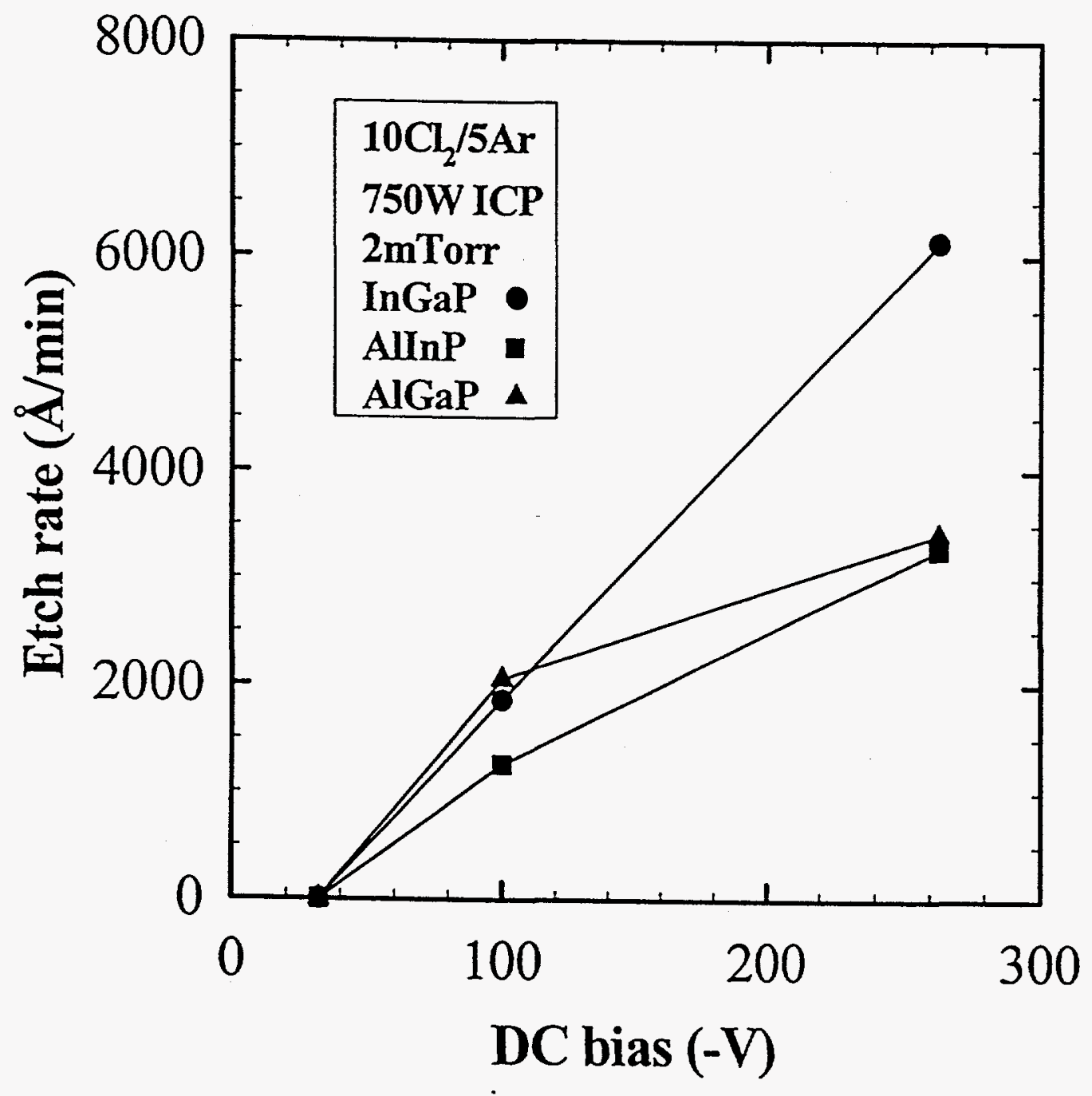

Figis of 65
Hoig st.all 


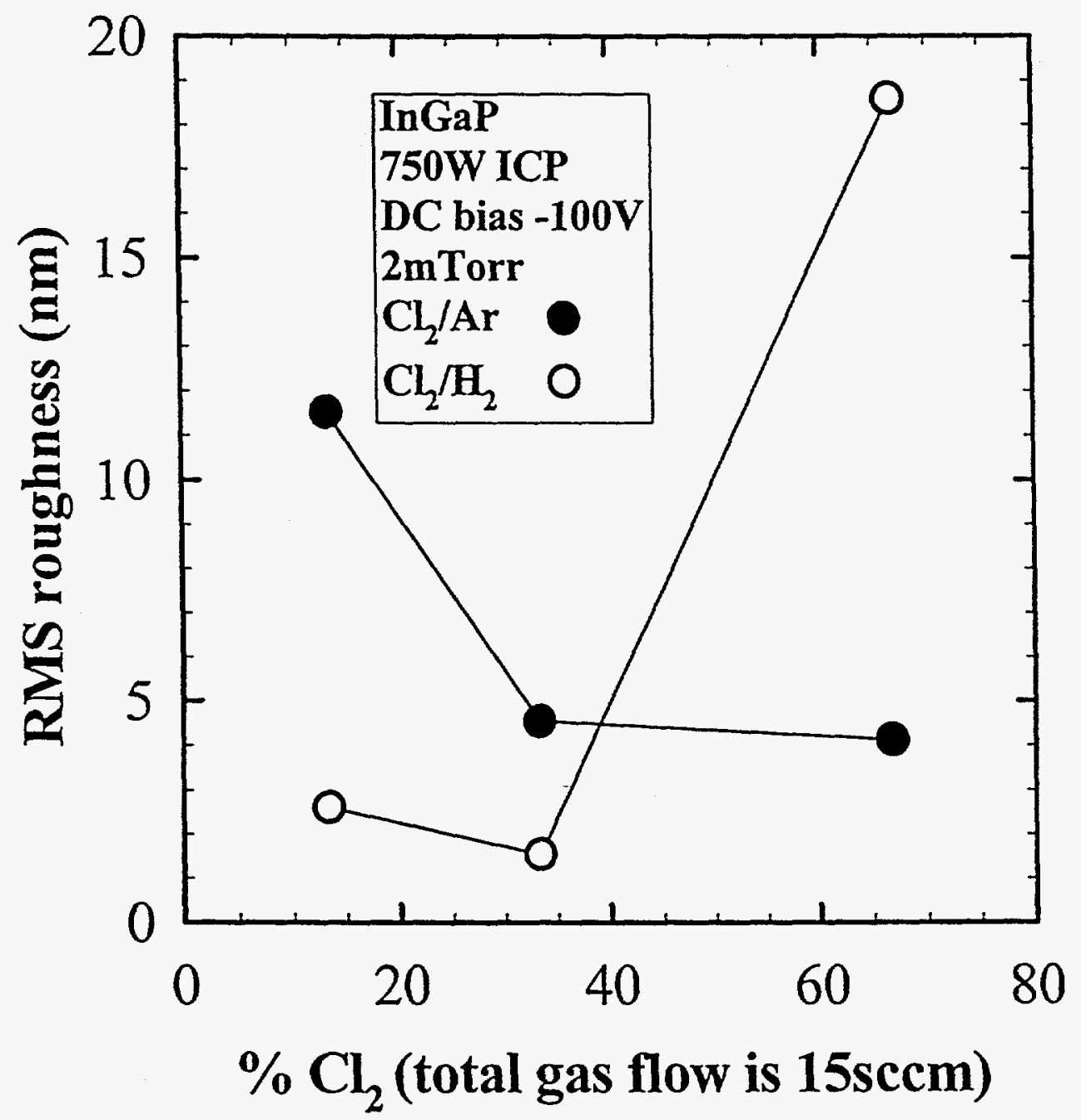

Fig $19 \times f 63$ Honjet.al. 


\section{InGaP \\ $10 \mathrm{Cl}_{2} / 5 \mathrm{Ar}, \mathrm{DC}$ bias $-100 \mathrm{~V}$}

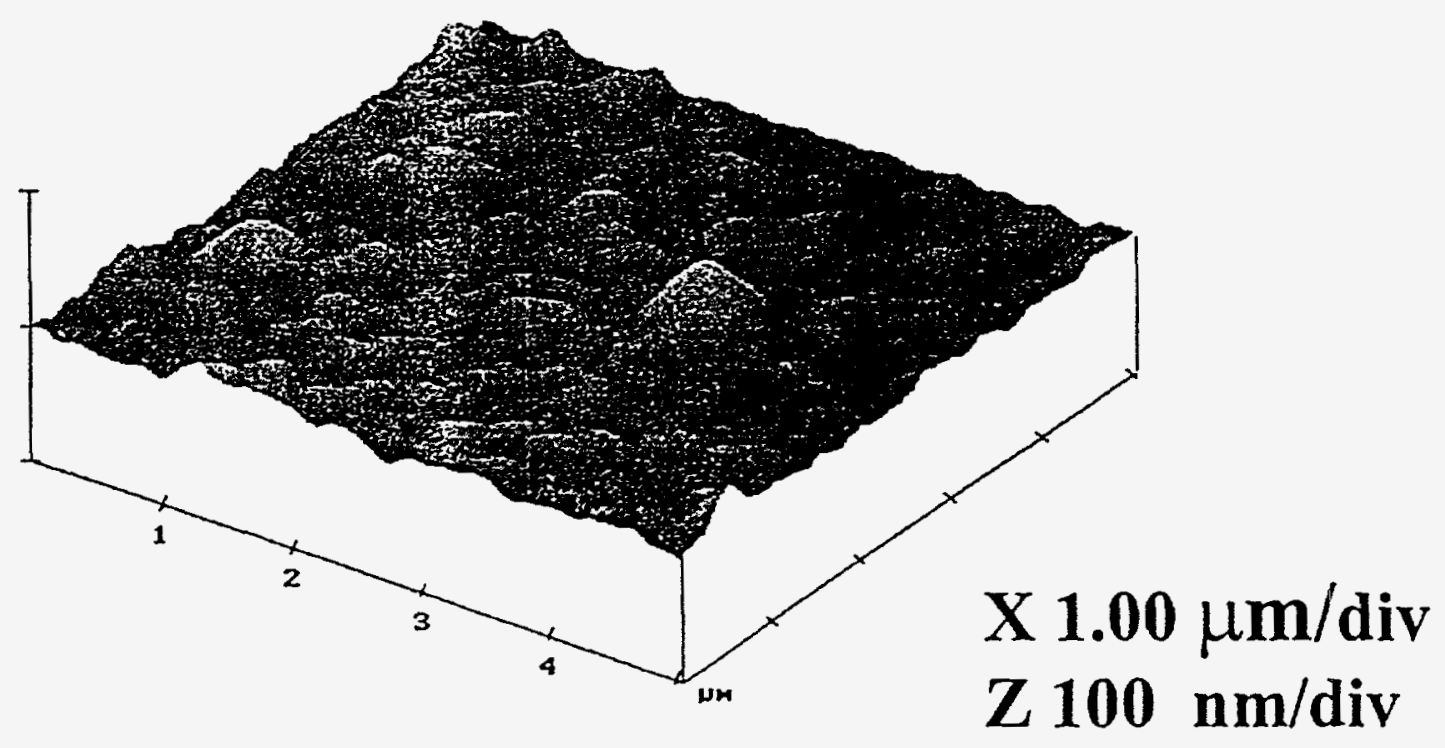

750W ICP, RMS :4.1nm

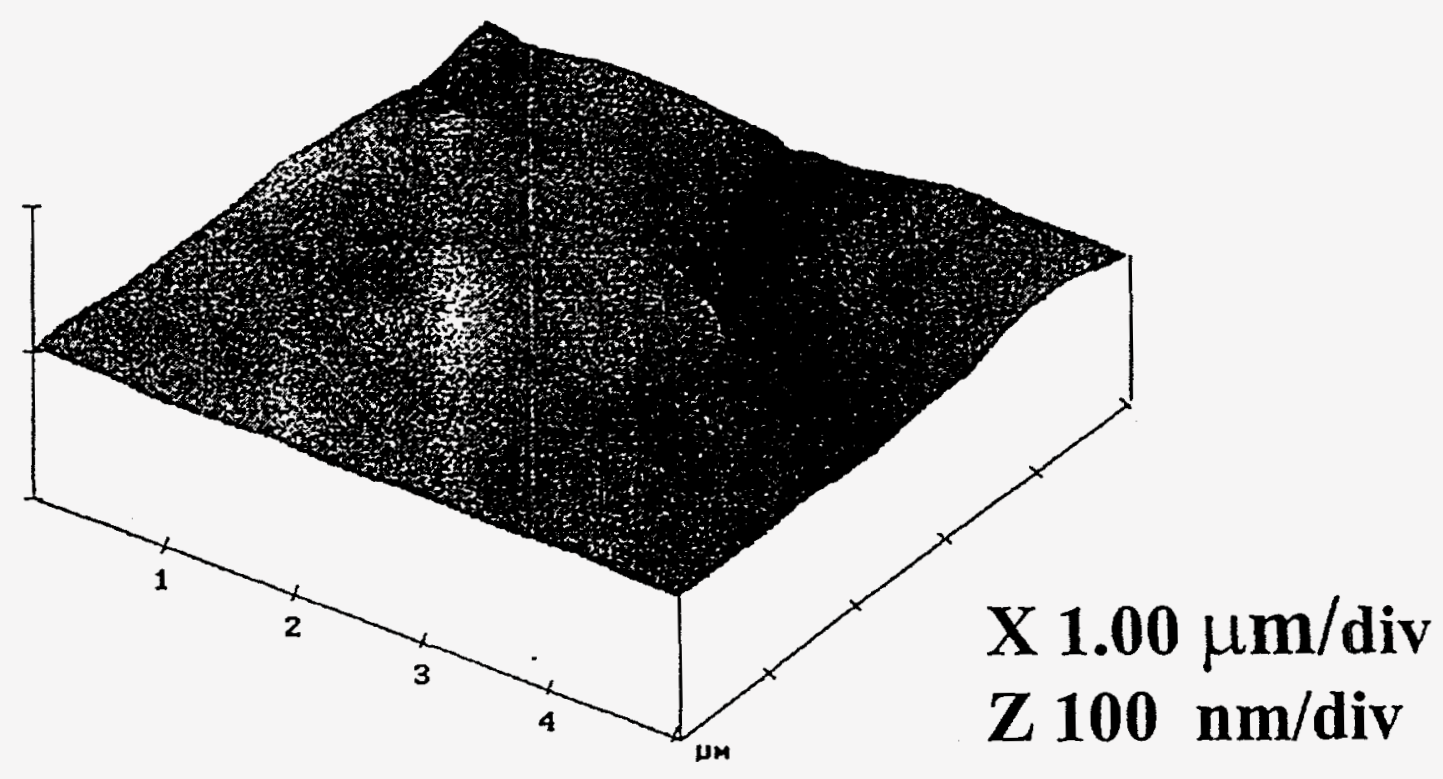

1000W ICP, RMS : 2.8nm

Figize of Hoing et.al. 


\section{AlInP \\ $10 \mathrm{Cl}_{2} / 5 \mathrm{Ar}$}

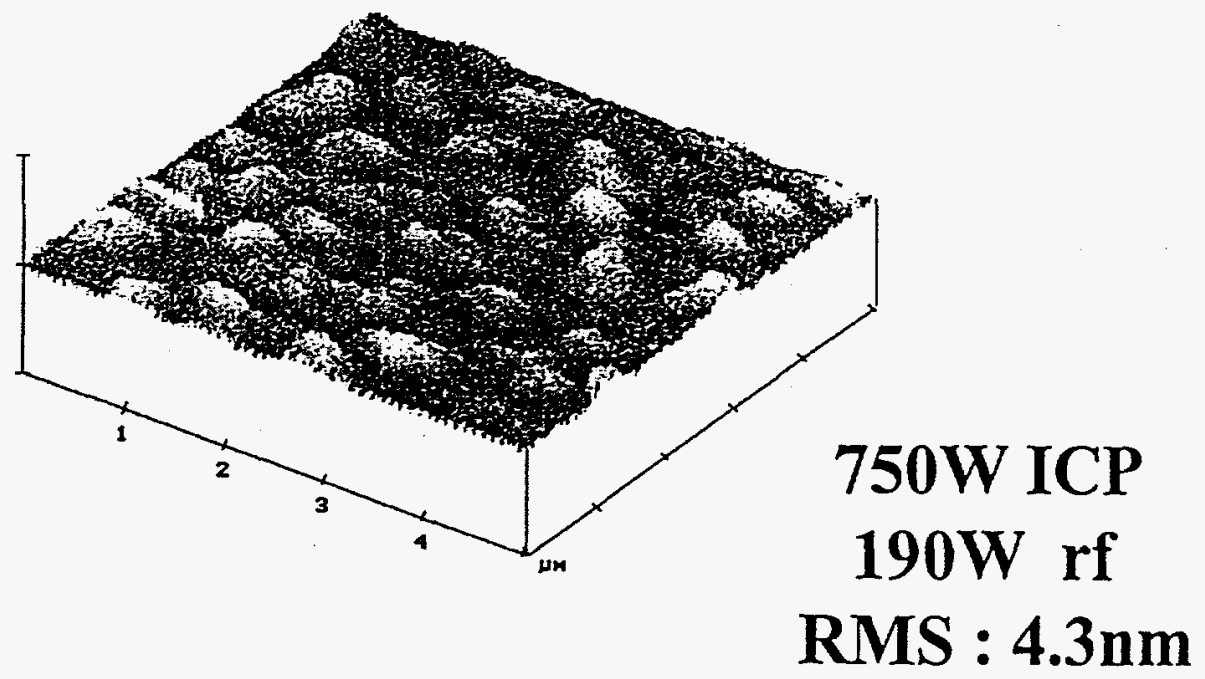

$X \mathbf{1 . 0 0} \mu \mathrm{m} / \mathrm{div}$

$\mathrm{Z} 100 \mathrm{~nm} / \mathrm{div}$

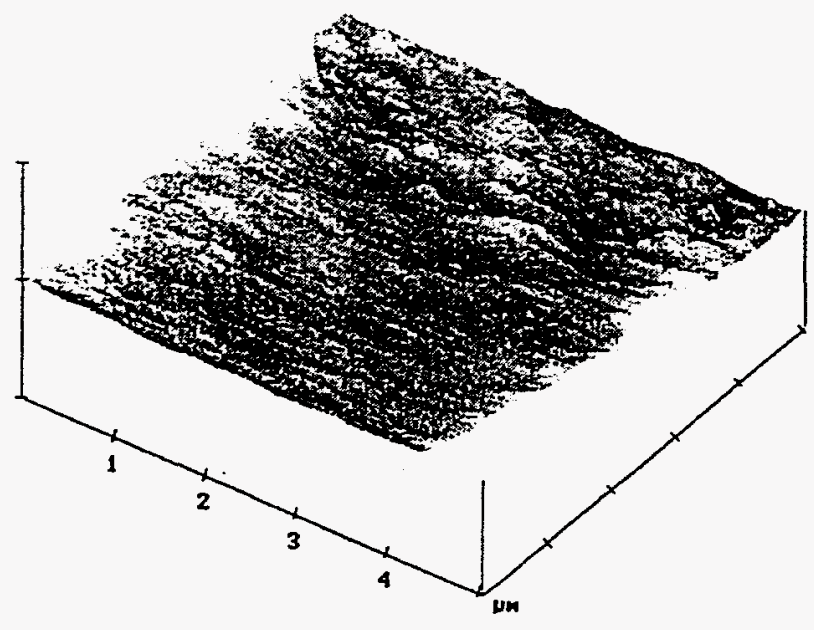

$750 \mathrm{~W}$ ICP

400W rf

RMS :2.8nm
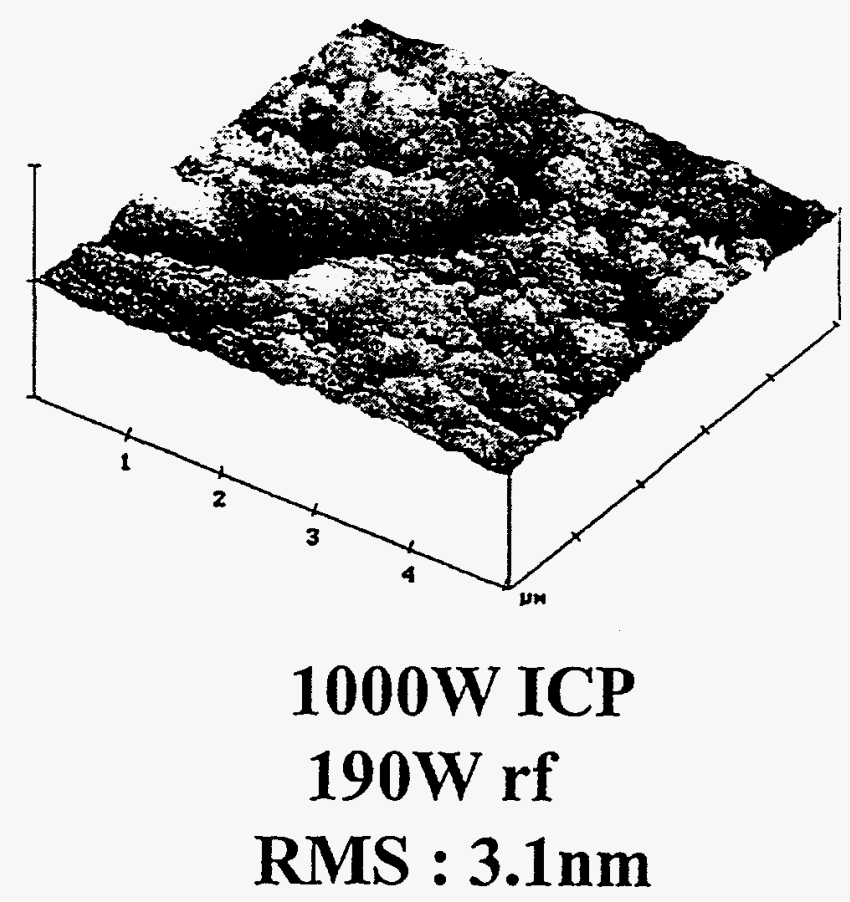

Fig $21=663$

Hoing et in 


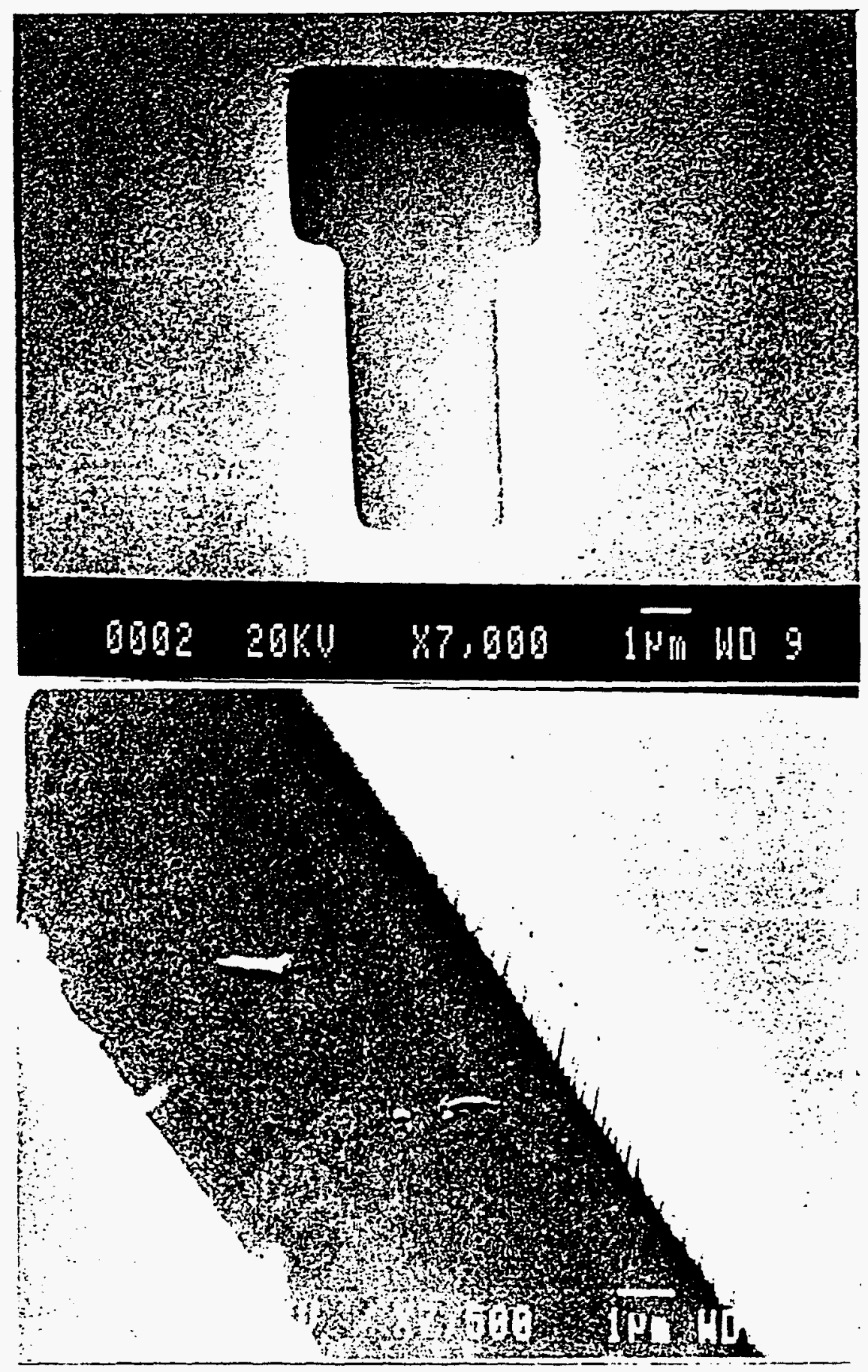

Fijoscoffis
Hing et.all. 

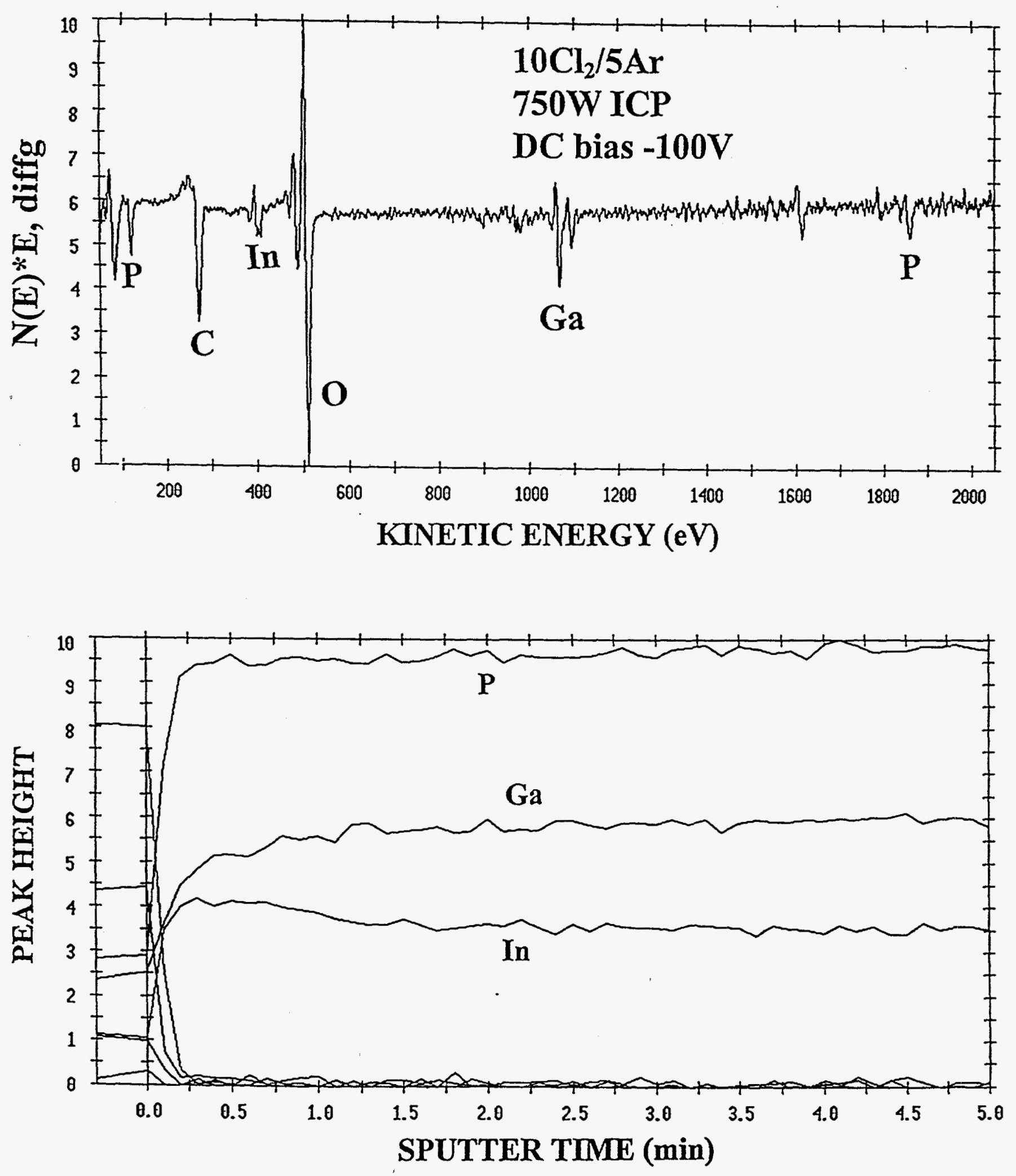

Fig 23 of 63 

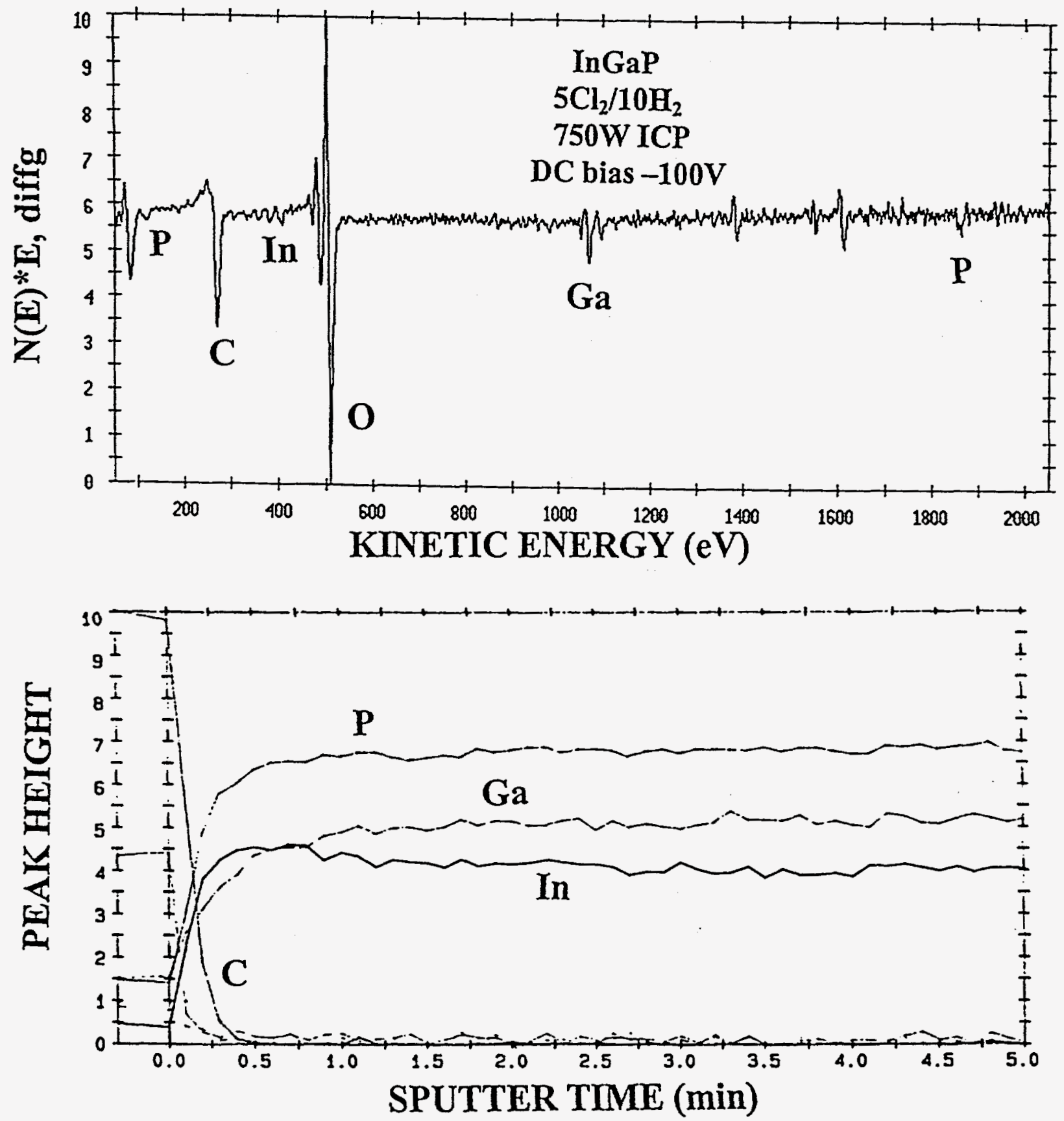

Fig 24.66 Hingetial. 

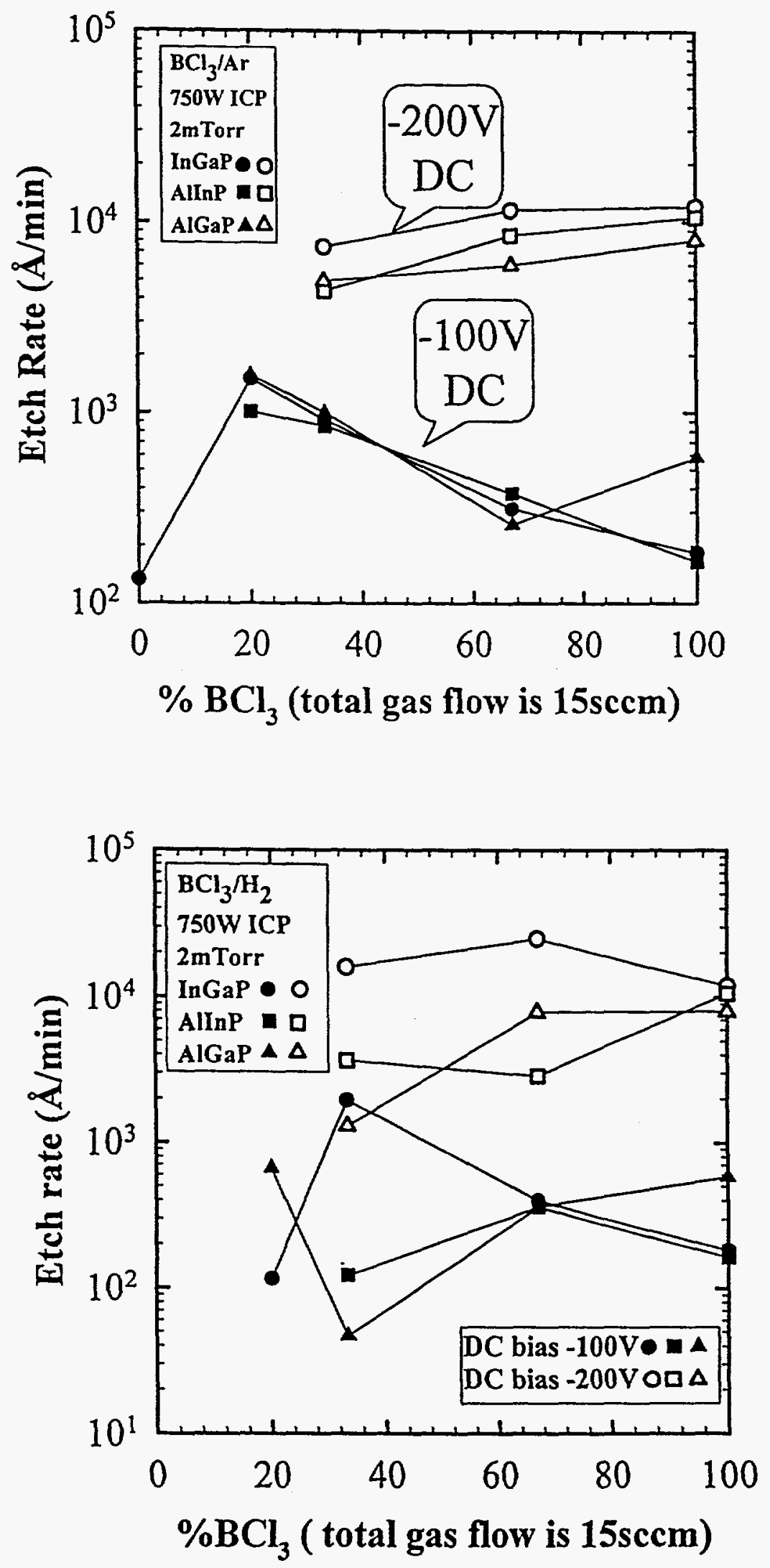

Fig 25 of 13 


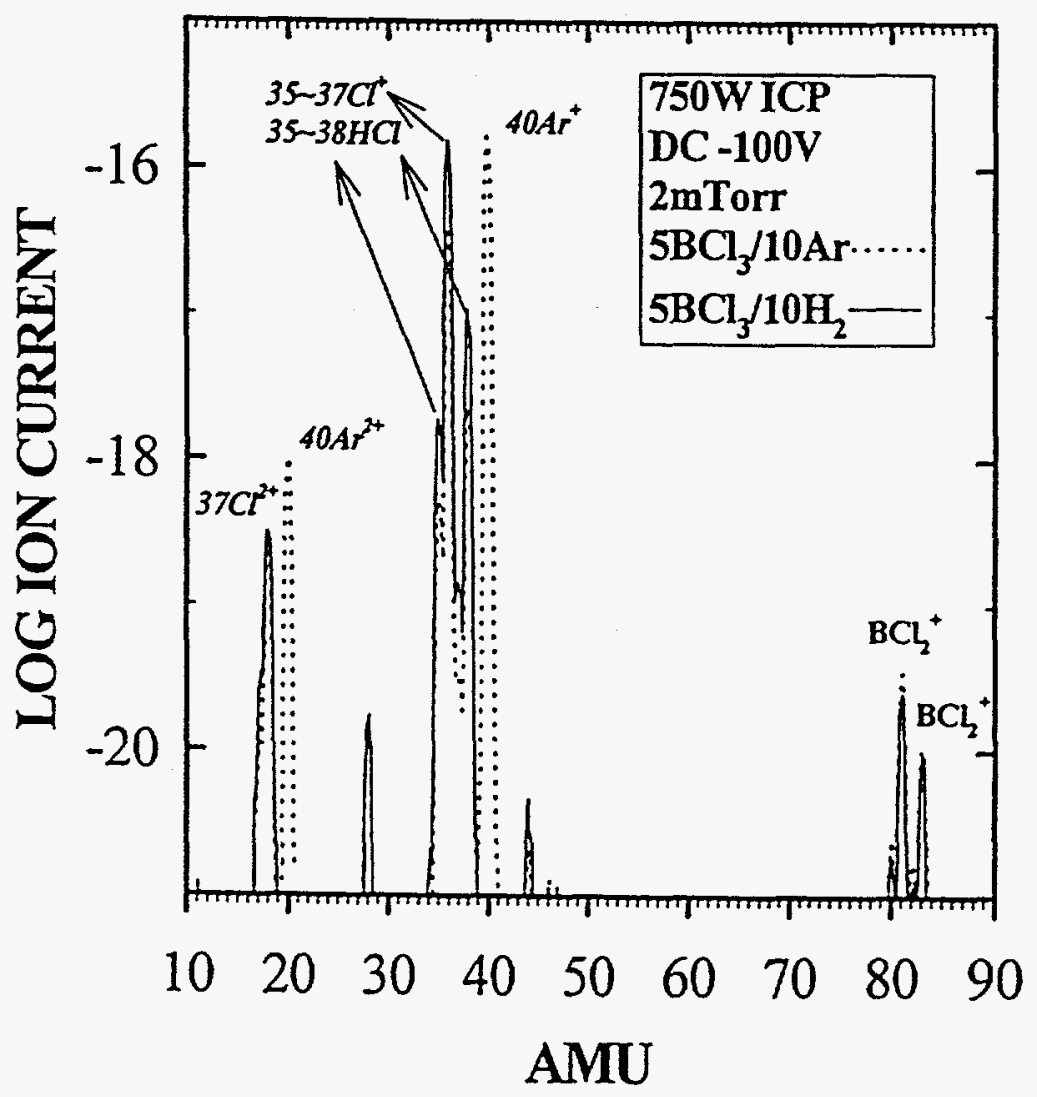



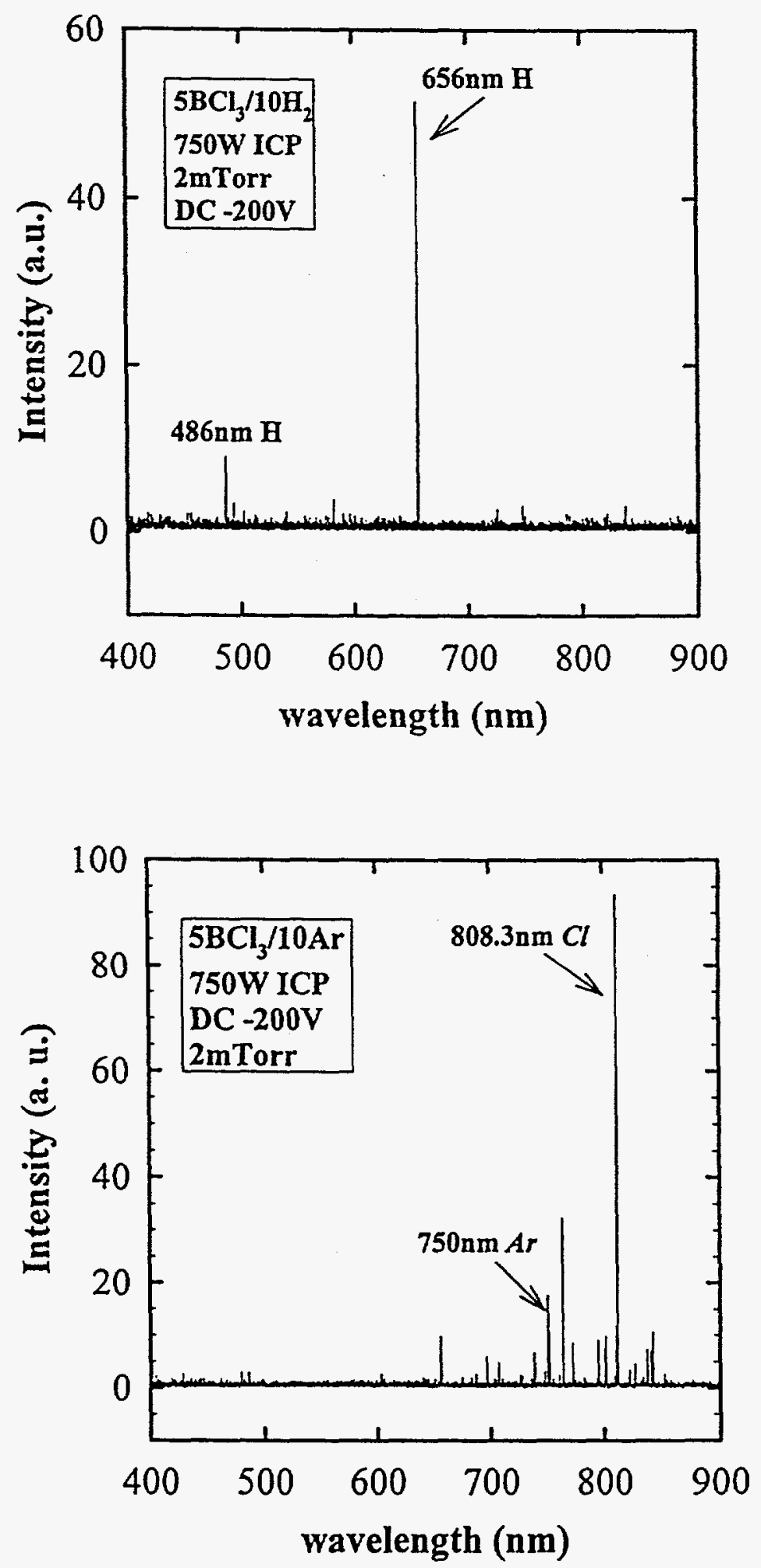

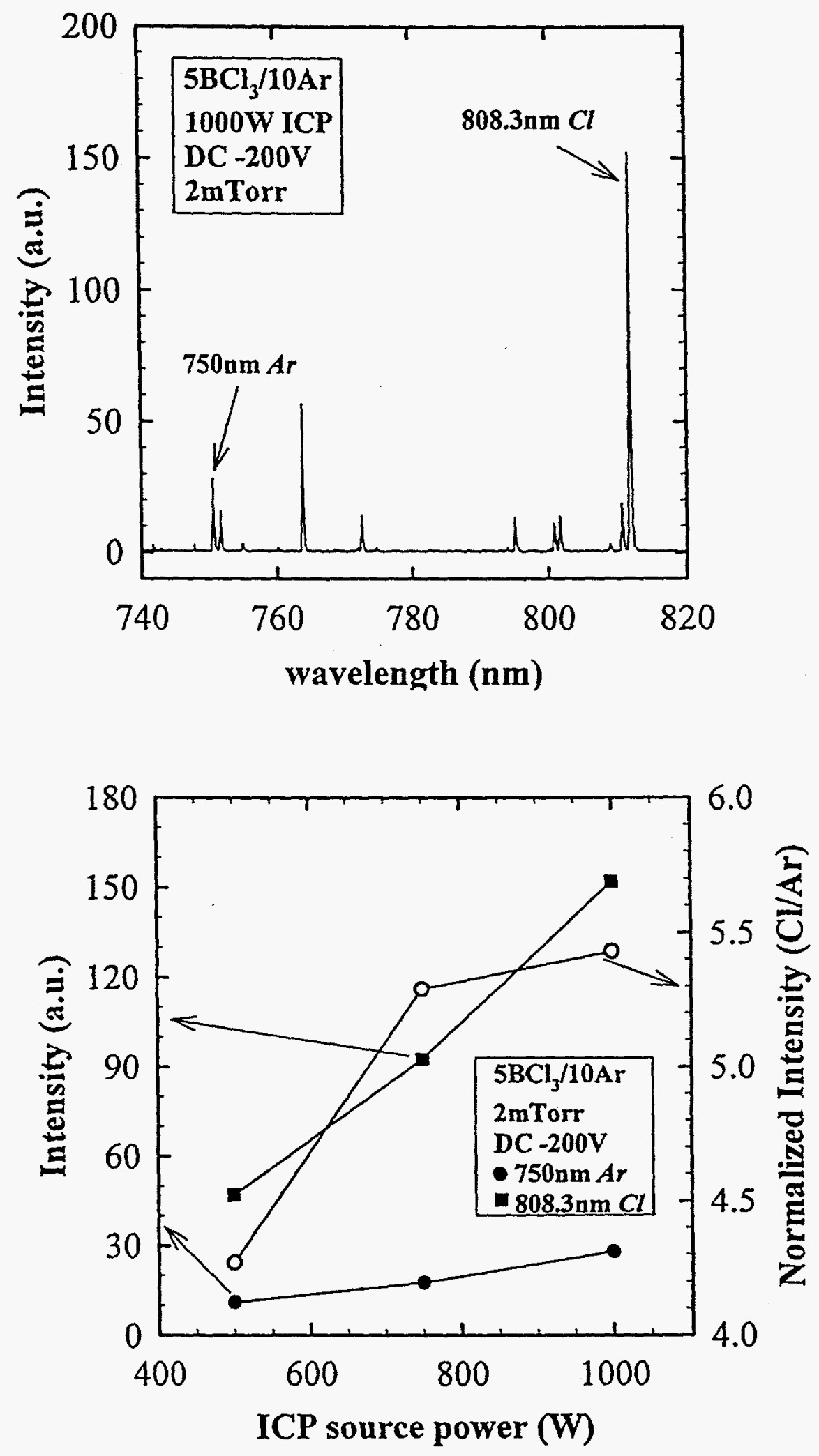

Figg2s of 63
Hogy thial. 

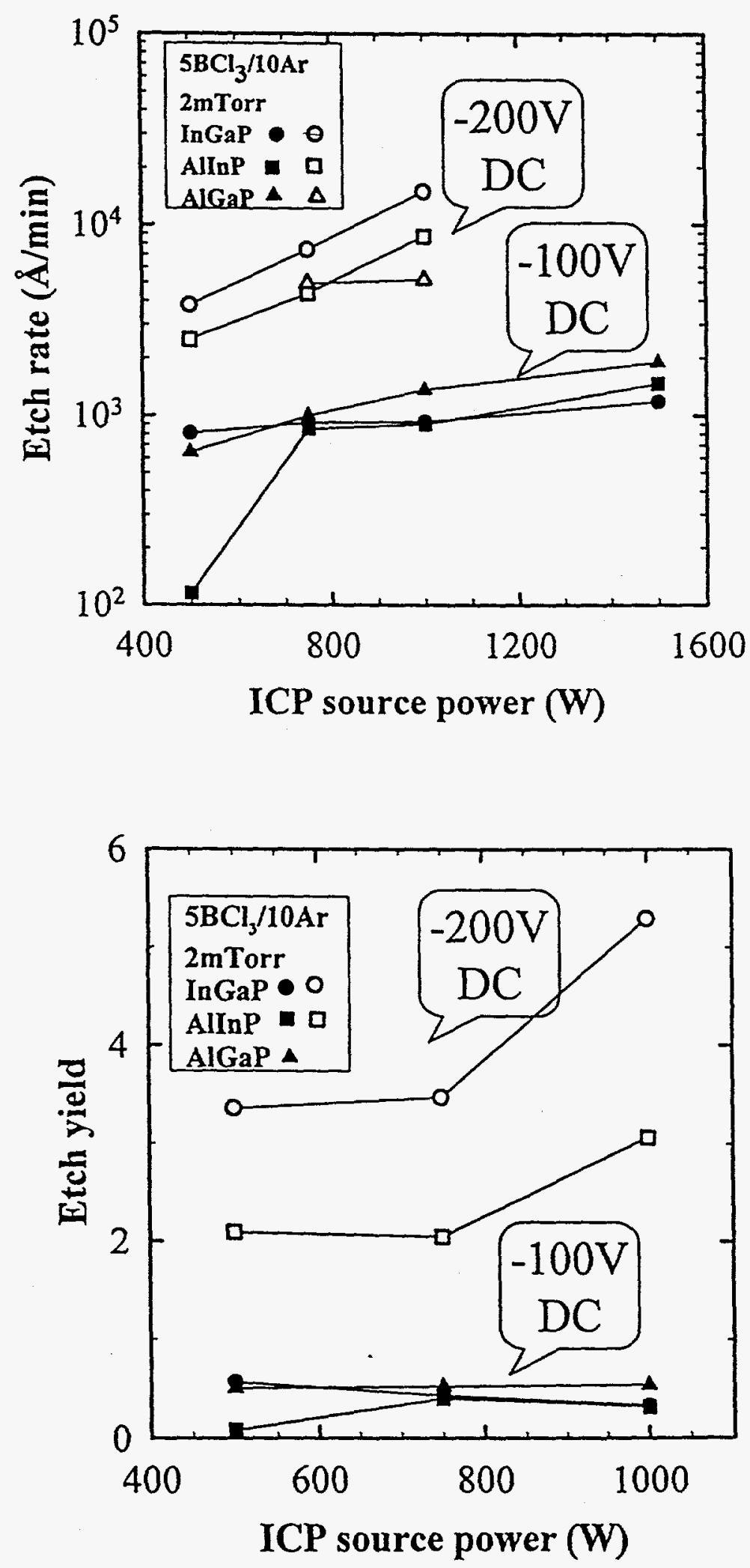

$F i g 29$ of 63
H.gig et. of. 


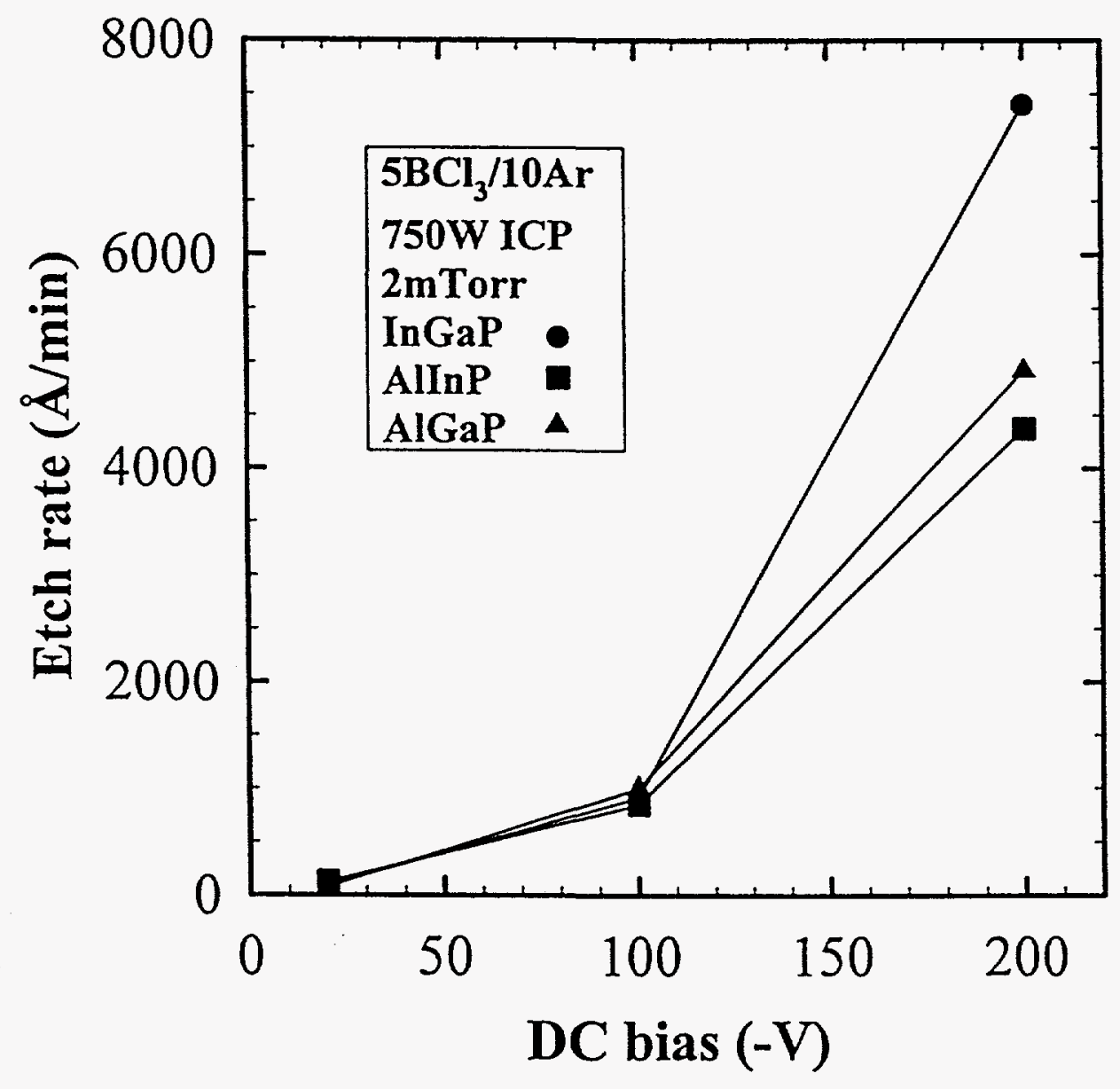

Figy 30 if 65 Hogig et.al 


\section{InGaP \\ 750W ICP, DC bias -100V}

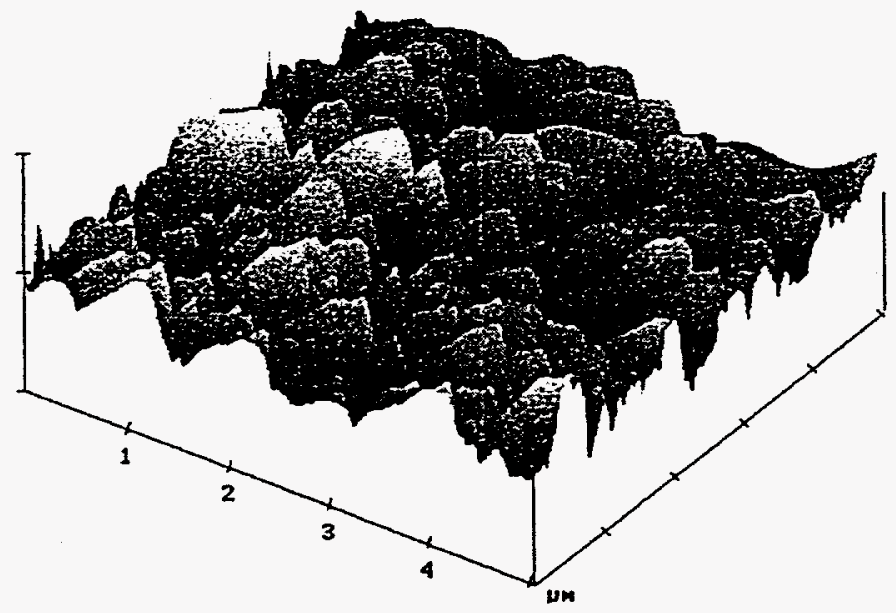

$3 \mathrm{BCl}_{3} / 12 \mathrm{Ar}$
$\mathrm{RMS}: 17.0 \mathrm{~nm}$

$X 1.00 \mu \mathrm{m} / \mathrm{div}$

$\mathrm{Z} 100 \mathrm{~nm} / \mathrm{div}$

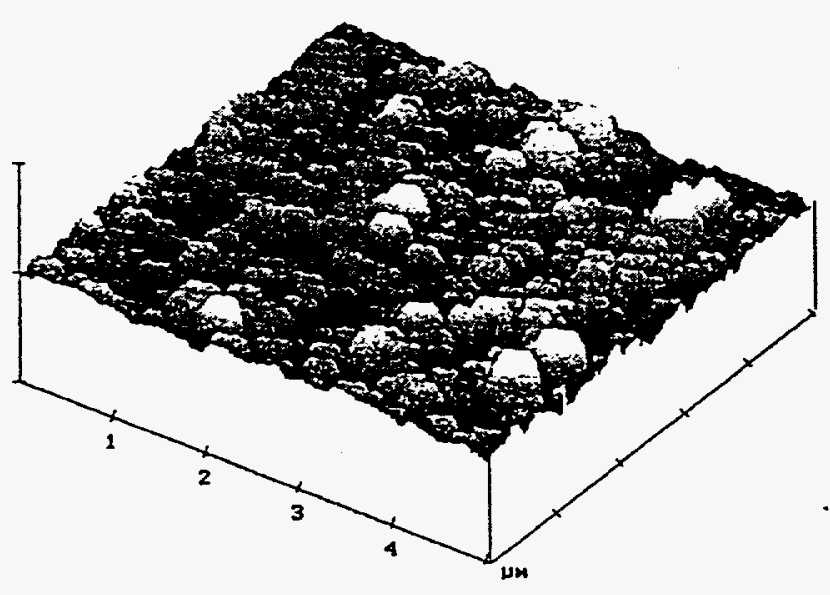

$5 \mathrm{BCl}_{3} / 10 \mathrm{Ar}$

RMS : 5.9 nm

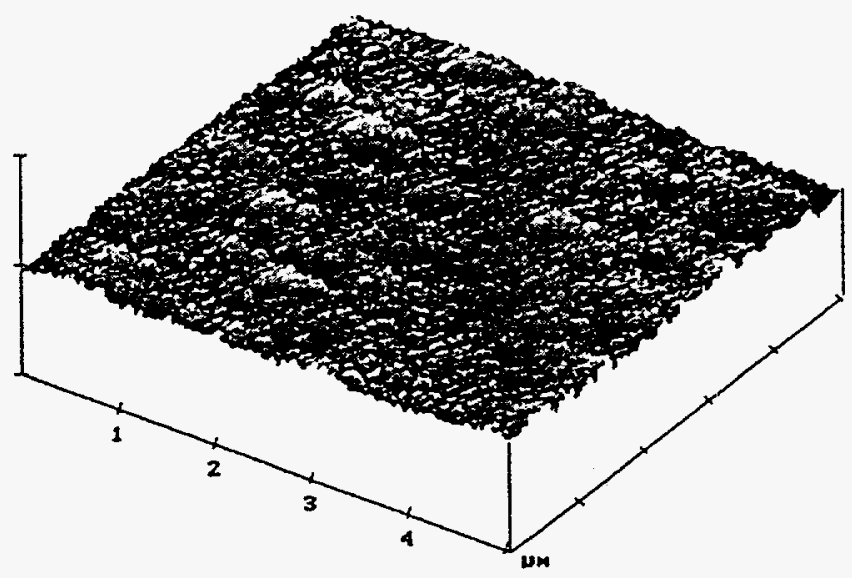

$\mathbf{5 B C l} 3 / \mathbf{1 0 H}_{2}$

RMS : 3.2 nm

Fig3i oflis:

Hong st. inl. 

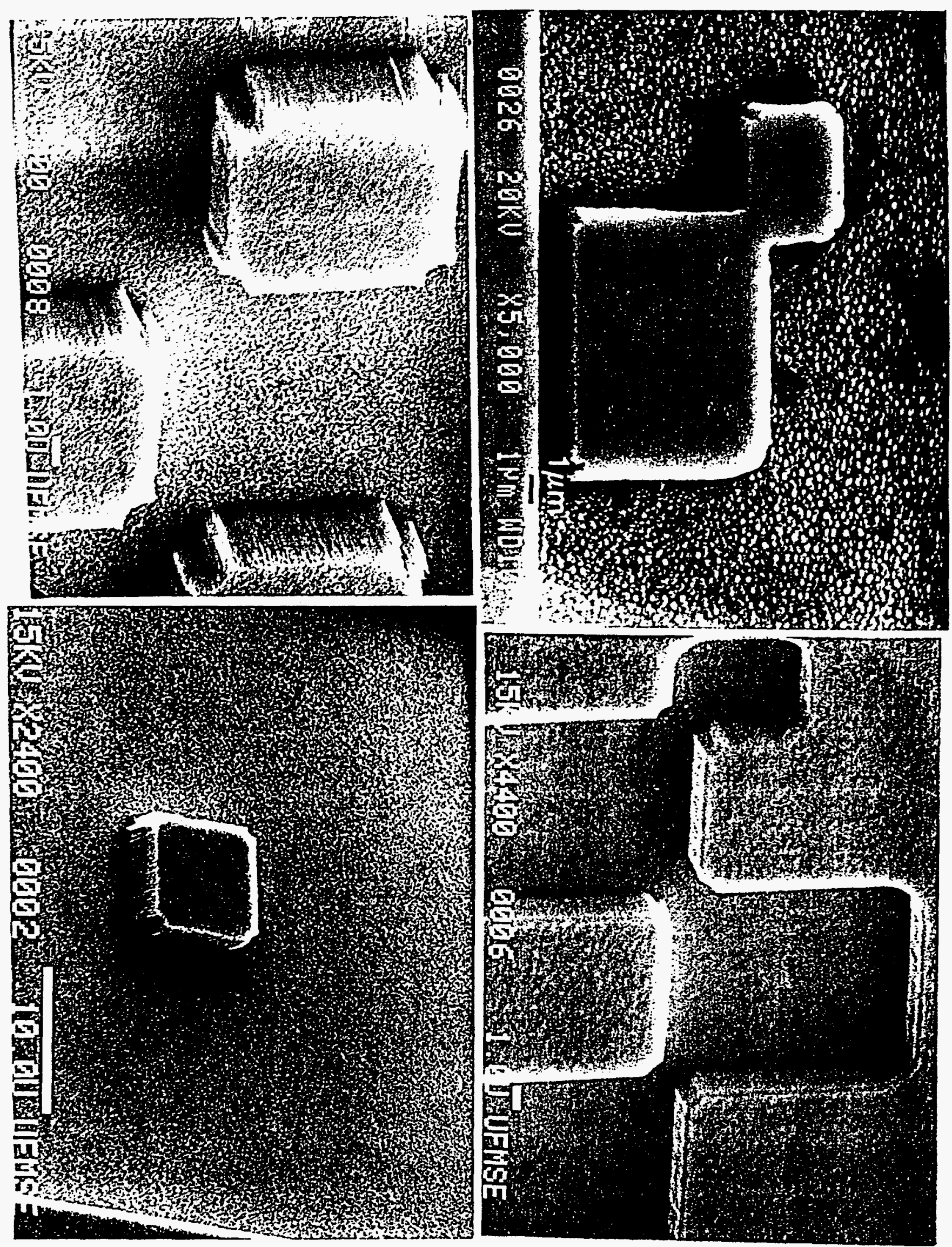

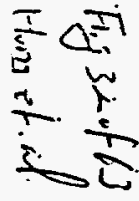



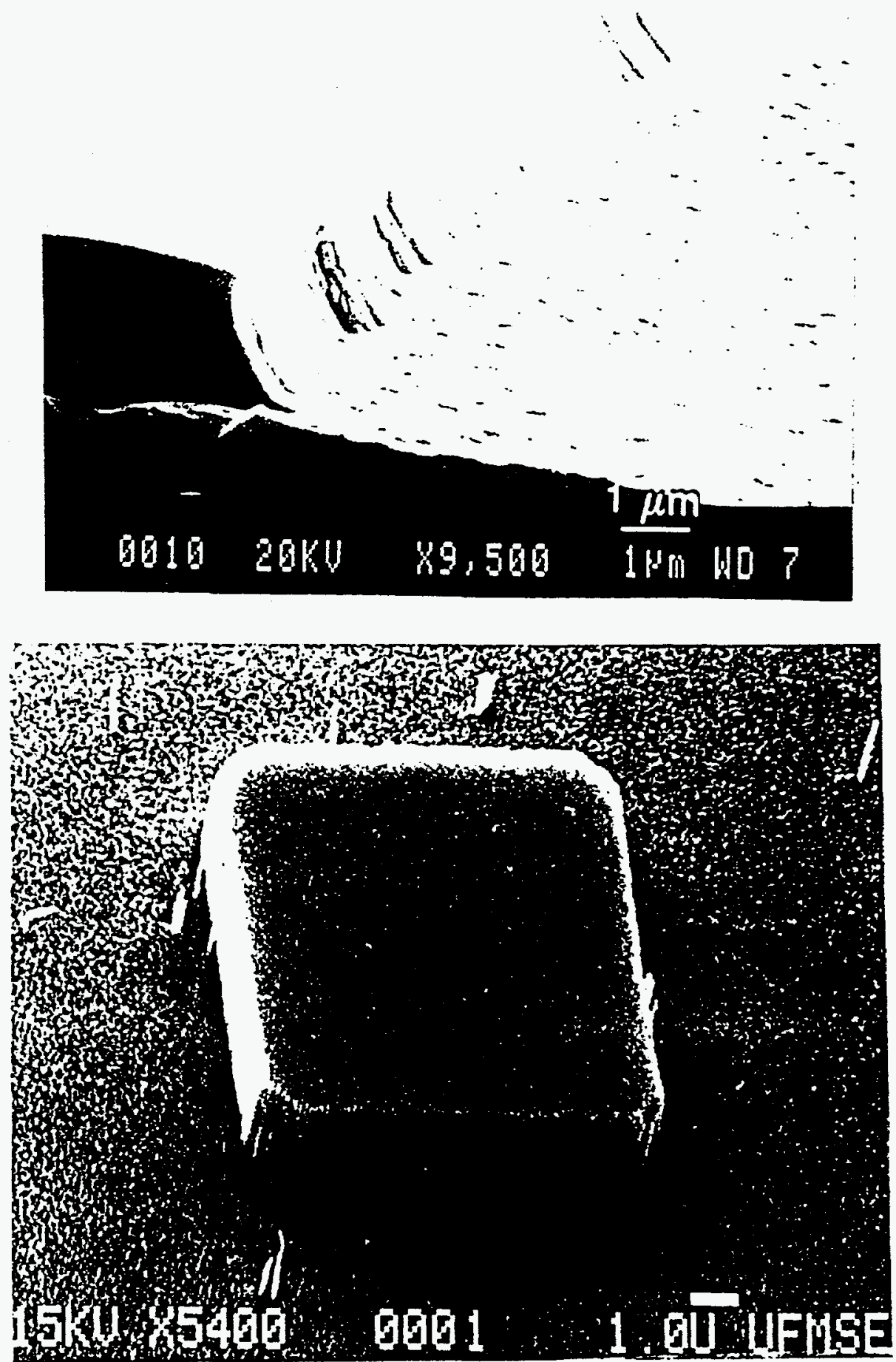

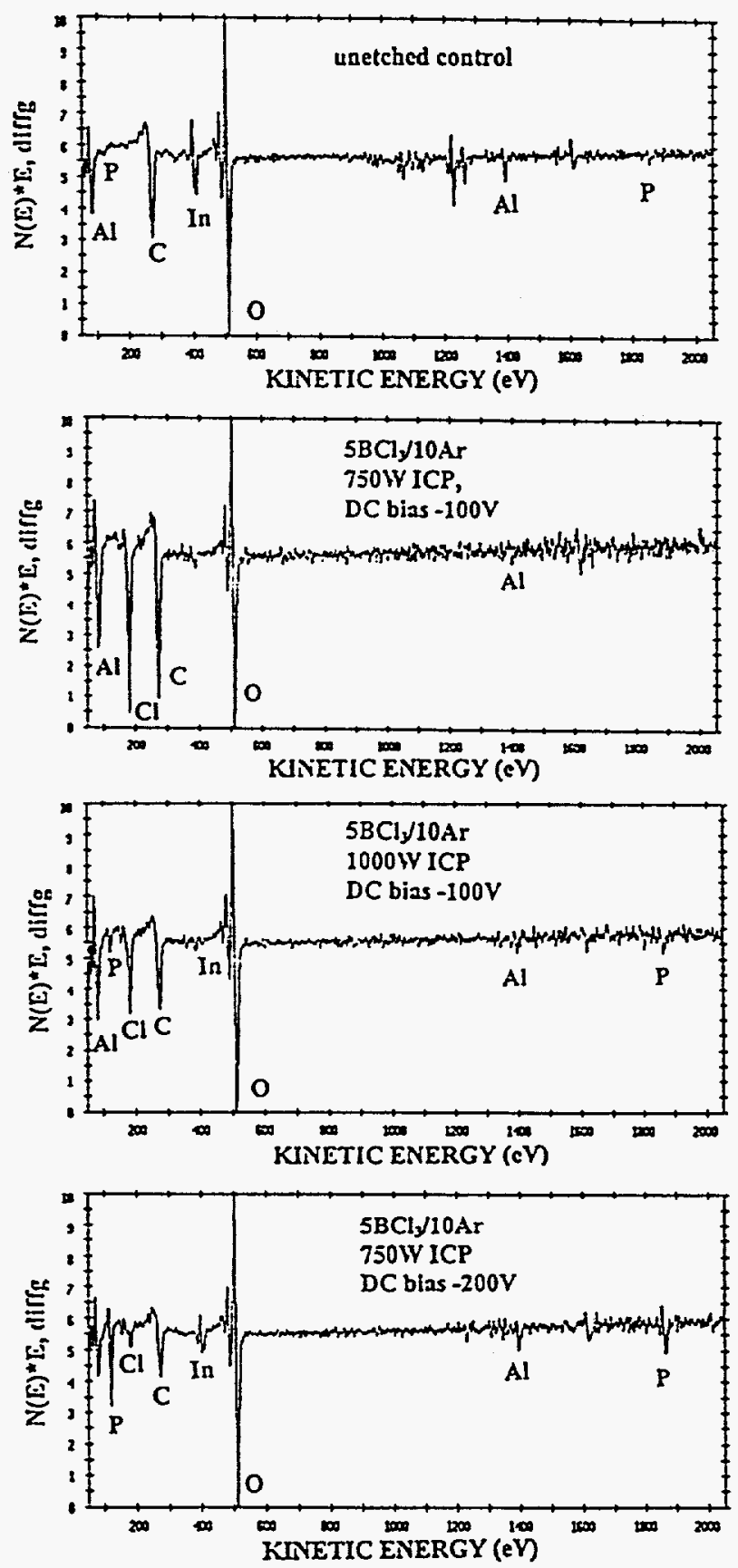

Fij34 of 63
Higj ot. all. 

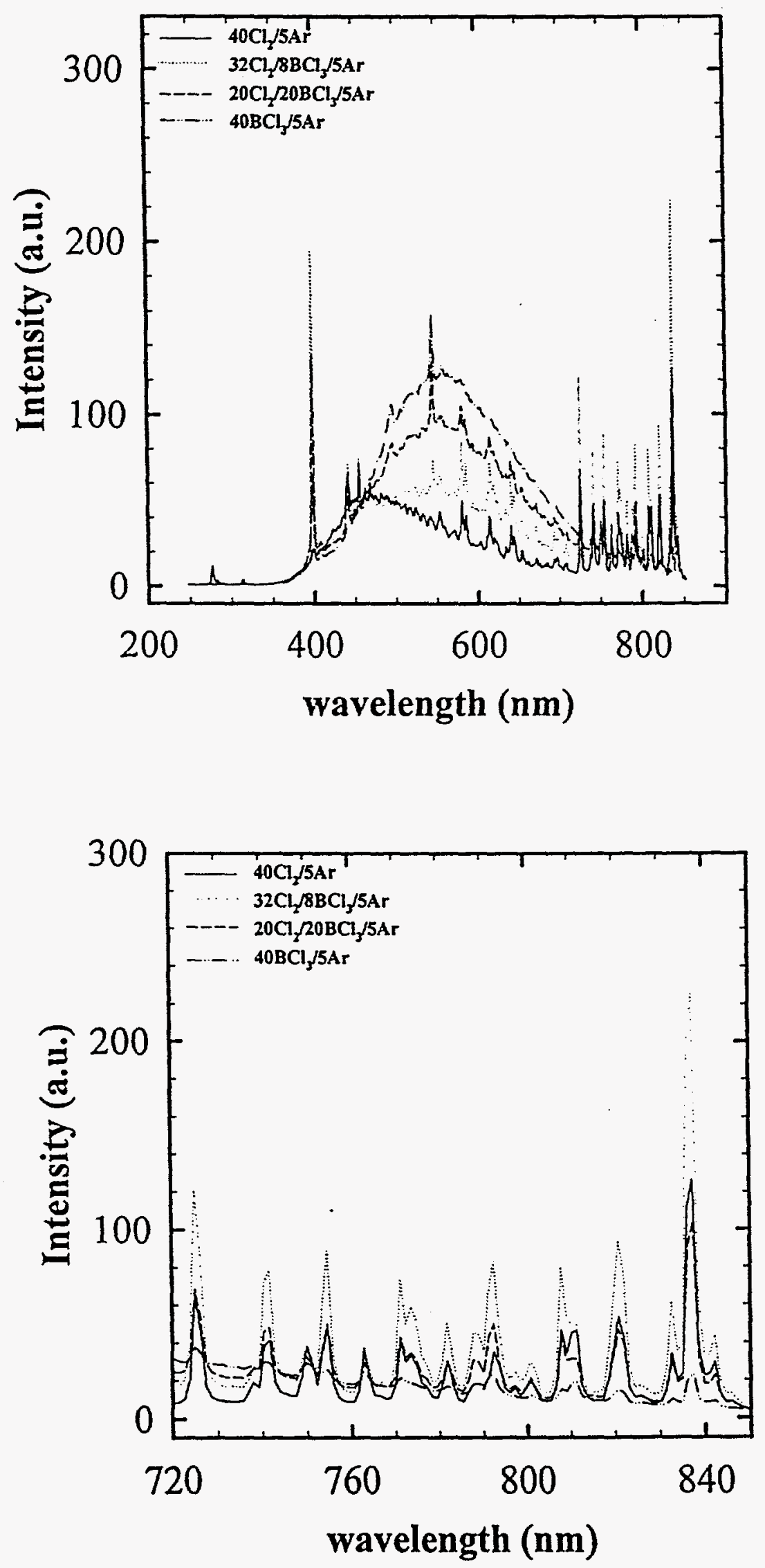

Figs5 0.65 Hogiet at 

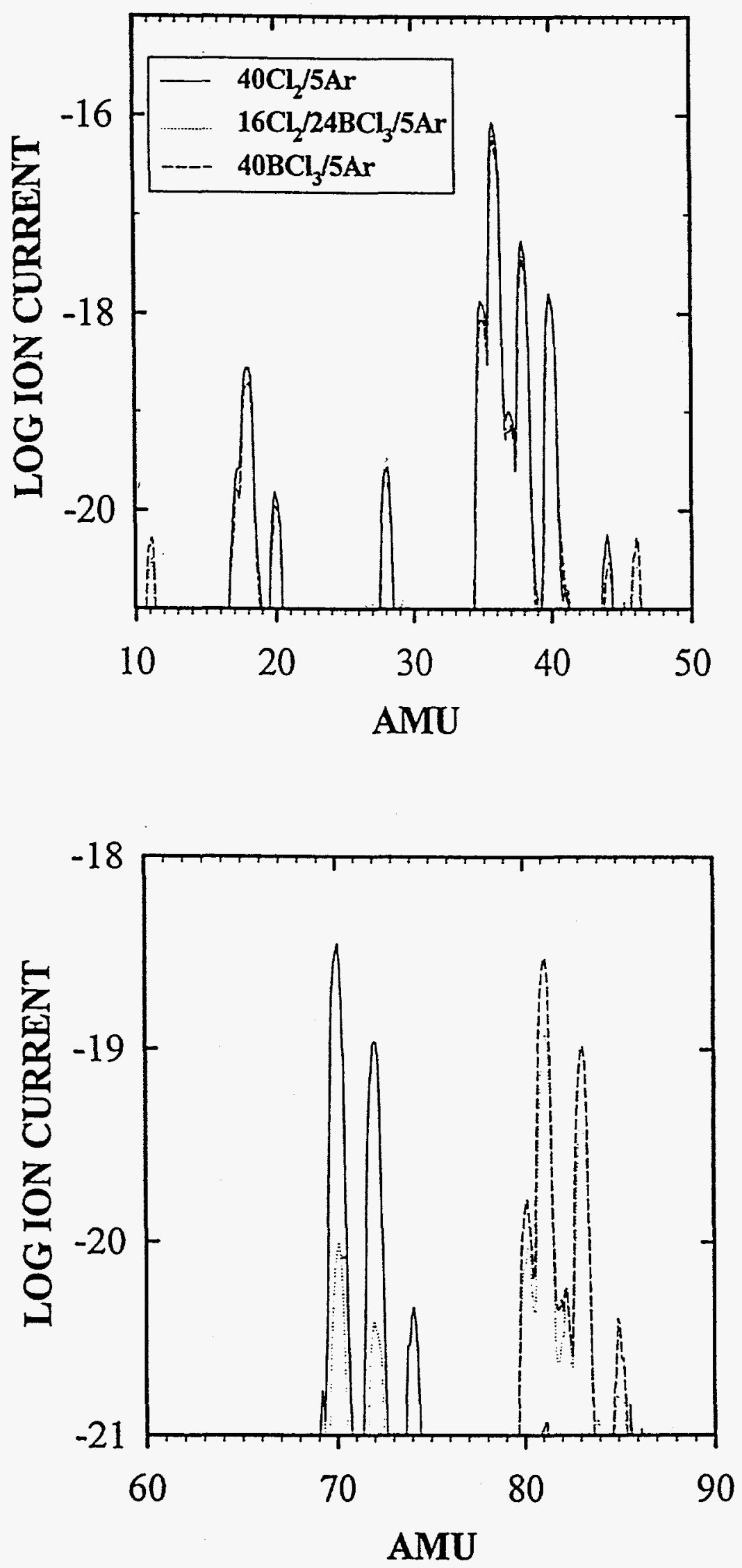

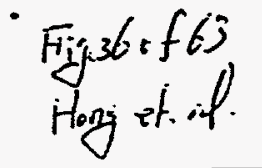



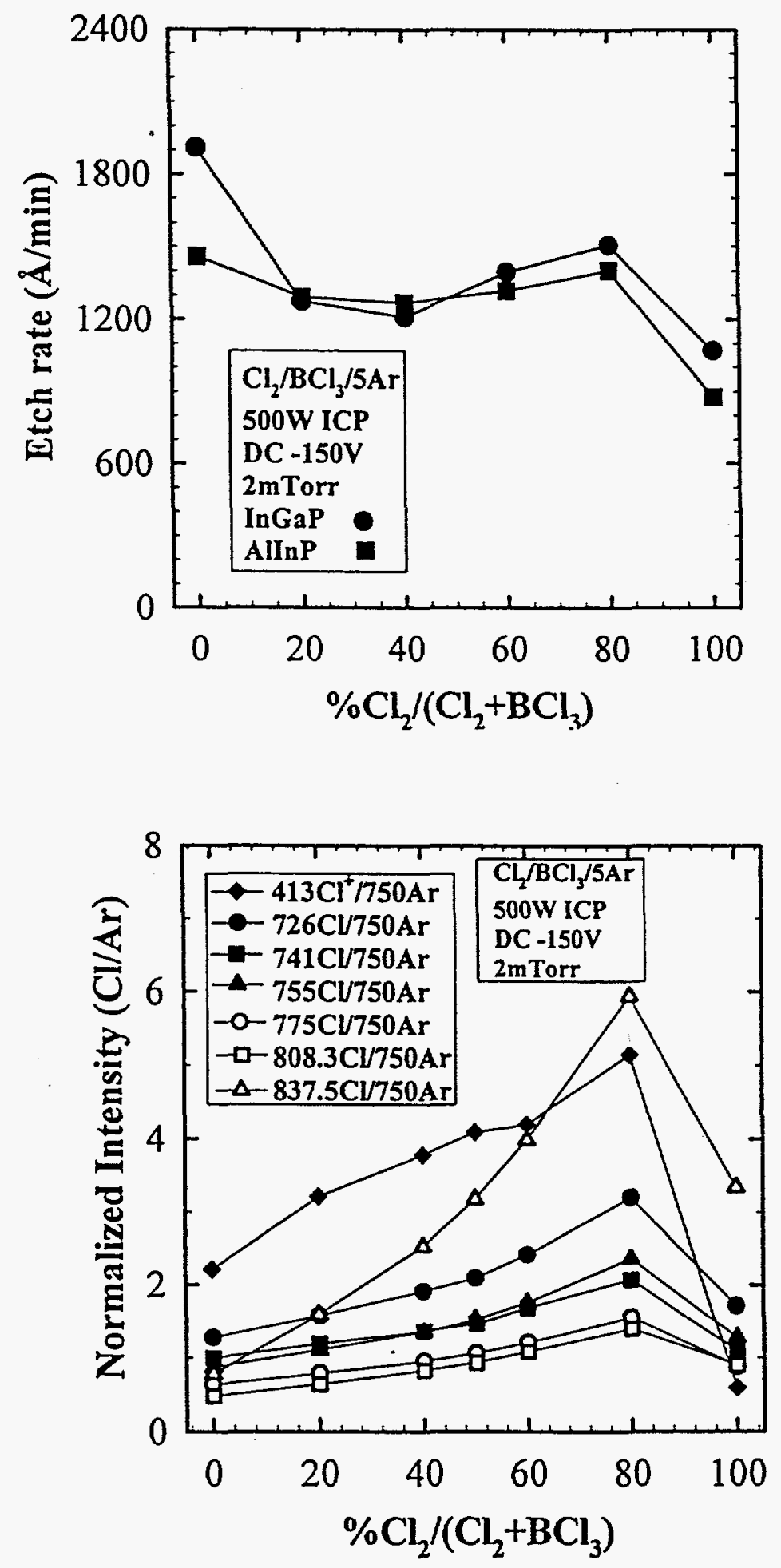

Figj7 of 63 


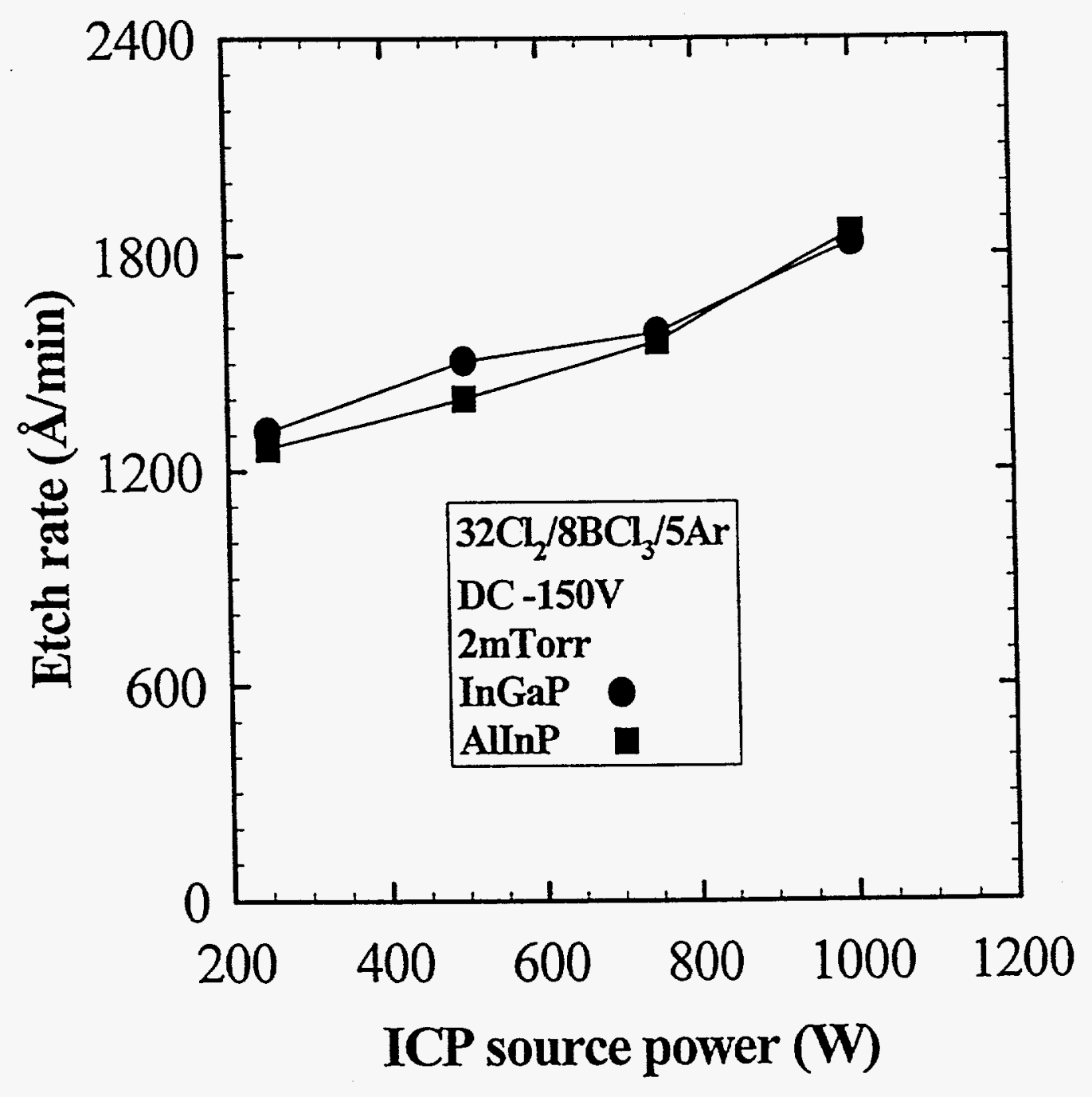

Figizofo
Hoingt. 

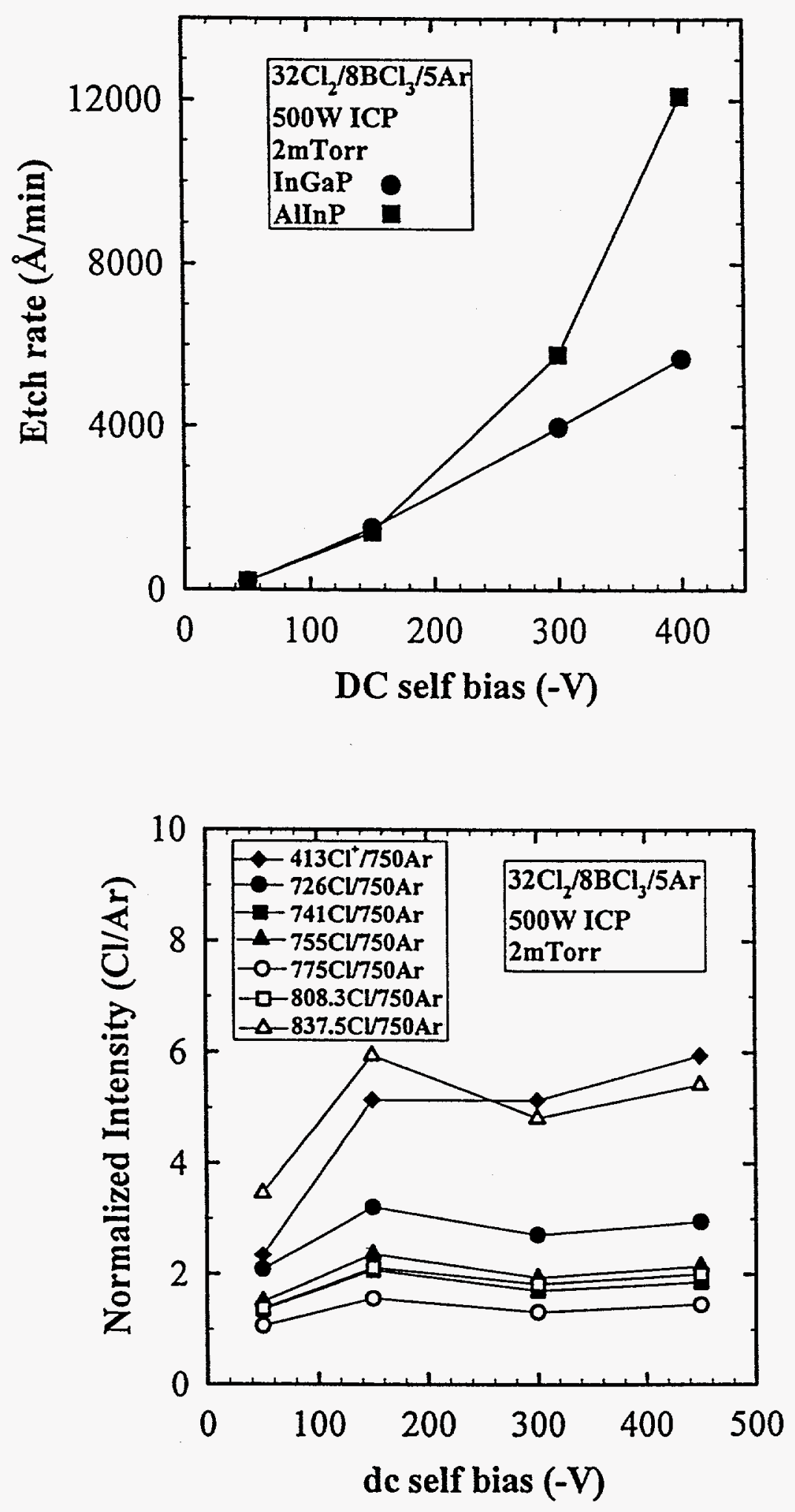

$\left.F_{i j 3} 3\right)^{\circ} \circ 65$ Hoingetall. 

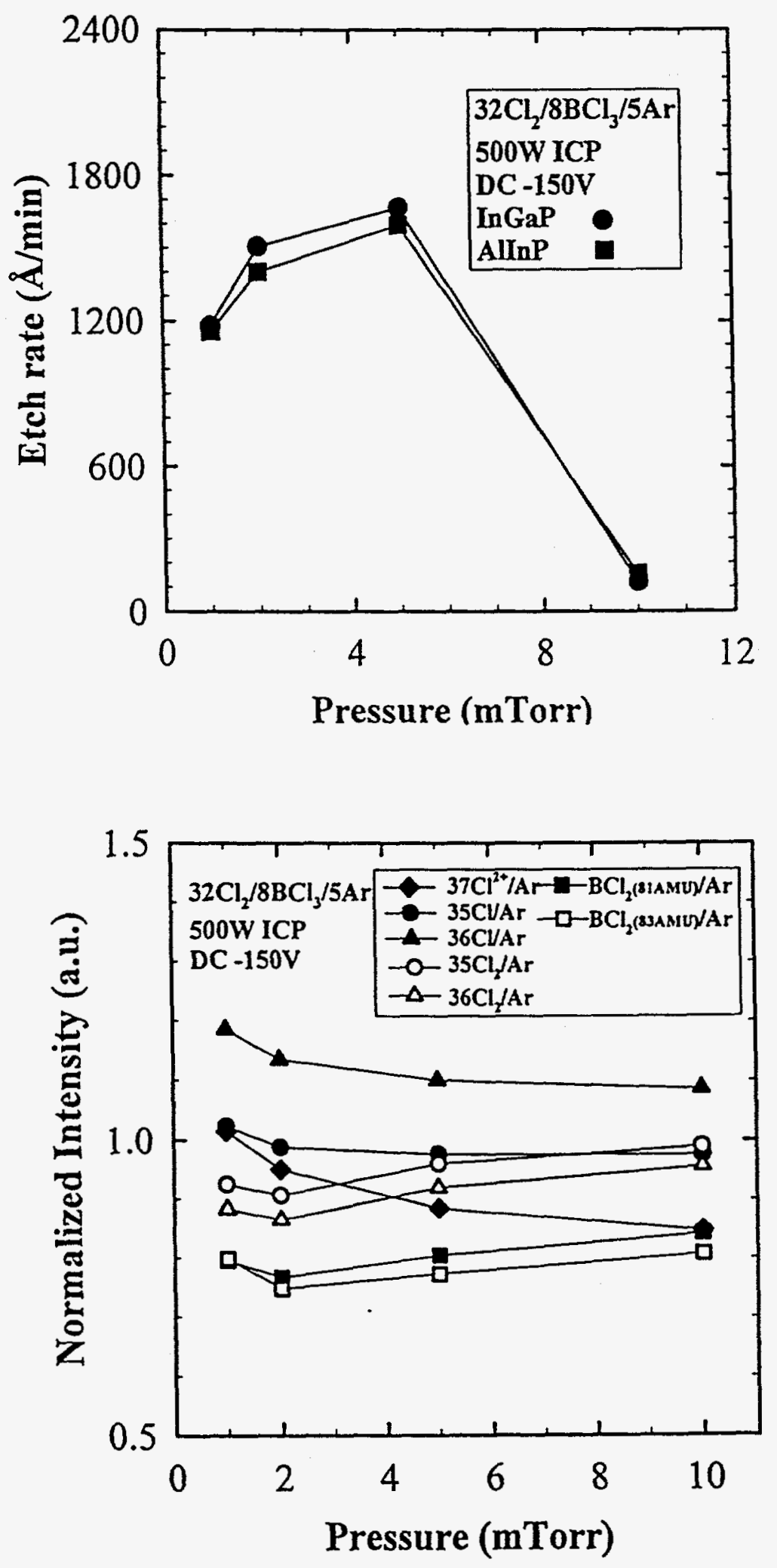

$\mathrm{F}_{i j} 40$ : 663 


\section{AlInP \\ $32 \mathrm{Cl}_{2} / 8 \mathrm{BCl}_{3} / 5 \mathrm{Ar}$}

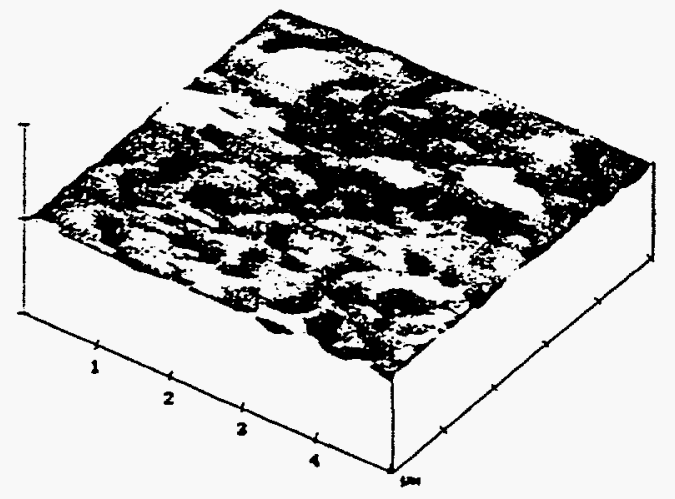

500W ICP

DC -150V

RMS : 2.1nm

$X 1.00 \mu \mathrm{m} / \mathrm{div}$

$\mathrm{Z} 100 \mathrm{~nm} / \mathrm{div}$

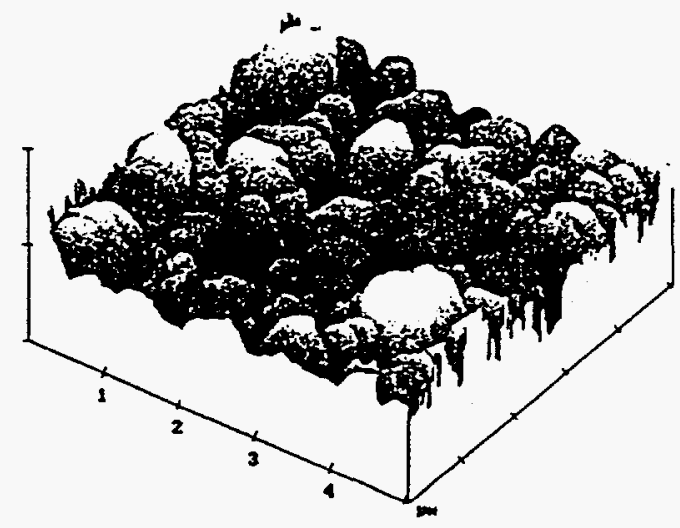

1000W ICP

DC -150V

RMS : 16.2nm

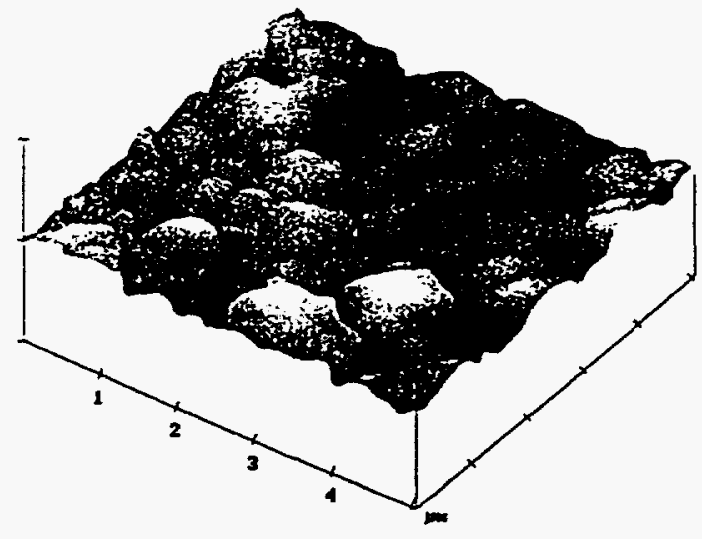

500W ICP

DC $-400 \mathrm{~V}$

RMS : $6.8 \mathrm{~nm}$ 


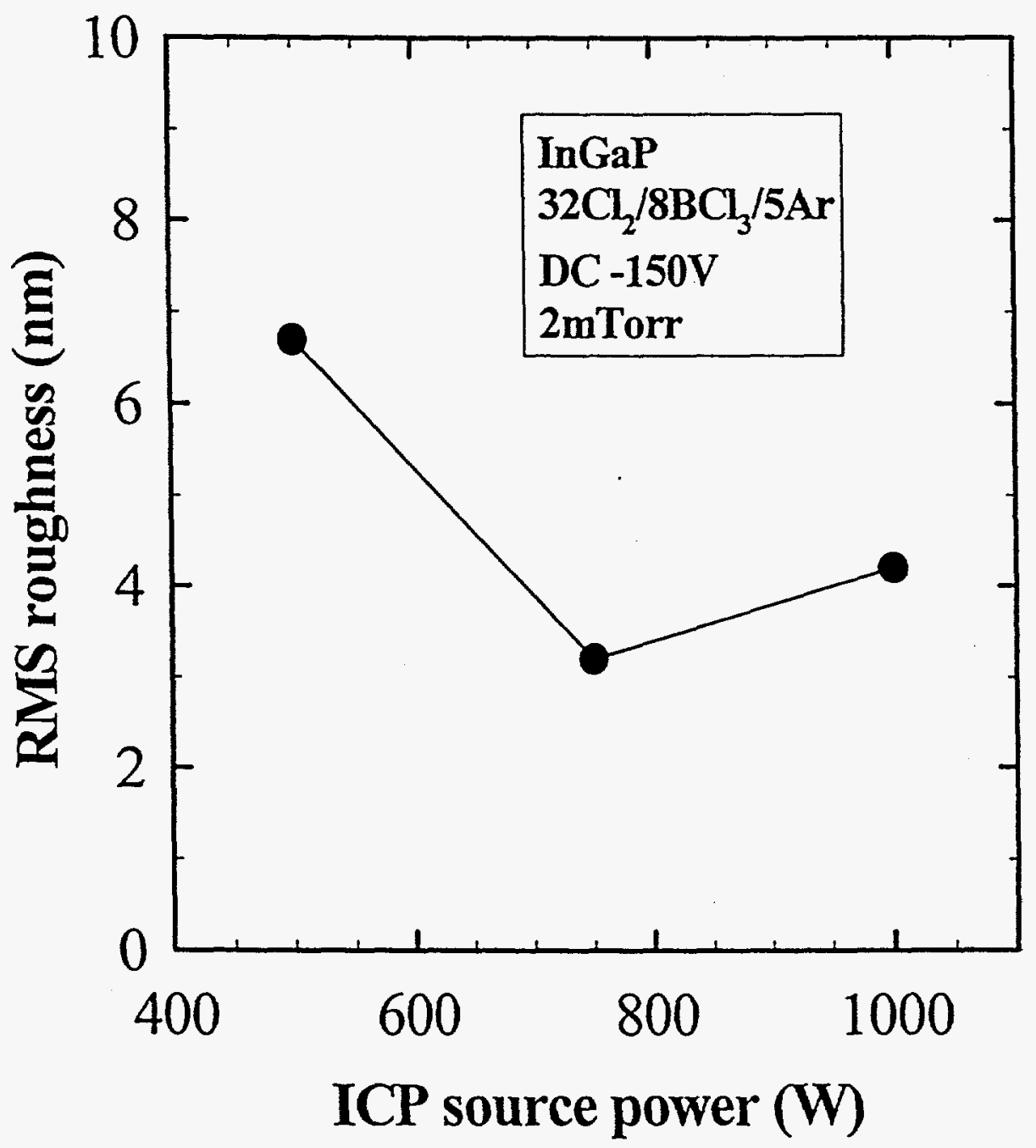

Fig 41 of 63
Hoiget.il. 


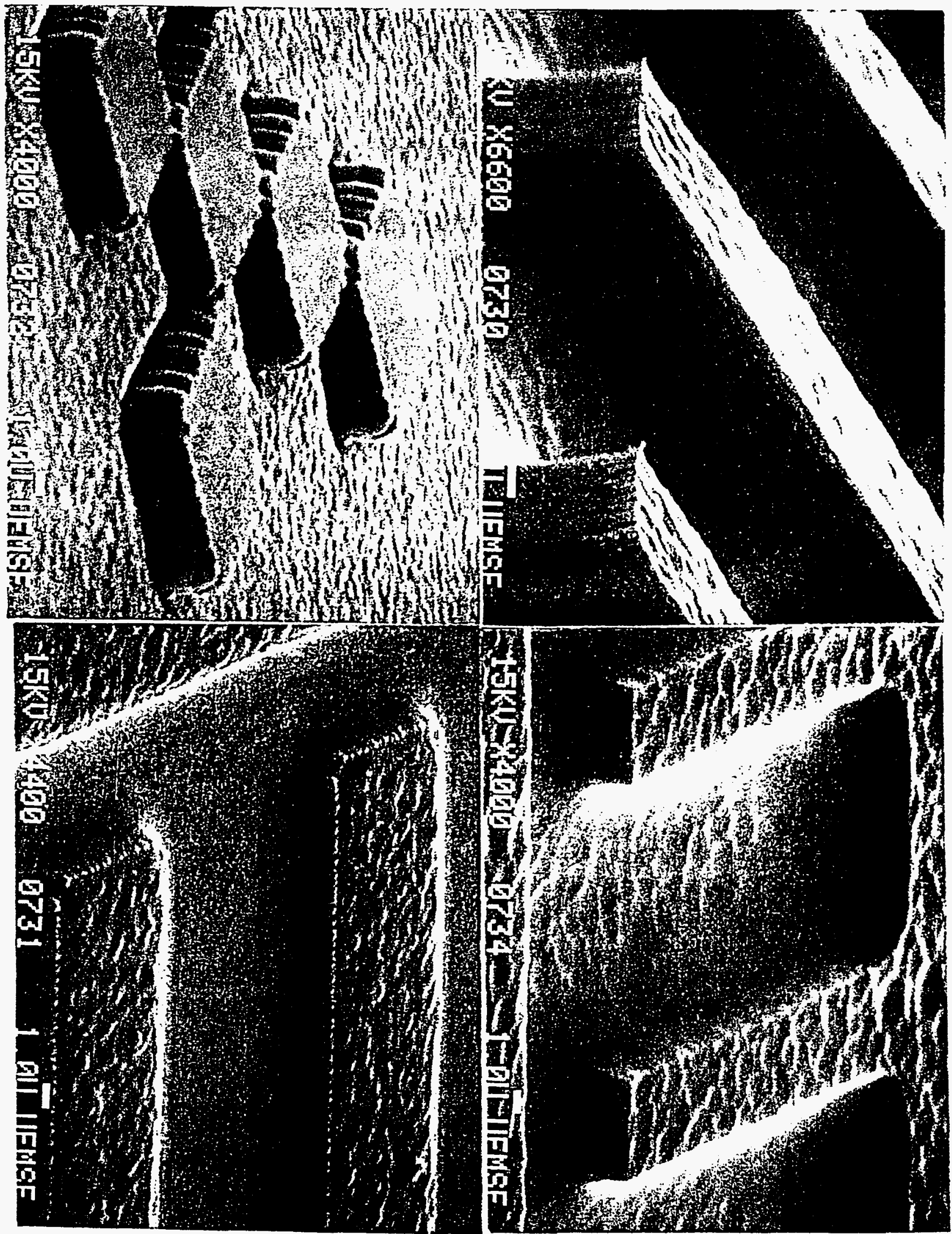




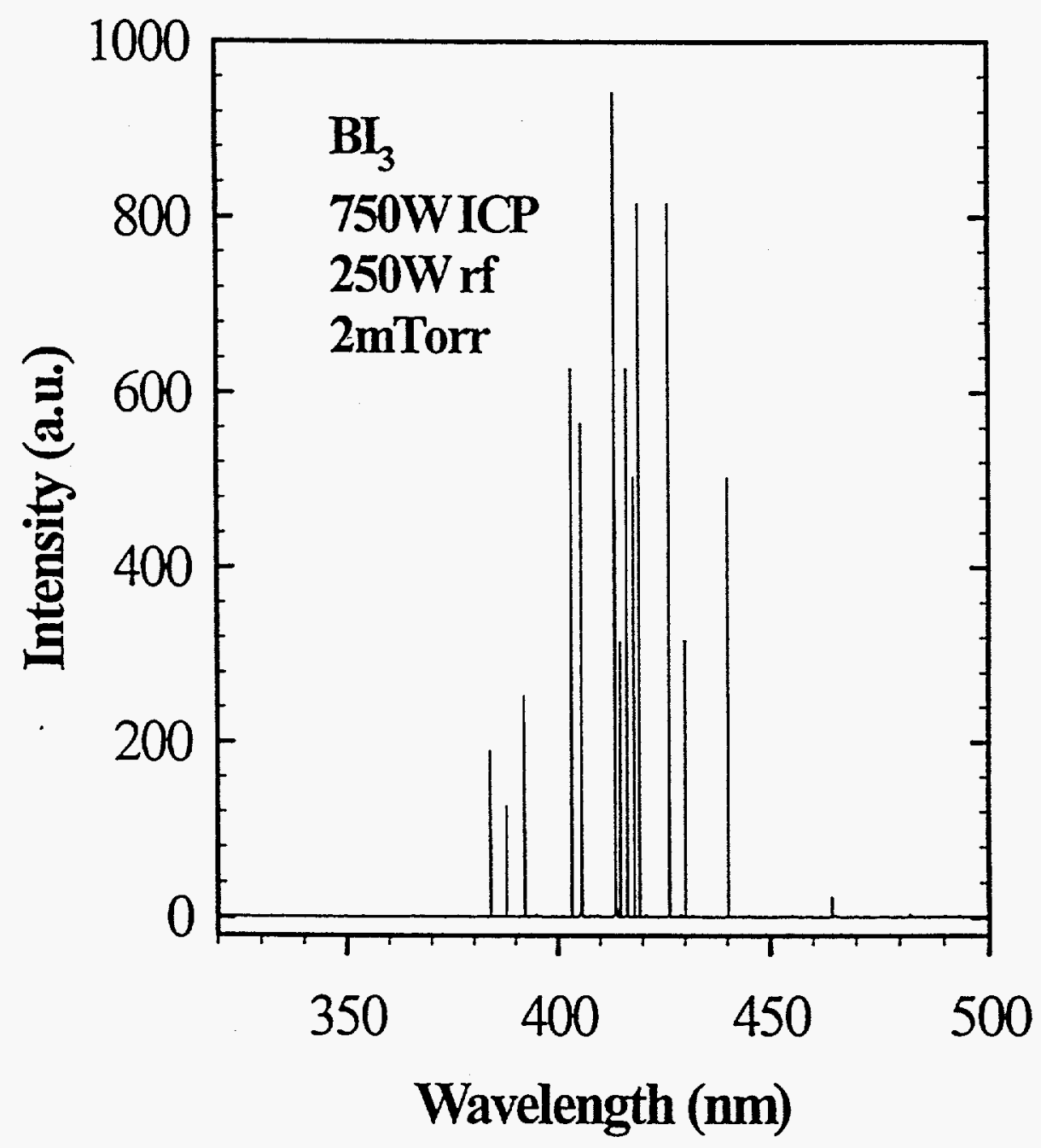

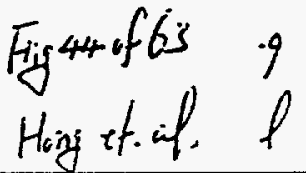



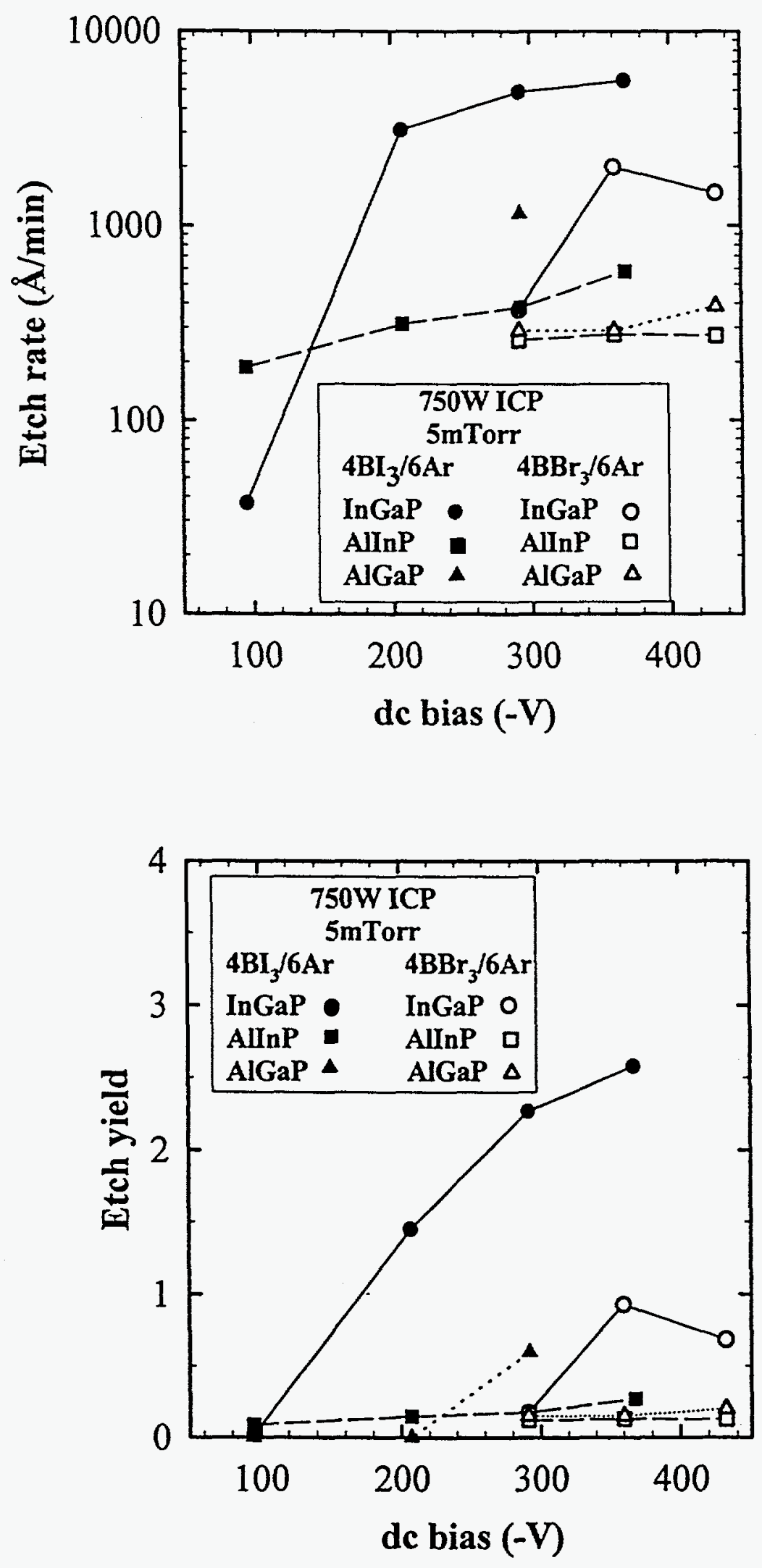

$F_{i j}+5$ of 6 H.aj et. oll. 

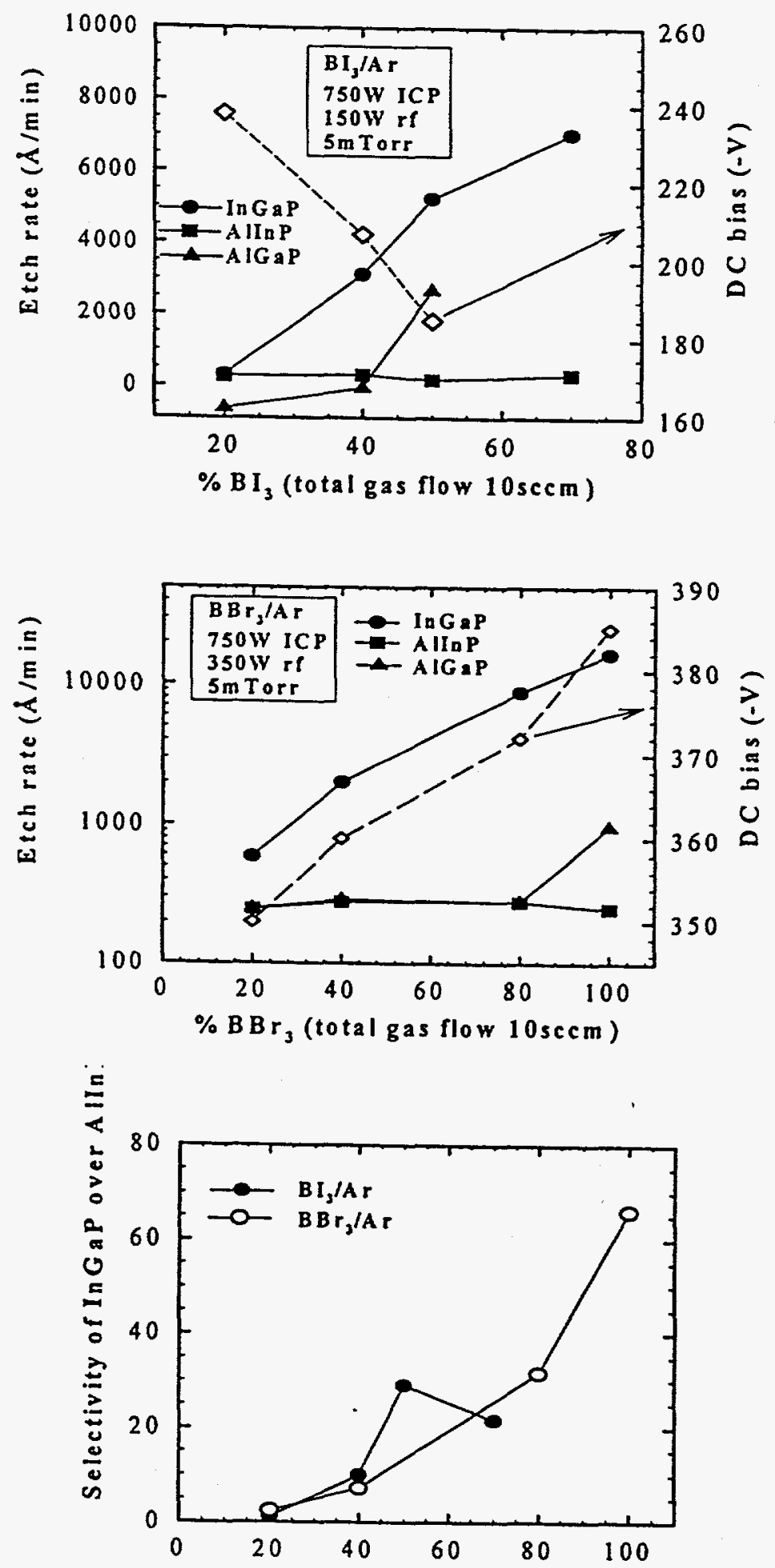

$\% \mathrm{BI}_{3}$ or $\mathrm{BBr}_{3}$ (total gas flow $10 \mathrm{secm}$ ) 

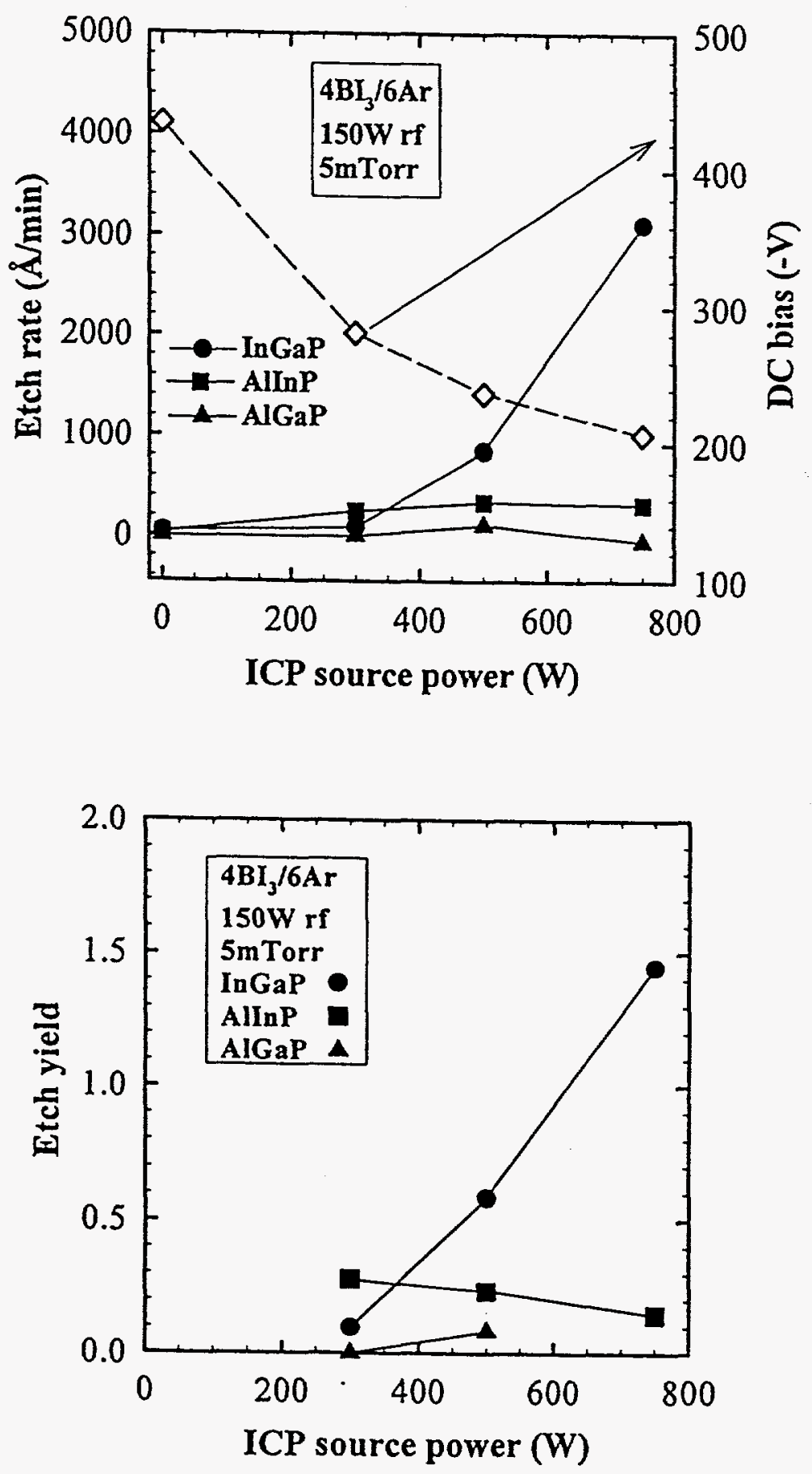

Fig47 of 65 

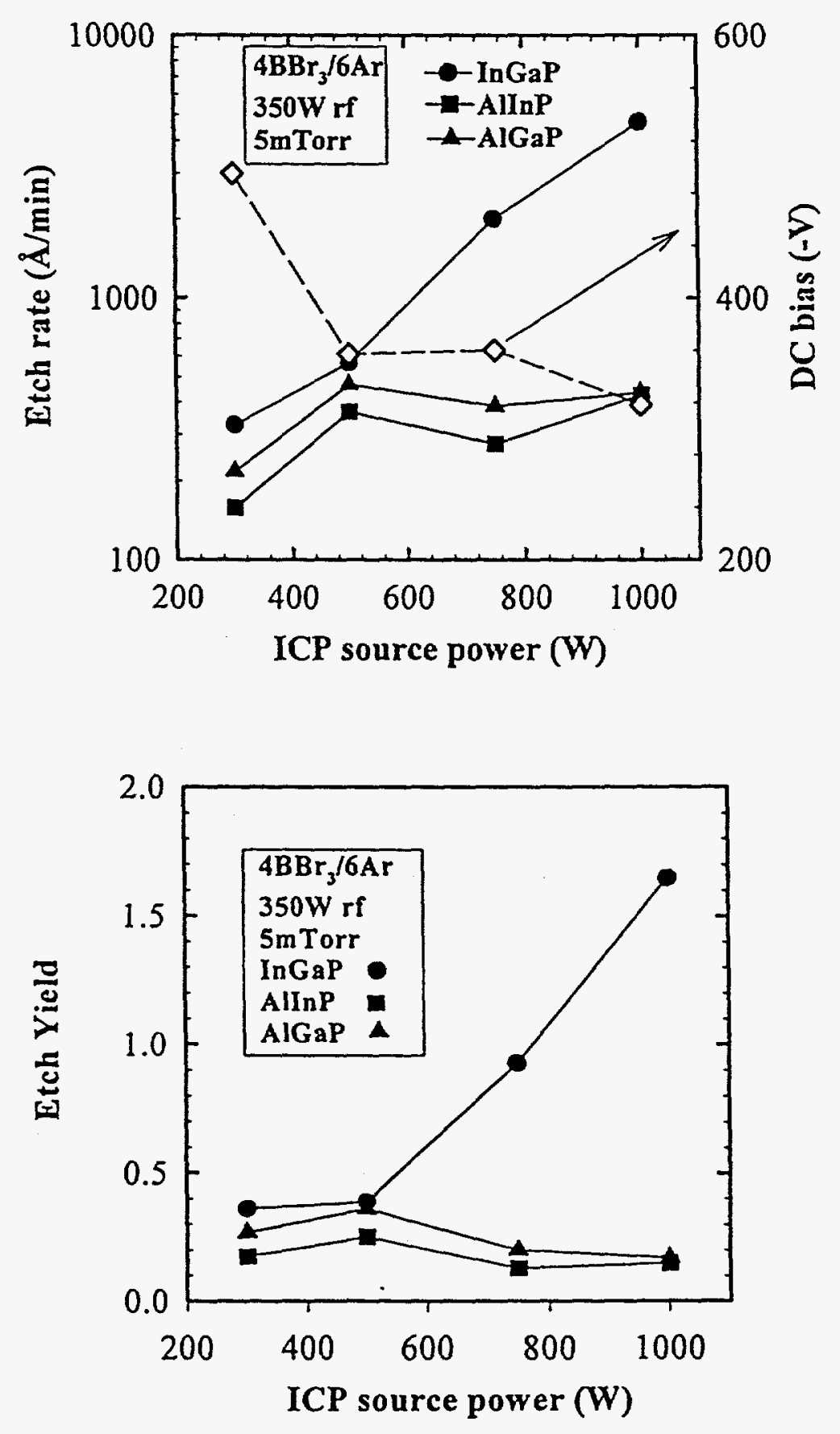

Fig 48 cf 65 Hongthall 


\section{InGaP \\ 750W ICP}

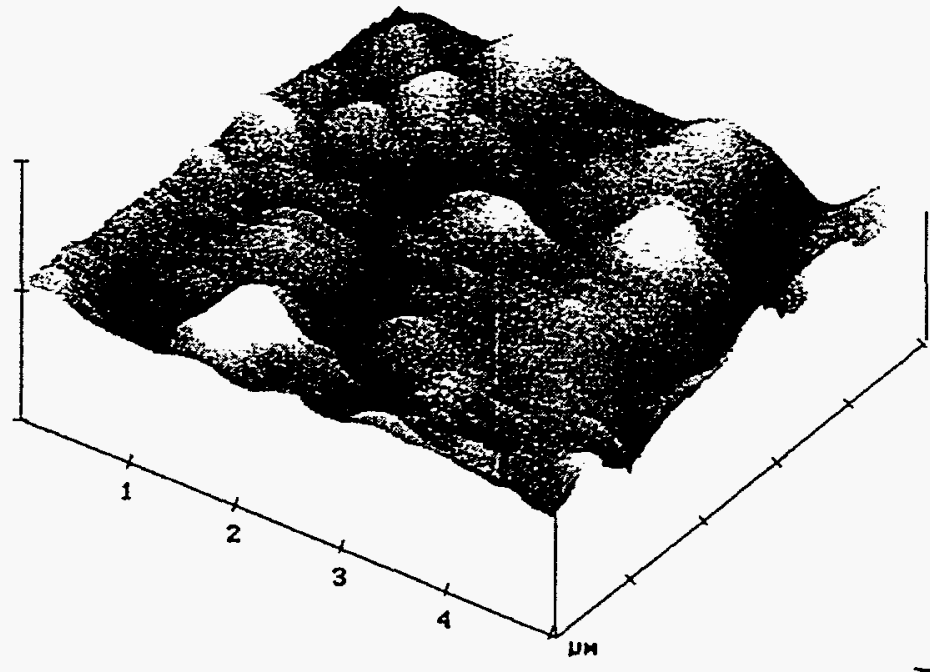

$4 \mathrm{BI}_{3} / 6 \mathrm{Ar}$

$150 \mathrm{~W}$ rf

RMS : $7.2 \mathrm{~nm}$

\section{$X: 1.00 \mu \mathrm{m} / \mathrm{div}$ \\ $\mathrm{Z}: 100 \mathrm{~nm} / \mathrm{div}$}

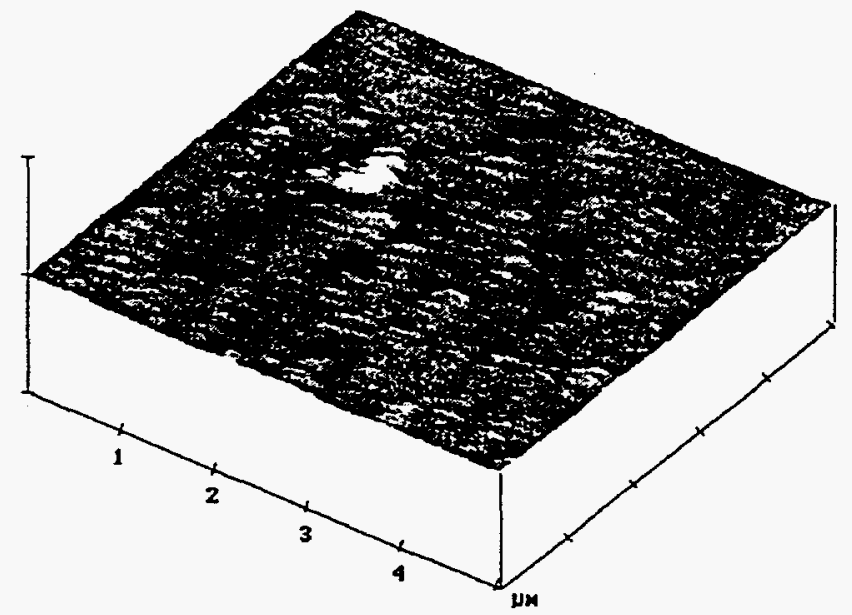

$5 \mathrm{BI}_{3} / 5 \mathrm{Ar}$

150W rf

RMS : $0.7 \mathrm{~nm}$
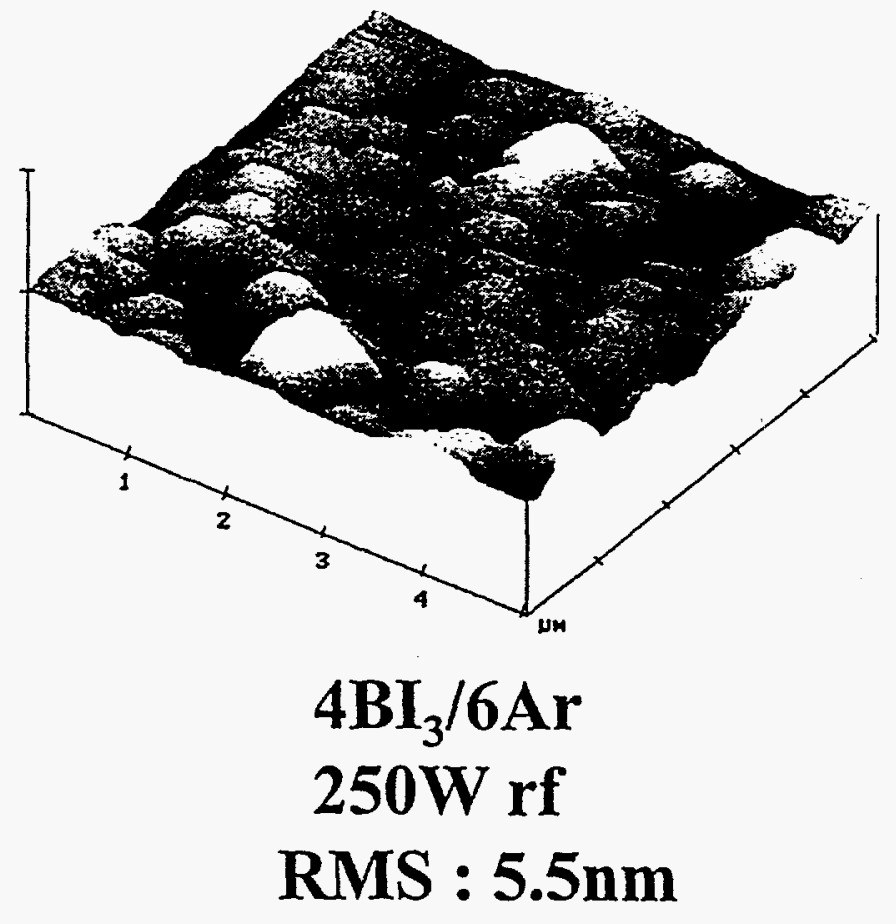

Figy 49 ofls Hogig et. al. 


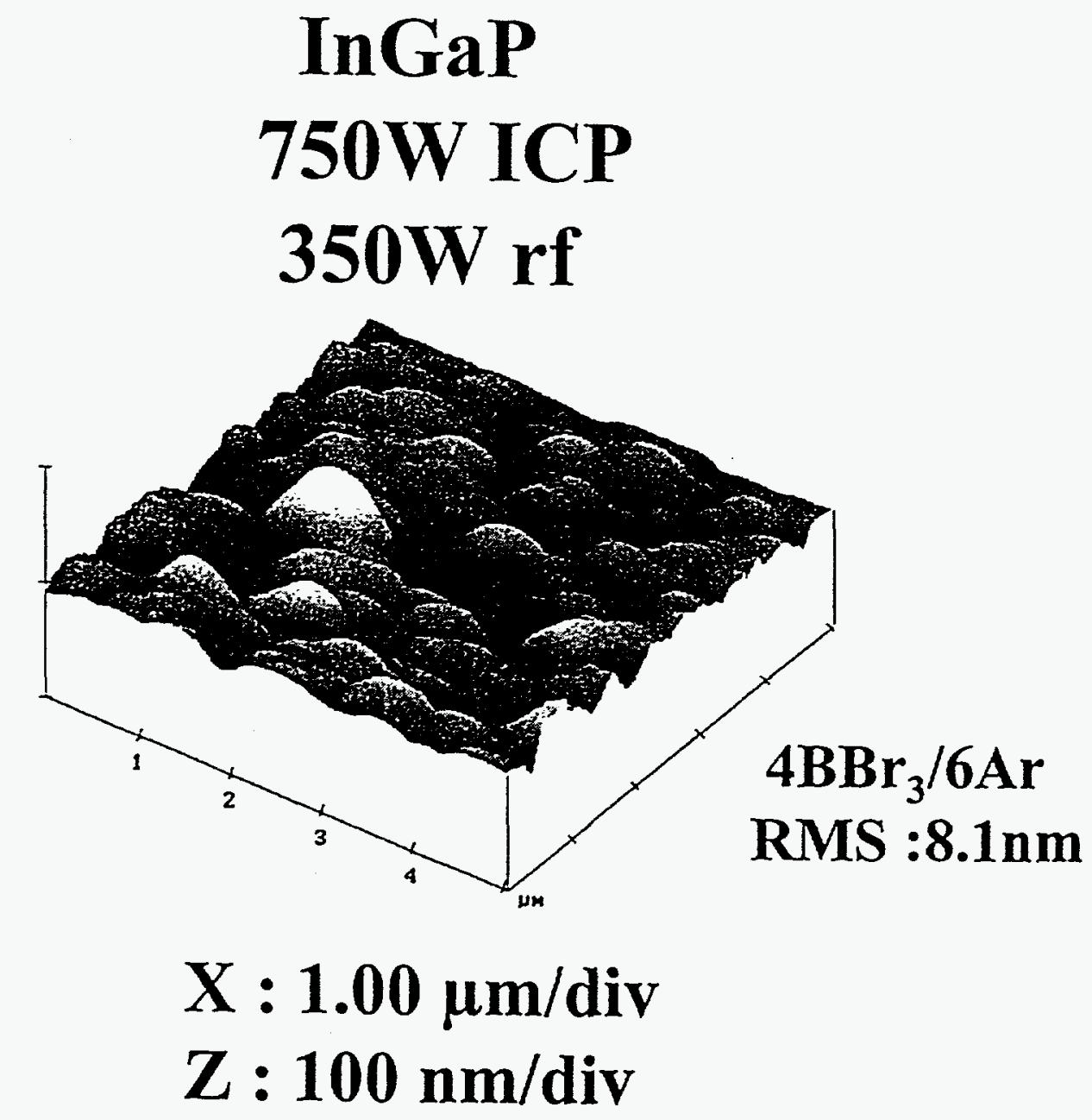

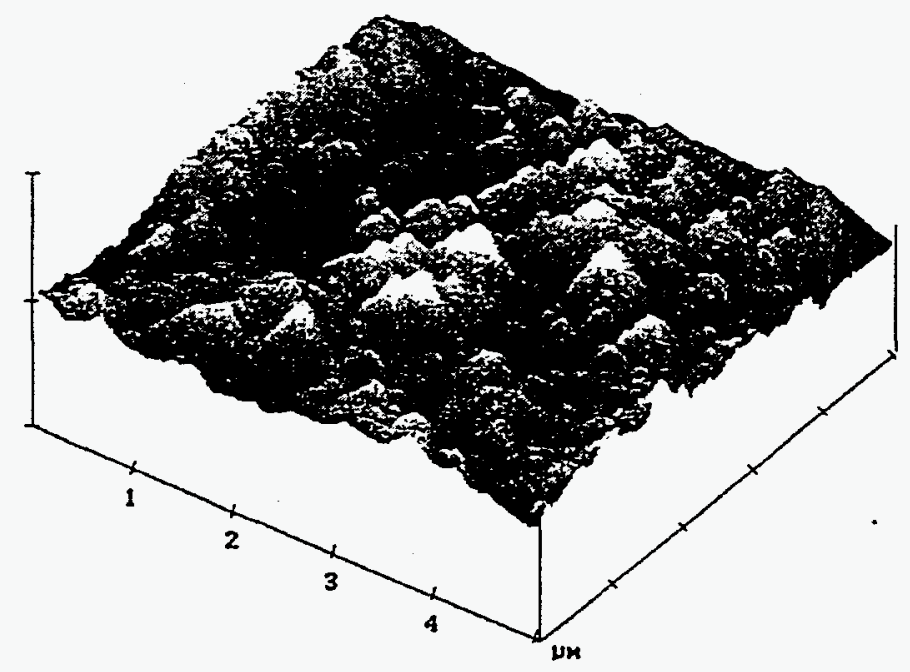

$8 \mathrm{BBr}_{3} / 2 \mathrm{Ar}$

RMS : $6.3 \mathrm{~nm}$

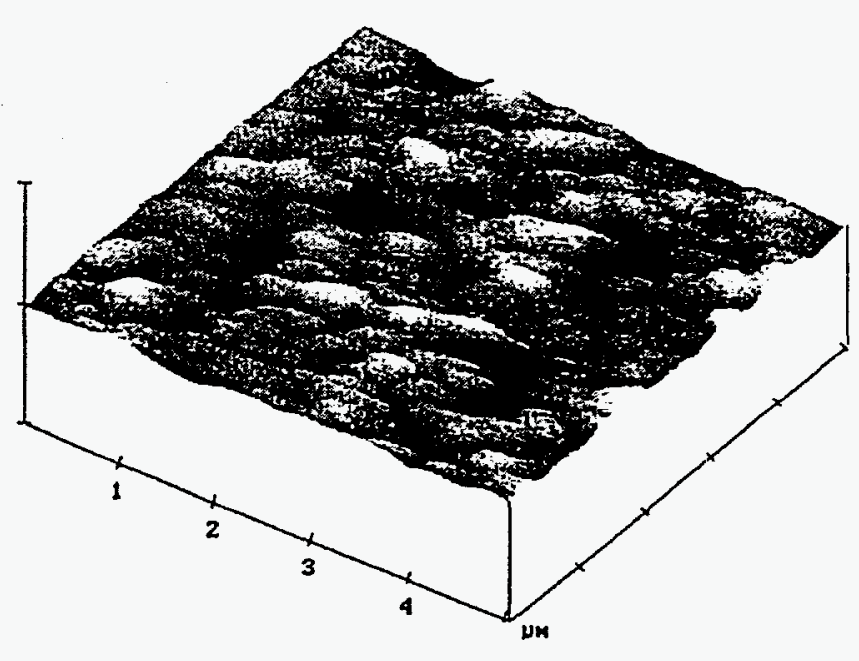

10BBr $_{3}$
RMS : $2.7 \mathrm{~nm}$ 

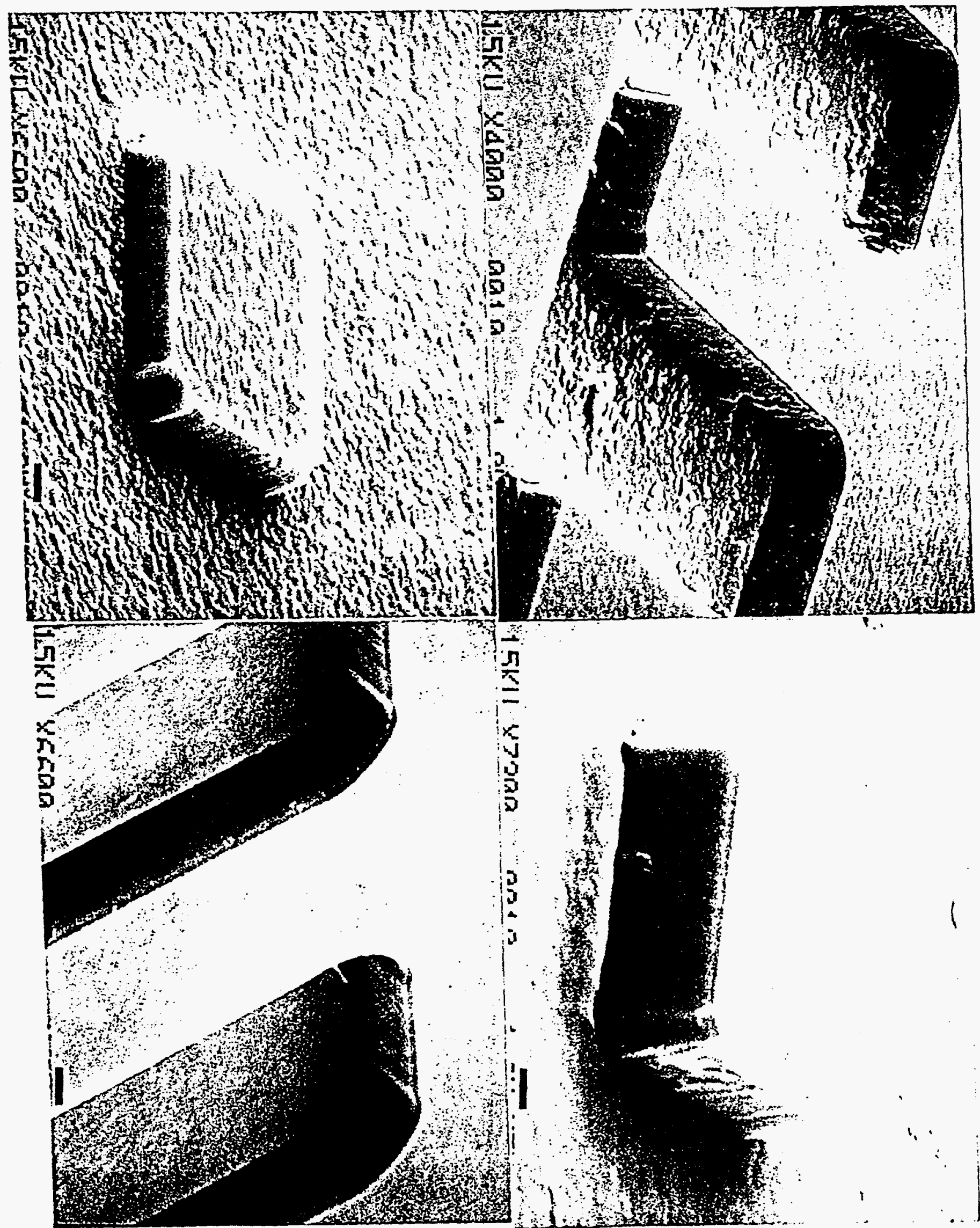

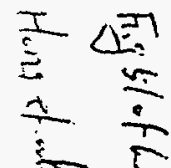




\section{AlInP}
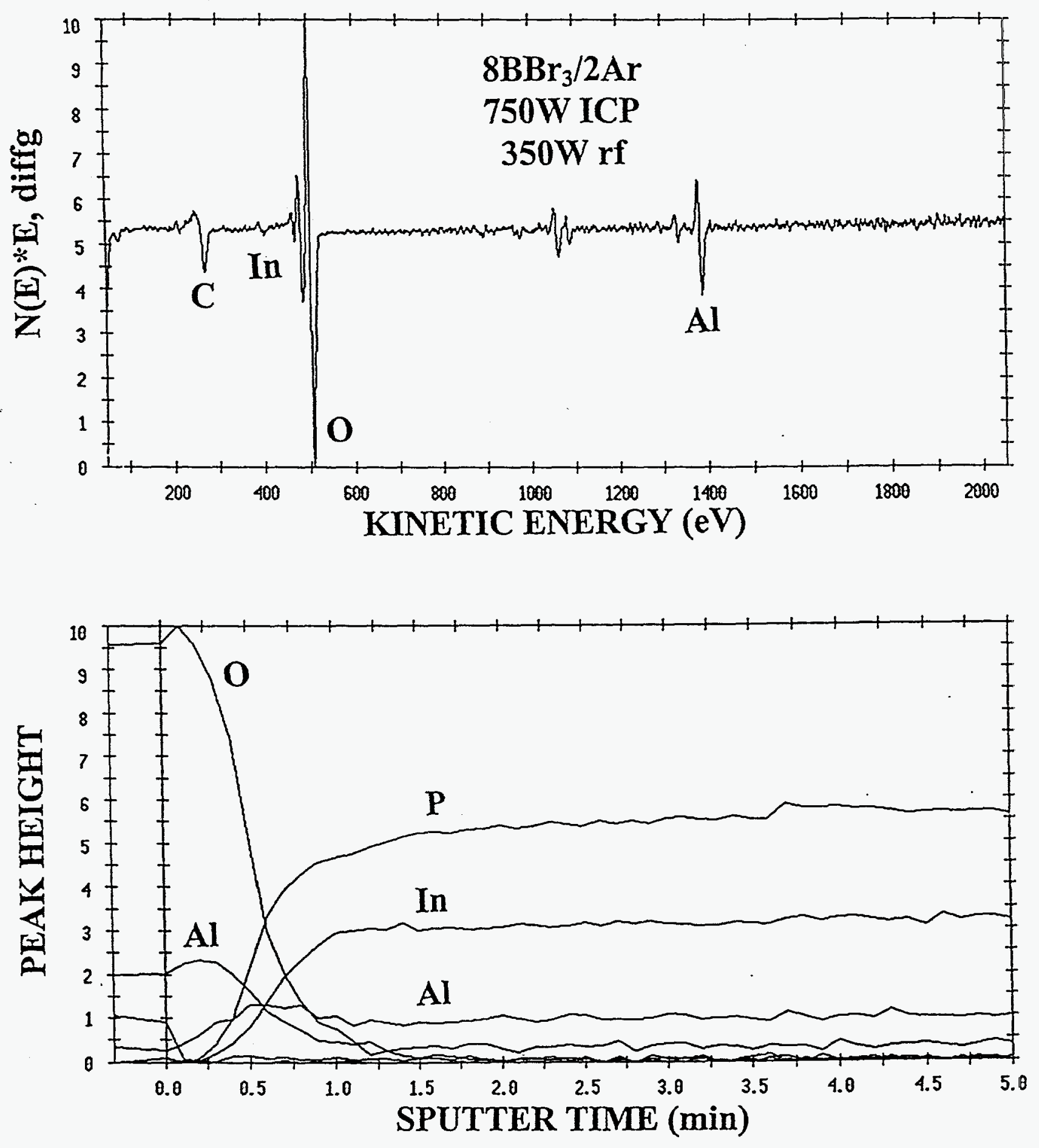

Fig $52+605$ 

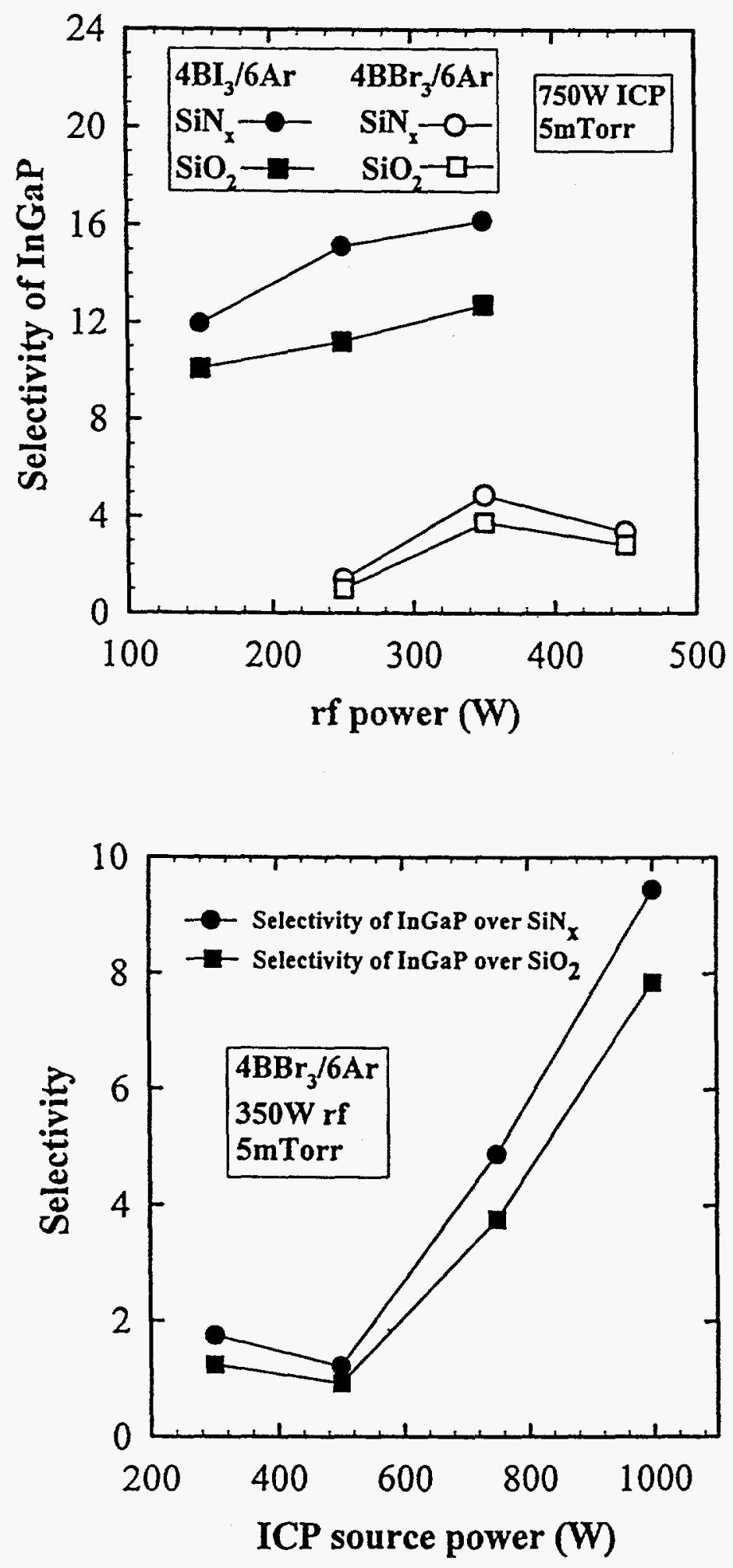

Fig 53 다 


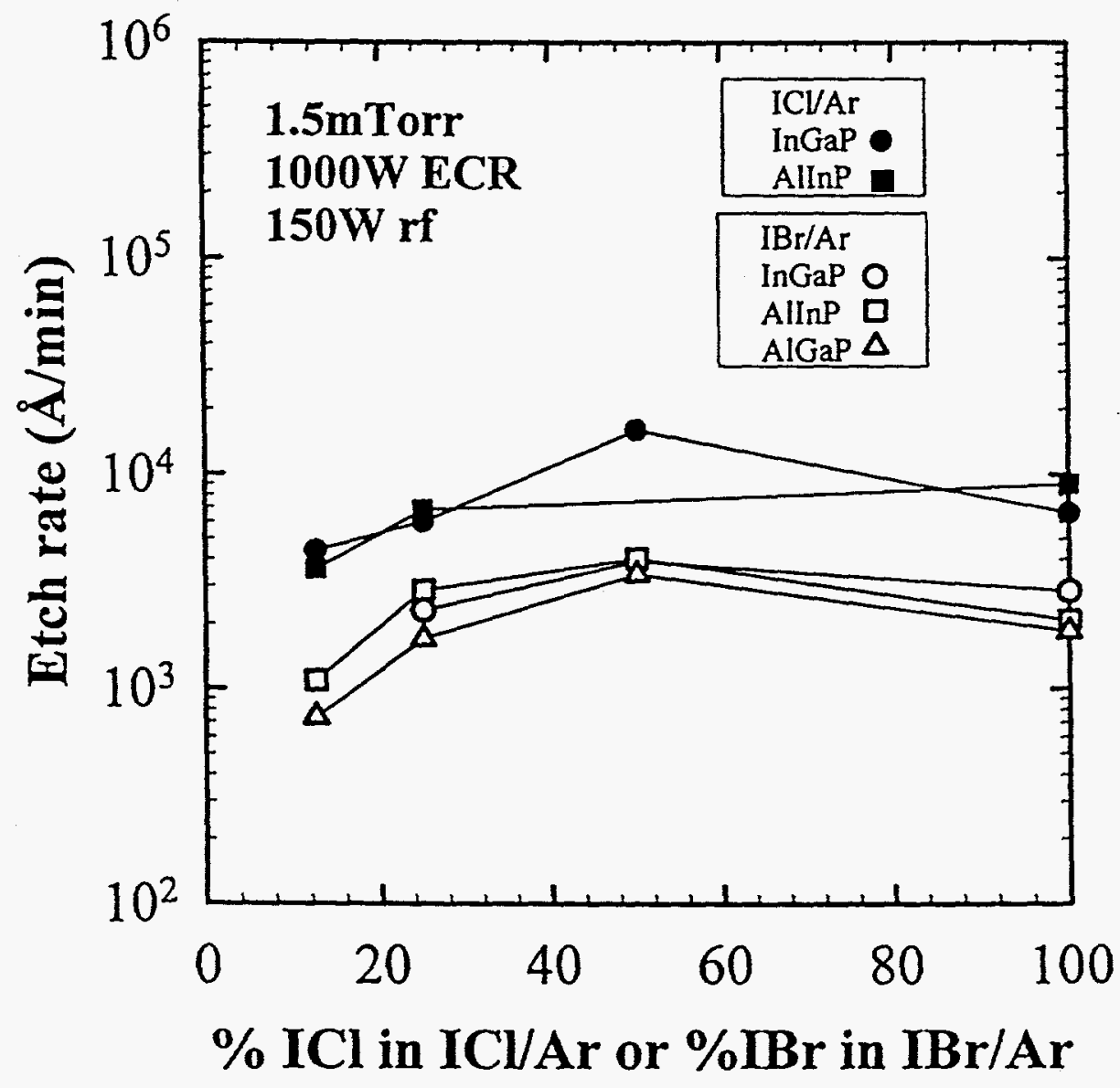

Fig 54 ofts 


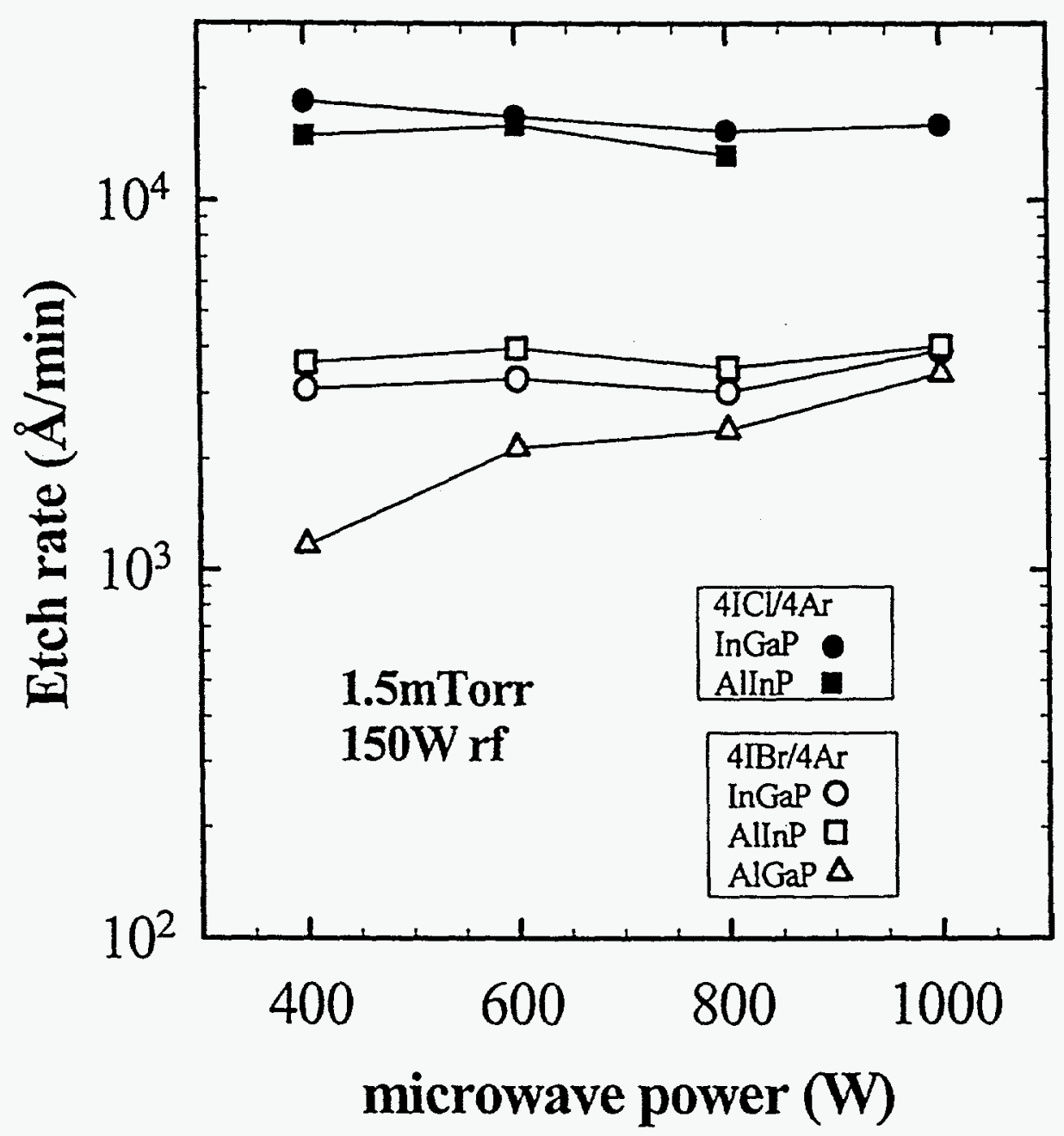

Fig 35 of 13 


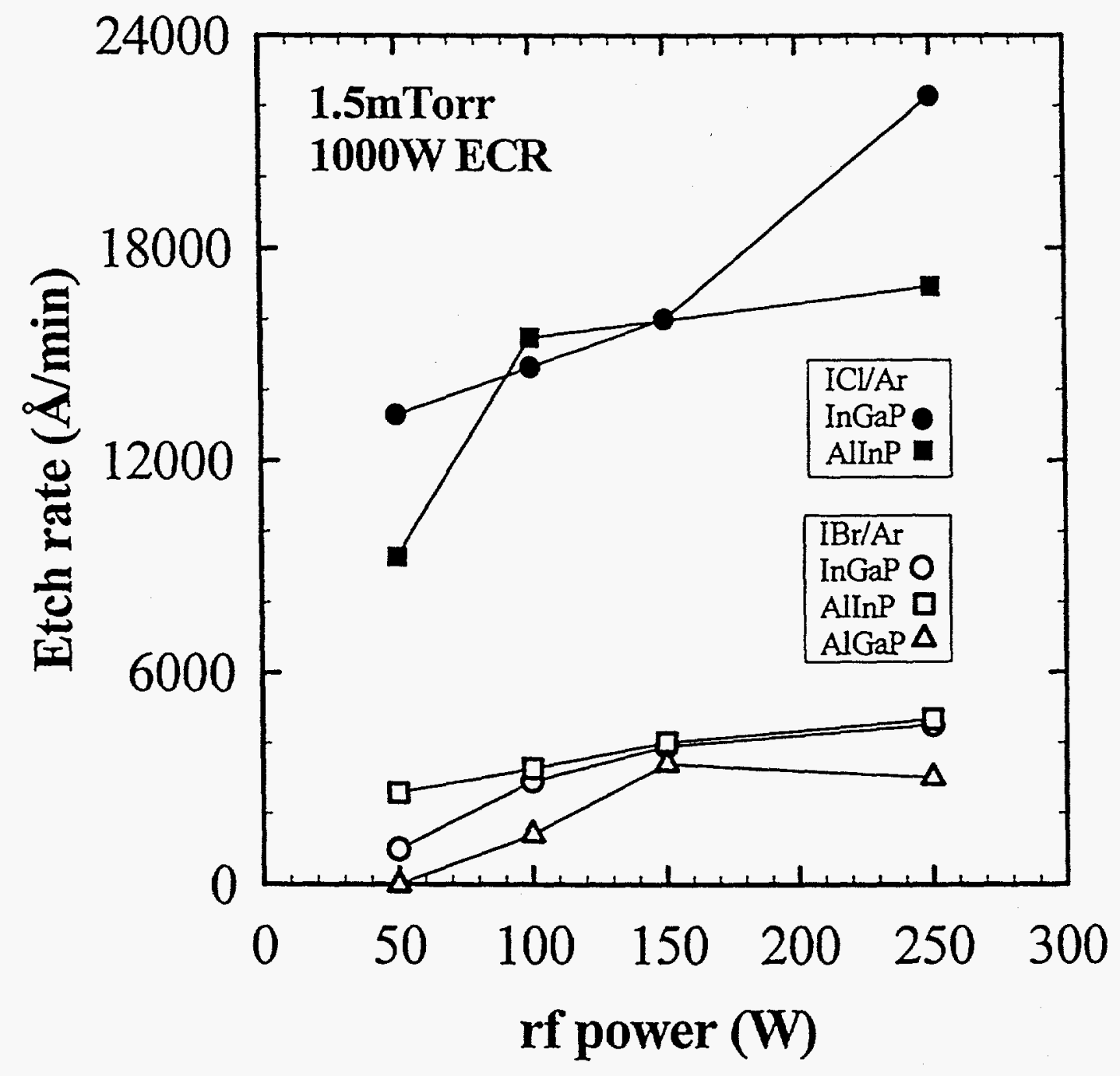

Fig 56 of 63 


\section{ICl/4Ar \\ 1.5mTorr}

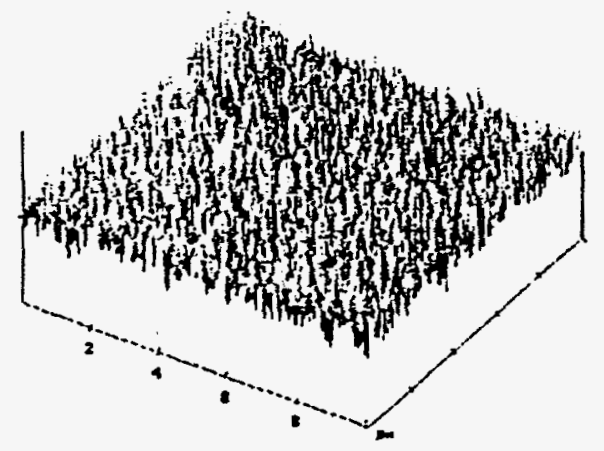

InGaP

1000W ECR

$150 \mathrm{~W}$ rf

RMS: 9.9nm

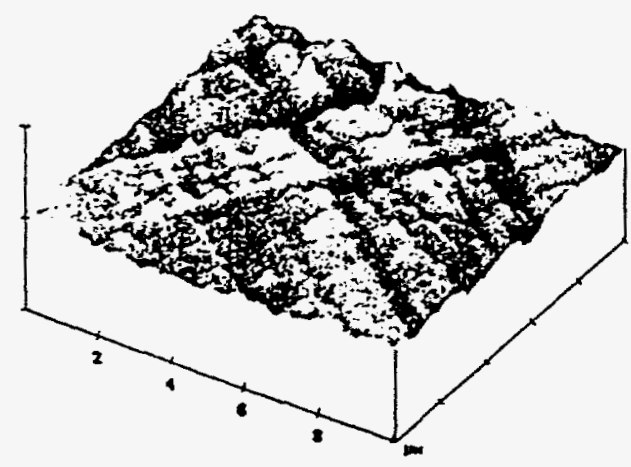

AllnP

800W ECR

$150 \mathrm{~W}$ rf

RMS: 4.8nm

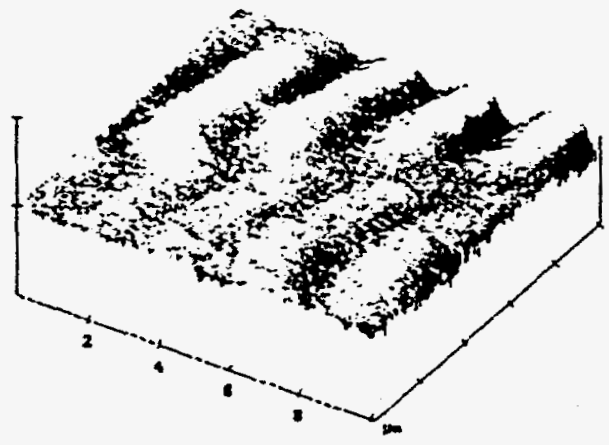

InGaP

$\mathrm{X}: 2.00 \mu \mathrm{m} / \mathrm{div} \quad$ 600W ECR 150W rf RMS: 7.5nm

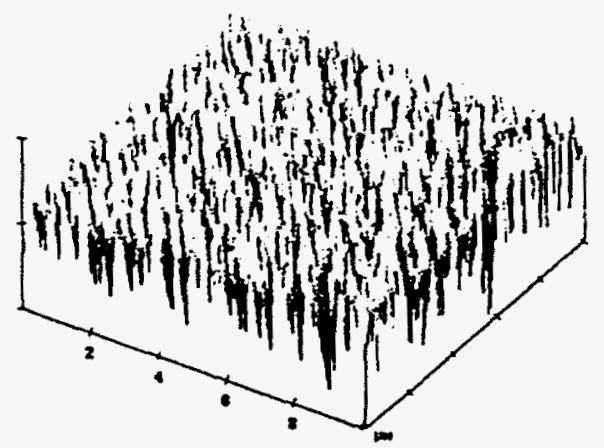

AlInP

1000W ECR

250W rf

RMS: 27nm 


\section{AlInP \\ 1000W ECR, 150W rf \\ $1.5 \mathrm{mT}$ Torr}

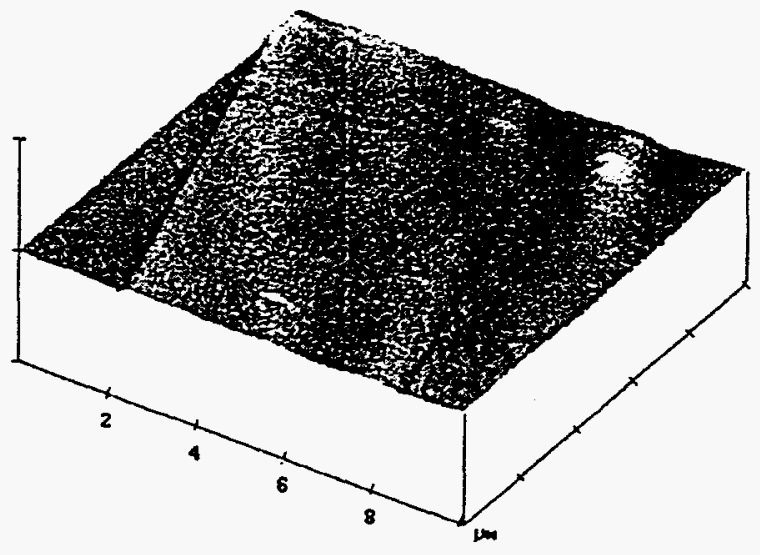

$X: 2.00 \mu \mathrm{m} / \mathrm{div}$

$\mathrm{Z}: 100 \mathrm{~nm} / \mathrm{div}$

2IBr/6Ar

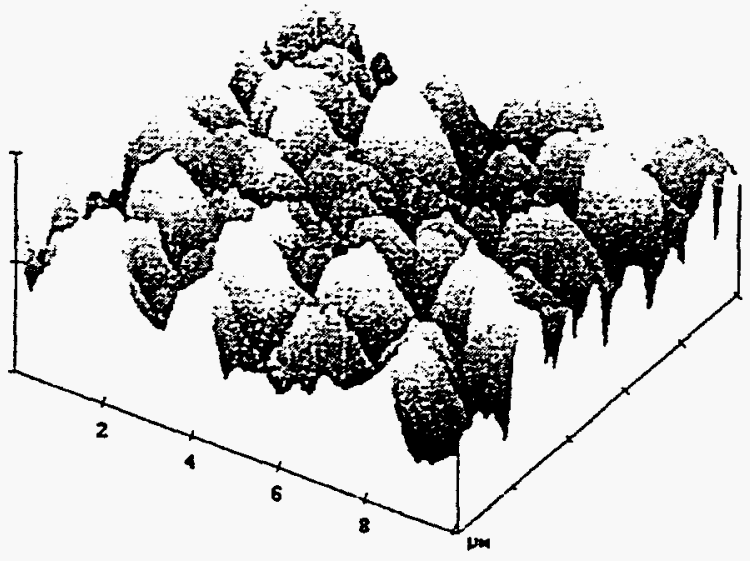

$X: 2.00 \mu \mathrm{m} / \mathrm{div}$

$\mathrm{Z}: 100 \mathrm{~nm} / \mathrm{div}$

\section{IBr/4Ar}

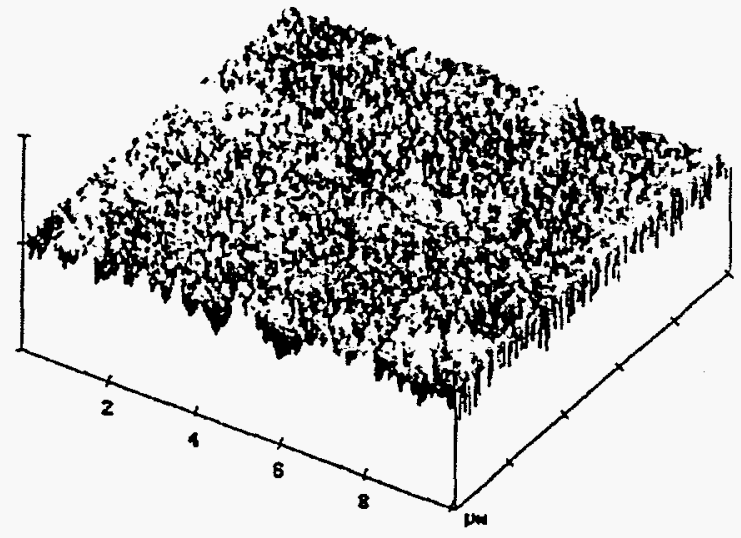

$\mathrm{X}: 2.00 \mu \mathrm{m} / \mathrm{div}$

$\mathrm{Z}: 100 \mathrm{~nm} / \mathrm{div}$

$8 \mathrm{IBr}$

Fig 58 of 63 


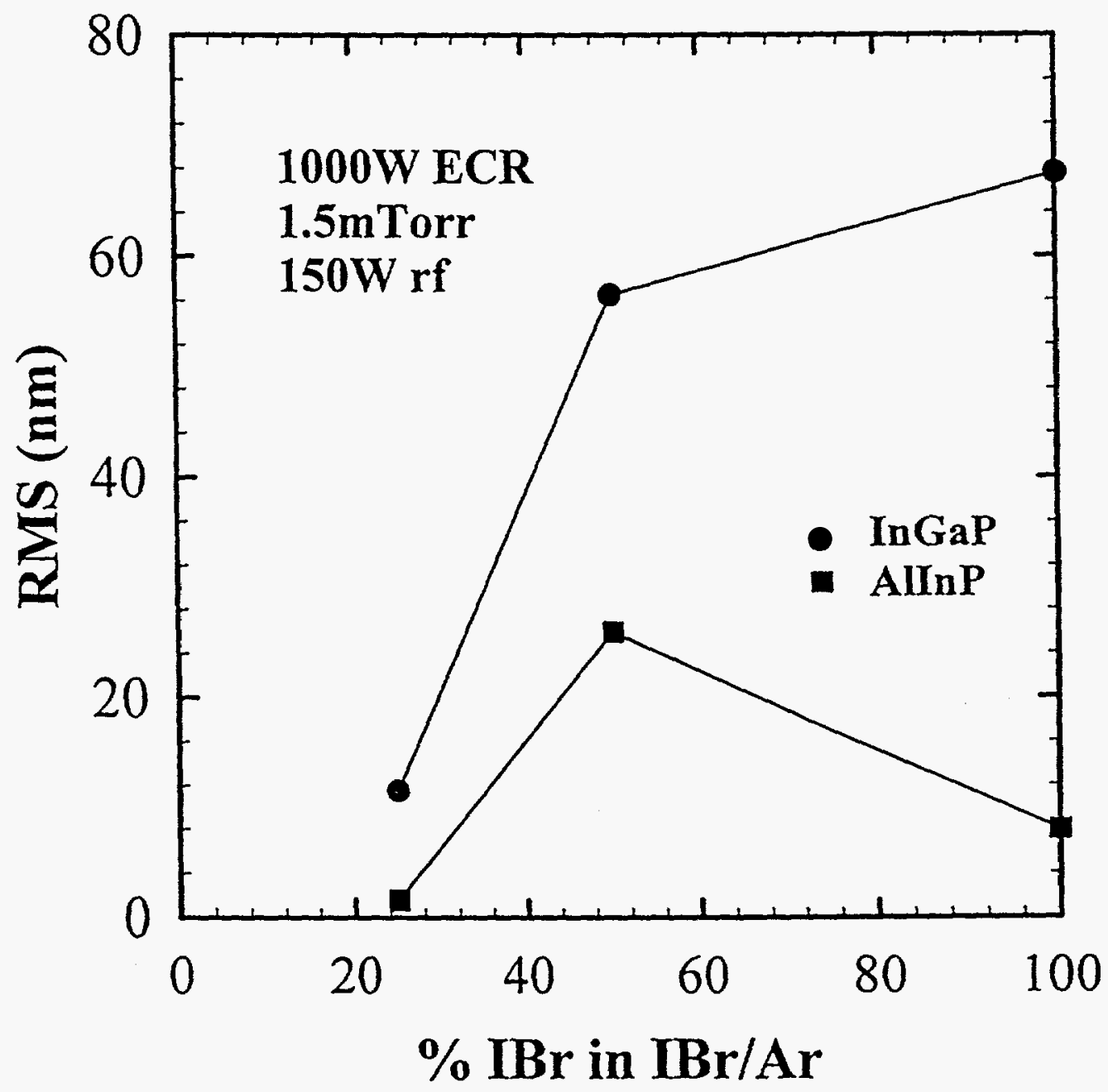

Fig 590663 


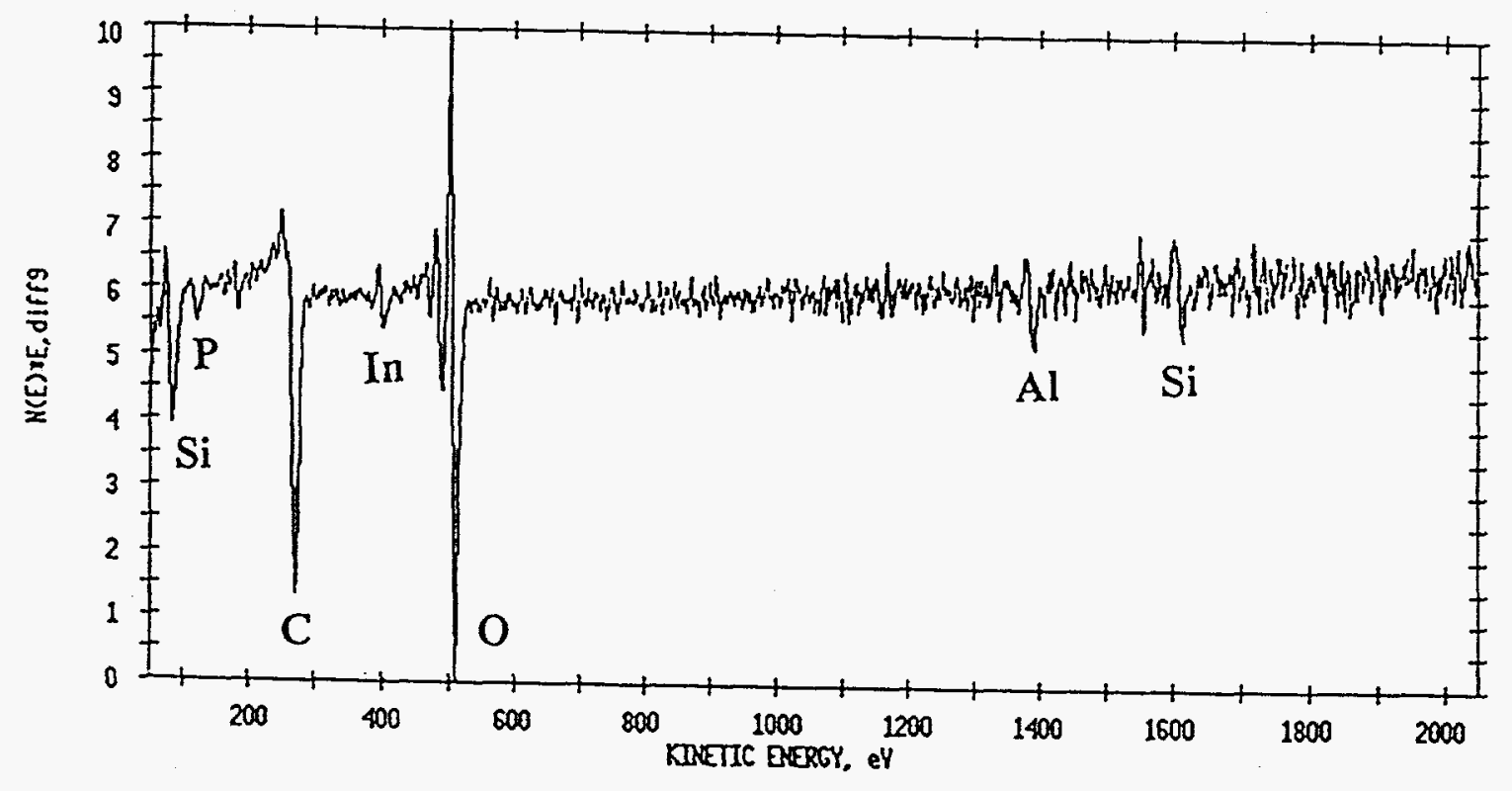

Fig6. of 63 

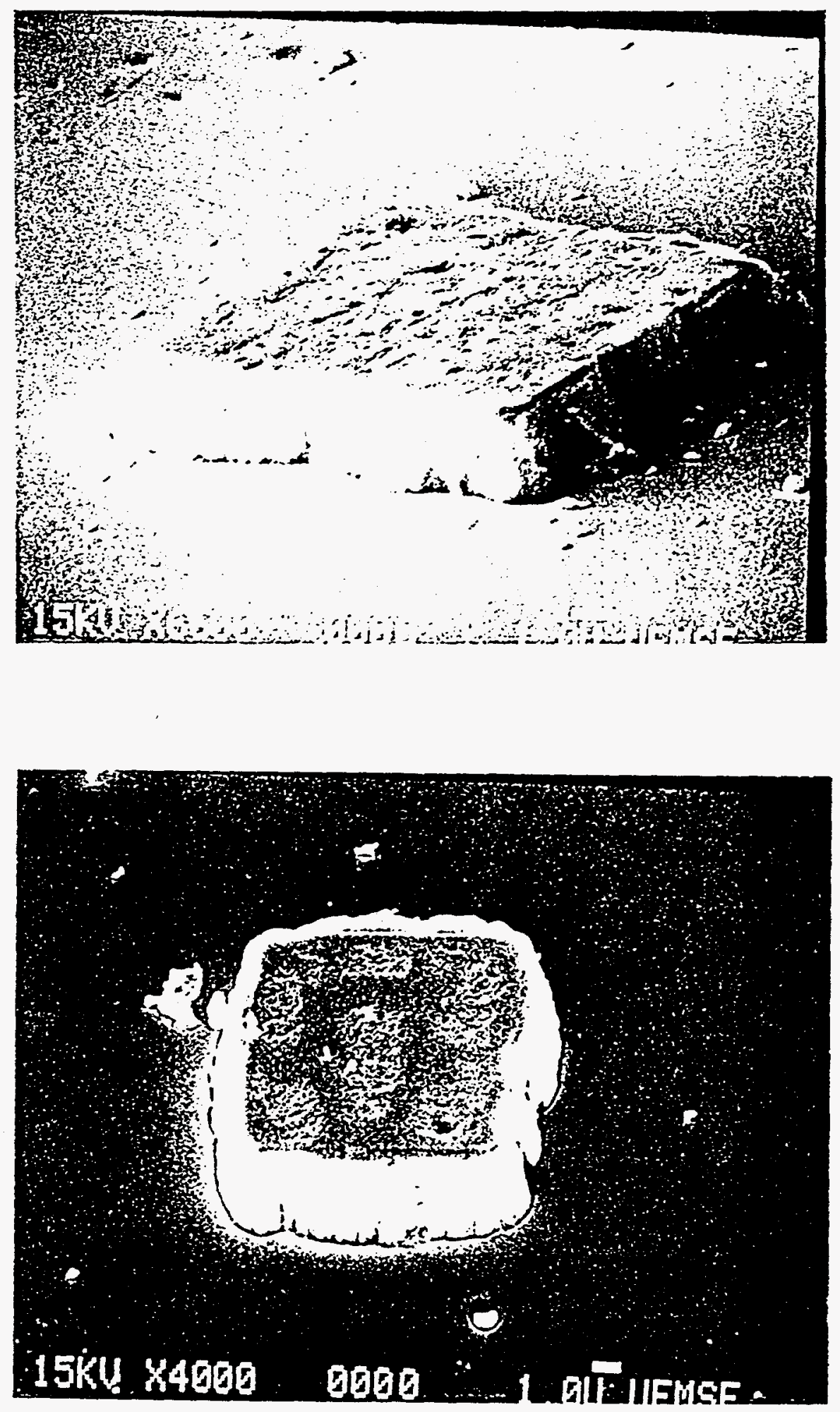

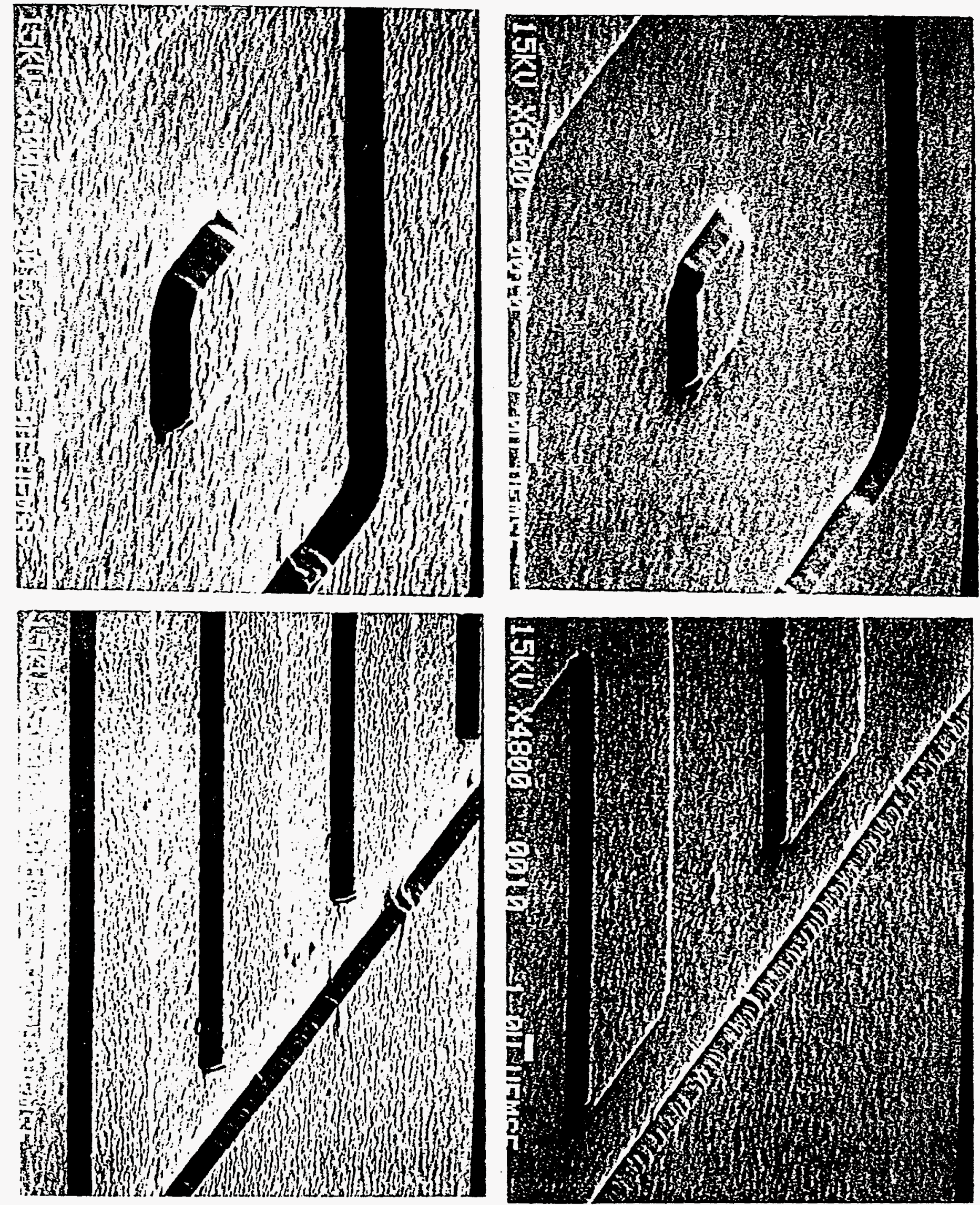


\begin{tabular}{cc|} 
Species & Boiling points (CC) \\
\hline $\mathrm{GaCl}_{3}$ & 201 \\
$\mathrm{InCl}_{3}$ & 600 \\
$\mathrm{AlCl}_{3}$ & 183 \\
$\mathrm{PCl}_{3}$ & 76
\end{tabular}




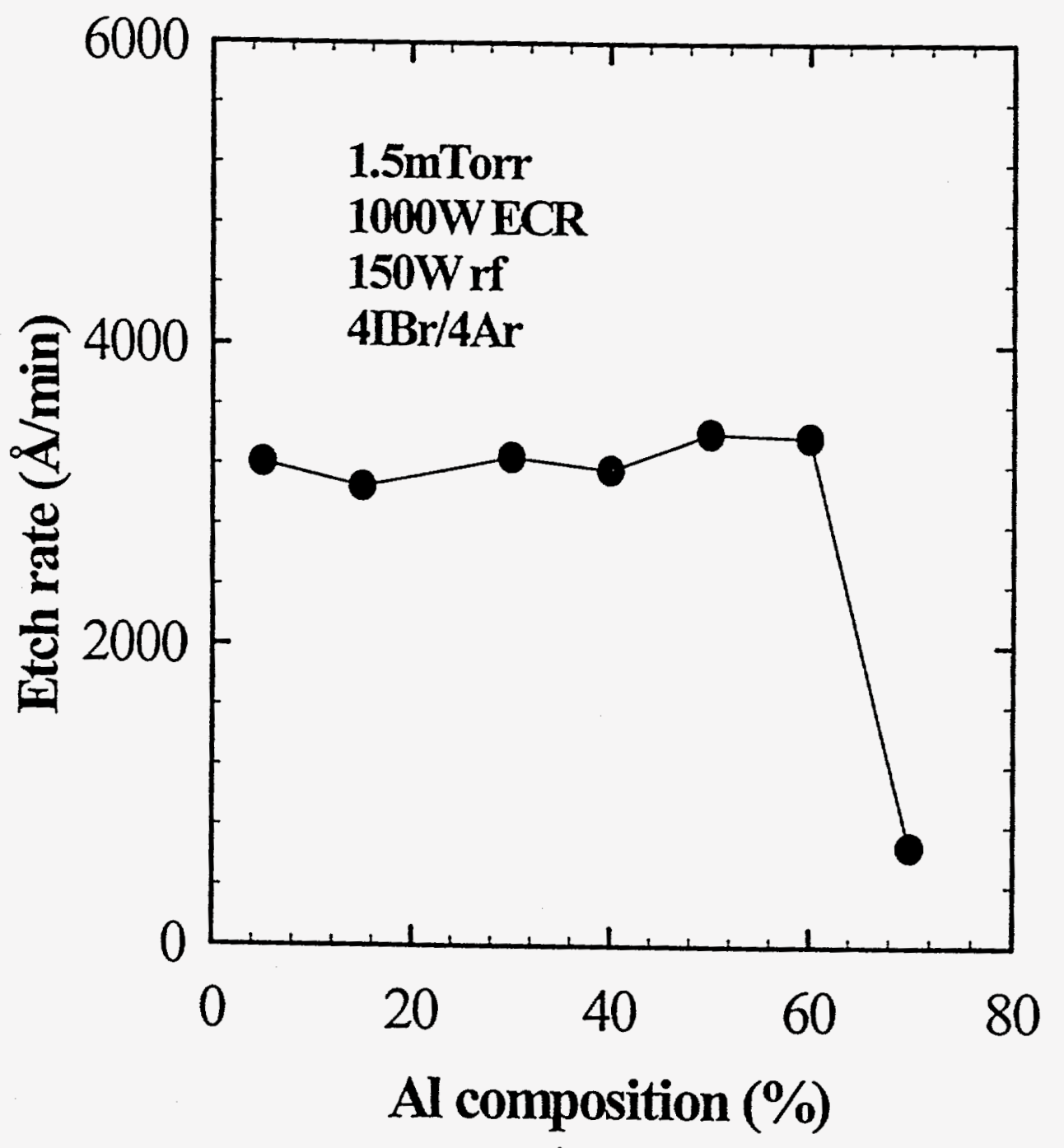

Fijtiofto Hongetial 


\begin{tabular}{|c|c|c|}
\hline $\begin{array}{c}\text { Gas Chemistry } \\
\text { (etch tool) }\end{array}$ & Comments & Typical rates \\
\hline $\begin{array}{l}5 \mathrm{CH}_{4} / 15 \mathrm{H}_{2} / 10 \mathrm{Ar} \\
(\mathrm{ECR}, \mathrm{ICP})\end{array}$ & $\begin{array}{l}\text { no ion-neutral synergism } \\
\text { (ion-driven mechanism) } \\
\text { - low etch rate } \\
\text { rough surface with sloped } \\
\text { side wall } \\
\text { non-stoichiometric surface } \\
\text { (In-enrichment) }\end{array}$ & $\begin{array}{l}\sim 1500 \AA / \mathrm{min} \text { for InGaP } \\
<1000 \AA / \text { for AllnP, AlGaP }\end{array}$ \\
\hline $\begin{array}{l}\mathrm{Cl}_{2} / \mathrm{Ar}, \mathrm{Cl}_{2} / \mathrm{H}_{2} \\
\text { (ICP) }\end{array}$ & $\begin{array}{l}\text { - ion-neutral synergism } \\
\text { - threshold ion energy } \\
\text { - smooth surface ( }<4 \mathrm{~nm} \\
\text { RMS for InGaP) } \\
\text { - no In-enrichment, no } \mathrm{P} \\
\text { deficiency at the near } \\
\text { surface } \\
\text { - } \mathrm{HCl} \text { creation with } \mathrm{H}_{2} \\
\text { (higher etch rate, smoother } \\
\text { surface) }\end{array}$ & $\begin{array}{c}>1 \mu \mathrm{m} / \mathrm{min} \text { for InGaP } \\
>3000 \AA / \mathrm{min} \text { for AlInP, AlGaP }\end{array}$ \\
\hline $\begin{array}{l}\mathrm{BCl}_{3} / \mathrm{Ar}, \mathrm{BCl}_{3} / \mathrm{H}_{2} \\
\text { (ICP) }\end{array}$ & $\begin{array}{l}\text { - ion-driven at low ion } \\
\text { energy (rough surface, } \\
\text { high coverage of chlorine } \\
\text { residues) } \\
\text { chemical-driven at high } \\
\text { ion energy (smooth } \\
\text { surface) } \\
\text { - threshold ion energy } \\
\text { - } \mathrm{BCl}_{3} / \mathrm{H}_{2} \text { produced } \mathrm{HCl} \\
\text { with faster etching }\end{array}$ & $\begin{array}{c}>1 \mu \mathrm{m} / \mathrm{min} \text { for InGaP } \\
<5000 \AA / \mathrm{min} \text { for } \mathrm{AlIn} \mathrm{P}, \mathrm{AlGaP}\end{array}$ \\
\hline $\begin{array}{c}\mathrm{Cl}_{2} / \mathrm{BCl}_{3} / \mathrm{Ar} \\
\text { (ICP) }\end{array}$ & $\begin{array}{l}\text { - Selectivity of AllnP over } \\
\text { InGaP }(-2) \text { at high ion } \\
\text { energy } \\
\text { smooth surface with } \\
\text { anisotropic profile }\end{array}$ & $\begin{array}{l}\sim 6000 \AA / \mathrm{min} \text { for } \operatorname{InGaP} \\
\sim 1.2 \mu \mathrm{m} / \mathrm{min} \text { for AlInP }\end{array}$ \\
\hline $\begin{array}{l}\mathrm{BI}_{3} / \mathrm{Ar}, \mathrm{BBr}_{3} / \mathrm{Ar} \\
\quad(\mathrm{ICP})\end{array}$ & $\begin{array}{l}\text { - higher etch rates with } \\
\mathrm{BI}_{3} / \mathrm{Ar} \\
\text { - high selectivity of } \\
\text { InGaP/AlInP } \\
\text { - chemical enhancement } \\
\text { only for InGaP } \\
\text { - involatile etch products of } \\
\mathrm{Al}\end{array}$ & $\begin{array}{c}0.7 \sim 1.0 \mu \mathrm{m} / \mathrm{min} \text { for } \mathrm{InGaP} \\
<500 \AA / \mathrm{min} \text { for AlInP, AlGaP }\end{array}$ \\
\hline $\begin{array}{l}\mathrm{ICl}, \mathrm{IBr} \\
(\mathrm{ECR})\end{array}$ & $\begin{array}{l}\text { - fastest etching with } \mathrm{ICl} \\
\text { etching not dependent on } \\
\mu \text { wave in } 400 \sim 1000 \mathrm{~W}\end{array}$ & $\begin{array}{c}2.0 \mu \mathrm{m} / \mathrm{min} \text { for InGaP with } \mathrm{ICl} \\
1.6 \mu \mathrm{m} / \mathrm{min} \text { for Aln } \text { with } \mathrm{ICl} \\
<4000 \AA / \mathrm{min} \text { for InGaP, } \\
\text { AlInP, AlGaP with } \mathrm{IBr}\end{array}$ \\
\hline
\end{tabular}

